Florida International University

FIU Digital Commons

FIU Electronic Theses and Dissertations

University Graduate School

3-22-2011

\title{
Development of an Instrument to Measure High School Students' Global Awareness and Attitudes: Looking Through the Lens of Social Sciences
}

Renita Ferreira

Florida International University, rferr008@fiu.edu

DOI: $10.25148 /$ etd.FI1 1050306

Follow this and additional works at: https:// digitalcommons.fiu.edu/etd

\section{Recommended Citation}

Ferreira, Renita, "Development of an Instrument to Measure High School Students' Global Awareness and Attitudes: Looking Through the Lens of Social Sciences" (2011). FIU Electronic Theses and Dissertations. 373.

https://digitalcommons.fiu.edu/etd/373 


\section{FLORIDA INTERNATIONAL UNIVERSITY}

Miami, Florida

\section{DEVELOPMENT OF AN INSTRUMENT TO MEASURE HIGH SCHOOL STUDENTS' GLOBAL AWARENESS AND ATTITUDES: LOOKING THROUGH THE LENS OF SOCIAL SCIENCES}

A dissertation submitted in partial fulfillment of the requirements for the degree of DOCTOR OF EDUCATION

in CURRICULUM AND INSTRUCTION

by

Renita Ferreira

2011 
To: Dean Delia C. Garcia

College of Education

This dissertation, written by Renita Ferreira, and entitled Development of an Instrument to Measure High School Students' Global Awareness and Attitudes: Looking Through the Lens of Social Sciences, having been approved in respect to style and intellectual content, is referred to you for judgment.

We have read this dissertation and recommend that it be approved.

Bruce Nissen

Hilary Landorf

Leonard Bliss

Mohammed K. Farouk, Major Professor

Date of Defense: March 22, 2011

The dissertation of Renita Ferreira is approved.

\begin{tabular}{r}
$\begin{array}{r}\text { Dean Delia C. Garcia } \\
\text { College of Education }\end{array}$ \\
\hline Interim Dean Kevin O’Shea \\
University Graduate School
\end{tabular}

Florida International University, 2011 
C) Copyright 2011 by Renita Ferreira

All rights reserved. 


\section{DEDICATION}

To my late parents, Minnie and Albert Fernandes who instilled in me that education was the best instrument to help me maneuver through the complexities of life. 


\section{ACKNOWLEDGMENTS}

I wish to thank the members of my committee for their continued support. Dr. Hilary Landorf was integral in introducing me to the concepts of global citizenship and for keeping me focused on my topic. Dr. Bruce Nissen's keen interest and driving force in getting me to work diligently towards the interpretations of the findings of my study was much appreciated. Dr. Leonard Bliss has my gratitude because of his willingness to join the committee at a dire moment, and for his guidance through the psychometric process of my dissertation. Finally, my very special thanks to Dr. Mohammed Farouk, my major professor and mentor who had more confidence in my abilities than myself. Very persuasively, he steered me towards my goal, and final success!

I would also like to thank Dr. Isadore Newman for making statistics meaningful and encouraging me to undertake a challenge, as well as, Dr. Linda Bliss for her understanding, constructive suggestions and ever reassuring smile. I would be remiss if I did not thank the principals and teachers of the schools that were receptive to my research. Of special mention is the Head of School, Dr. John Davies of Miami Country Day School, who made it possible for me to have all of his senior classes participate in this study. 


\author{
ABSTRACT OF THE DISSERTATION \\ DEVELOPMENT OF AN INSTRUMENT TO MEASURE HIGH SCHOOL \\ STUDENTS' GLOBAL AWARENESS AND ATTITUDES: LOOKING THROUGH \\ THE LENS OF SOCIAL SCIENCES \\ by
}

Renita Ferreira

Florida International University, 2011

Miami, Florida

Professor Mohammed Farouk, Major Professor

? The purpose of this study was to develop an instrument to measure high school students' perspectives on global awareness and attitudes toward social issues. The research questions that guided this study were: (a) Can acceptable validity and reliability estimates be established for an instrument developed to measure high schools students' global awareness? (b) Can acceptable validity and reliability estimates be established for an instrument developed to measure high schools students' attitudes towards global social issues? (c) What is the relationship between high school students' GPA, race/ethnicity, gender, socio-economic status, parents' education, getting the news, reading and listening habits, the number of classes taken in the social sciences, whether they speak a second language, and have experienced living in or visiting other countries, and their perception of global awareness and attitudes toward global social issues.

An ex post facto research design was used and the data were collected using a 4part Likert-type survey. It was administered to 14 schools in the Miami-Dade County, Florida area to 704 students. A factor analysis with an orthogonal varimax rotation was 
used to select the factors that best represented the three constructs - global education, global citizenship, and global workforce. This was done to establish construct validity. Cronbach's alpha was used to determine the reliability of the instrument. Descriptive statistics and a hierarchical multiple regression were used for the demographics to establish their relationship, if any, to the findings.

Key findings of the study were that reliable and valid estimates can be developed for the instrument. The multiple regression analysis for model 1 and 2 accounted for a variance of 3\% and 5\% for self-perceptions of global awareness (factor 1). The regression model also accounted for a $5 \%$ and $13 \%$ variance in the two models for attitudes toward global social issues (factor 2). The demographics that were statistically significant were: ethnicity, gender, SES, parents' education, listening to music, getting the news, speaking a second language, GPA, classes taken in the social sciences, and visiting other countries. An important finding for the study was those attending public schools (as opposed to private schools) had more positive attitudes towards global social issues (factor 2) The statistics indicated that these students had taken history, economics, and social studies - a curriculum infused with global perspectives. 


\section{TABLE OF CONTENTS}

CHAPTER

PAGE

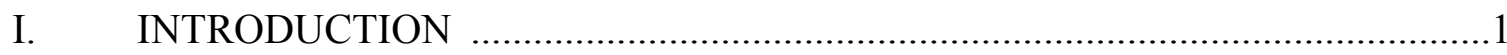

Background of the Study …………….......................................................

Statement of the Problem ..............................................................................

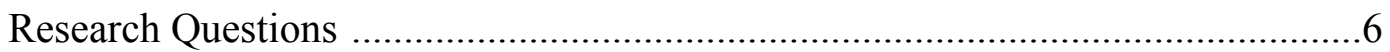

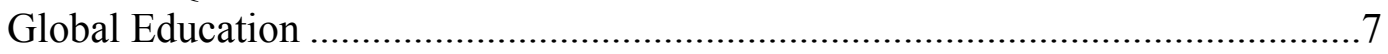

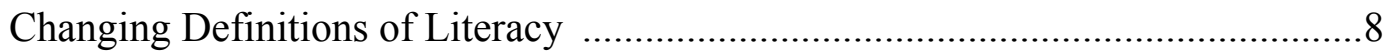

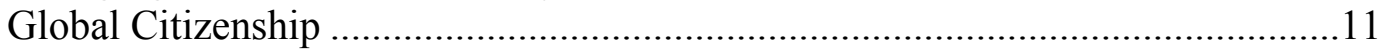

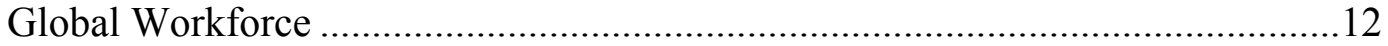

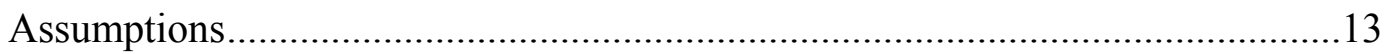

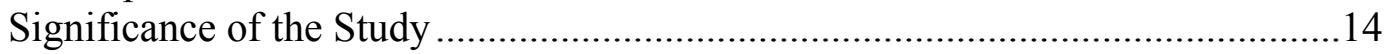

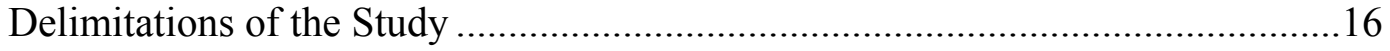

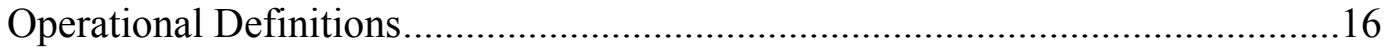

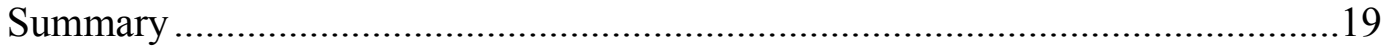

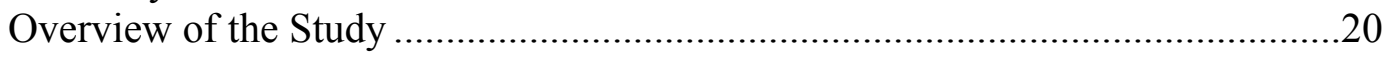

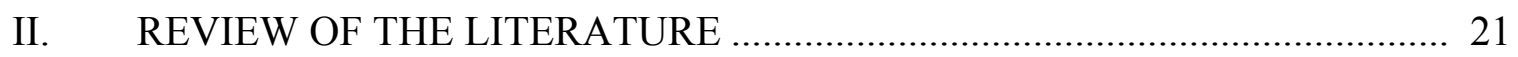

The Repercussion of Globalization ………………….................................22

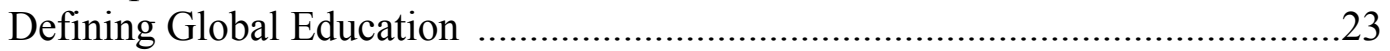

Relevance of Global Education to the Global Workforce .....................................28

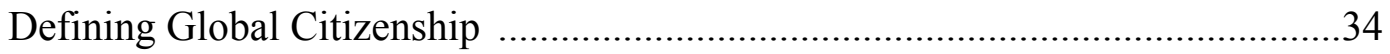

Relevance of Global Citizenship to the Global Workforce ...................................39

A Discussion on Research Done on Students' Attitudes and Opinions .................41

Review of Some Instruments Considered for This Study.....................................50

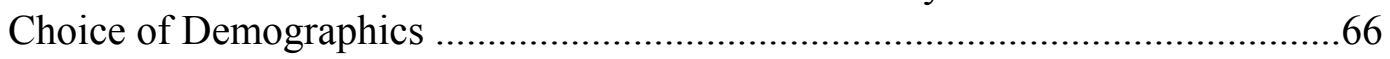

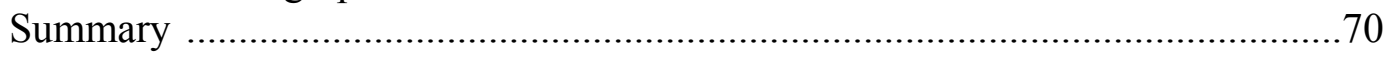

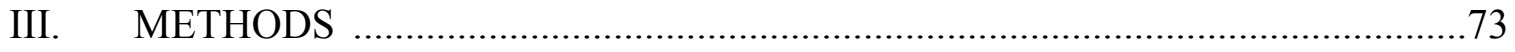

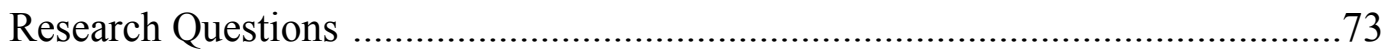

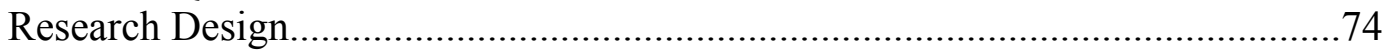

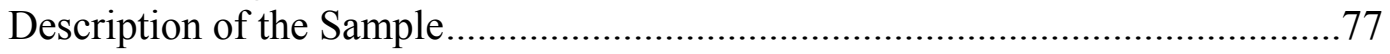

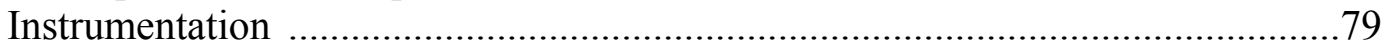

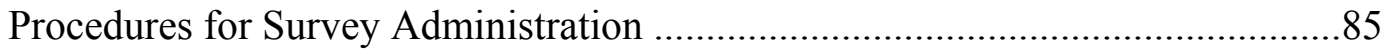

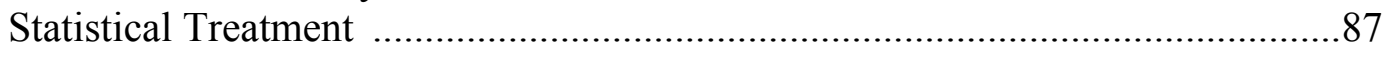

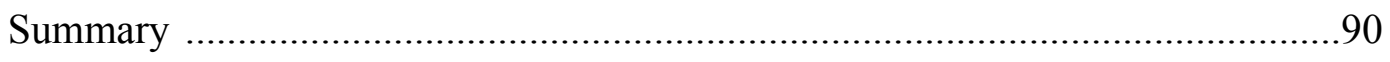

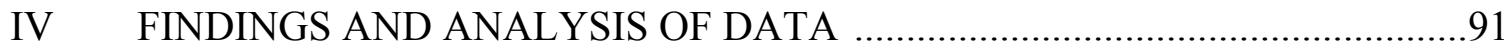

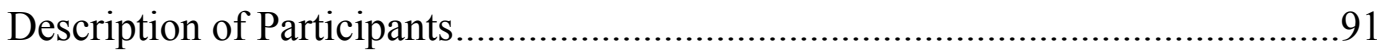

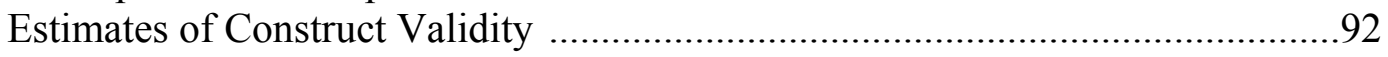

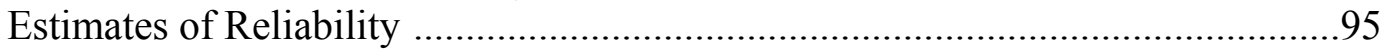

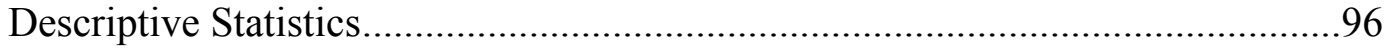


Multiple Regression Analysis

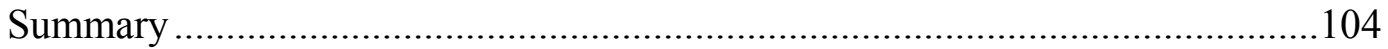

V. SUMMARY, DISCUSSION, AND CONCLUSION ……………....................107

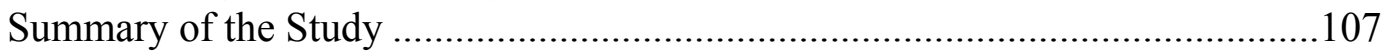

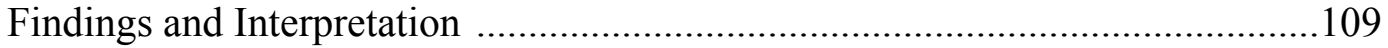

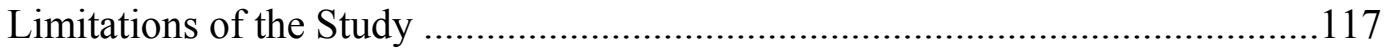

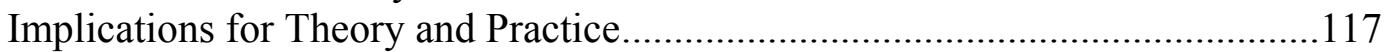

Recommendations for Future Research .........................................................120

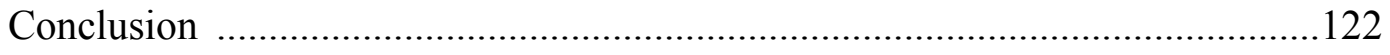

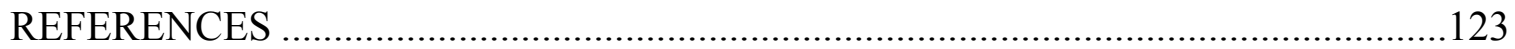

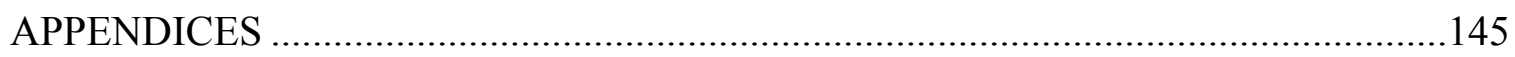

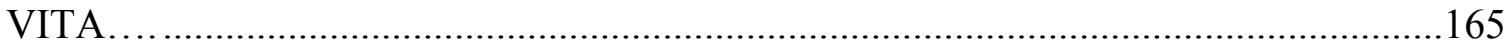




\section{CHAPTER I}

\section{INTRODUCTION}

\section{Background of the Study}

Globalization has touched almost every person and locale in today's world. As an economic force, globalization means increased power for organizations, people, and global markets (Friedman, 2000). As a political force, globalization has provided people, in once isolated countries in the continents of Africa and Asia, access to the ideals of democracy and international law (Lechner \& Boli, 2000). As a social force, globalization endangers less commonly spoken languages and cultural distinctions, increases cultural imperialism, and can even change people's identities (Barber, 1995; Said, 1993; Spring, 1998). "Some people see globalization as increasing the homogeneity of societies, whereas others see it as increasing the hybridization of cultures" (Torres, 2002, p. 365). Friedman (2000) maintains that globalization is not a mere phenomenon; "It is not just some passing trend" (p. 7), rather it is an overwhelming international system shaping domestic politics and the foreign relations of virtually every country in the world. Hence, depending on how it is perceived, globalization has its "advocates, adversaries, and ambivalents" (Zeleza, 2007, p. 80). For this study globalization denotes “The international flow of ideas and knowledge, the sharing of cultures, global civil society, and the environmental movement" (Stiglitz, 2004, p. 4).

Changes are taking place on every level: economic, social, and political; and although the implications of these changes are still blurred, it is clear that they are profound. Information, people, and ideas now traverse the globe with unprecedented speed and frequency. Yet, educational discourse in most cases has continued to remain 
passive, overwhelmed by issues and standards set years before the world was overpowered by technology and the open markets (Stewart \& Kagan, 2005). As a nation, "we can no more afford to isolate ourselves educationally than we can economically" (Stewart \& Kagan, 2005, p. 241). This situation requires the same urgency for reform in education as we would give to any crisis in this country. The global transformations that are shrinking the world and innovating the way business is done in the global marketplace should mandate a modification in the school curriculum to include global education and global citizenship to get high school students ready to join the global workforce. Wehling (2007) voices a similar concern about education not reflecting global changes taking place when he states, "I simply don't understand why politicians, the news media, and even educators themselves aren't more alarmed by the fact that dozens of countries make education improvement a top national priority". He adds, "Why aren't more people concerned about the implications of this (downward trend of education) for our economy and the future of our society" (p. 5).

\section{Statement of the Problem}

The social studies curriculum includes subject matter on global education and global citizenship intended to create global awareness. However, an in-depth review of the current literature indicates that there is a paucity of research on global education and global citizenship and their combined relevance to high school students who are on the threshold of making life-changing decisions. This lack-luster interest even in social studies stems from the general neglect of the subject matter in the curriculum especially since high stakes testing took precedence (Barber, 2002; Hicks, 2003; Merryfield, 1997; Pike \& Selby, 2000). Although The No Child Left Behind (2001) legislation specifies 
history, geography, civics and government, and economics as core subjects, it does not include social science as an area to be tested (Neil \& Guisbond, 2005; Pascopella, 2004; \& Rabb, 2004). Petrilli, the then acting Assistant Deputy Secretary for the U.S. Department of Education's office of Innovation and Improvement reinforced this situation by proclaiming that "nowhere in the legislation are educators told they are not to teach social studies" (Manzo, 2005, p. 2). However, it is evident that pressures to increase instructional time for the subjects that are tested have resulted in a reduction of time spent on subjects that are not tested (Burroughs, Groce, \& Webeck, 2005). As a result, students may graduate with a good knowledge of the subjects that are tested but yet lack the skills of living in a mosaic world fraught with complexities such as social, political, cultural and environmental threats. In a study done by Fernandez, Massey, and Dornbusch (1978) in the high schools of San Francisco the findings seemed to suggest that social studies would be important to students if they believed that it prepared them for their future. There seems to be a disconnect between students' perception of the subject and the actual curriculum and pedagogy in social science education. This could possibly place students at a disadvantage in a competitive, innovative, and technologically progressive world that demands different literacies (Dubin \& Kuhlman, 1992) and competencies (Reimers, 2009).

A corollary to this problem is that students' voices are seldom heard or considered (Flutter \& Rudduck, 2004). The dearth of literature dealing with student opinions or views about their own schooling is evident in the field of research (Calvert, 1975; CookSather, 2002; Weinstein, 1983). Statements of educational aims such as those that appear in suggestions to teachers, school prospectuses and school mission statements correctly 
focus on the student as the "principal beneficiary of the education system" (Calvert, 1975, p. 3). Yet, "every other group concerned with education: teachers, administrators, planners, and parents, employers and society at large - can obtain a better hearing of their point of view than can the pupil" (Calvert, 1975, p. 3). Therefore, this study sought to develop an instrument that reflects high school students' perceptions and attitudes on topics related to global awareness. It also sought to determine whether students' considered global awareness and their attitudes towards social issues as essential ingredients for participation in the global workforce.

A comprehensive search of studies done over the last 75 years for an instrument to measure high school students' perspectives of global education, or an evaluation of the appropriateness of their current education to their future careers and global citizenship did not yield any relevant results. However, a few studies focused on high school and college students' attitudes and awareness about the world at large and these were reviewed for content. Neumann (1926), who developed The Attitude Indicator dealt with 12 “international attitudes of high school students" (p. 795). Lentz (1950) studied the "phenomenon of worldism vs. nationalism" (p. 207). Some years later in 1957, Sampson and Smith developed a scale to measure world-mindedness in university students. Bingham (1979) presented her Acceptance of Global Education Scale (ACES) for teachers, and it was the first time the phrase global education appeared in tests. Silvernail (1979) introduced the Future World Perspectives Scale. This was followed by two studies done by Barrows, one with in collaboration with Pike, Barrows, Mahoney, and Jungeblut (1979), who was the lead researcher, that was designed for grades 4, 8, and 12 . The second study by Barrows and a host of associates (1981) was done on undergraduate 
students called the Global Understanding Scale. Finally, the review of the literature revealed that the Global Mindedness Scale by Hett (1993), which had been very popular in its use in dissertations and in related studies was not feasible for this study since the scale dealt with knowledge of discrete issues, trends, and systems that have a global impact.

Some of the more recent instruments began to look more closely at beliefs, values about culture, world-mindedness, and having global perspectives. The Intercultural Development Inventory (IDI; Hammer \& Bennett, 1998) is a cross-culturally generalizable instrument with good validity and reliability estimates of an individual's and group's core orientations toward cultural differences. The Beliefs, Events, Values Inventory (BEVI; Shealy, 2000) was designed to understand whether, how, and to what degree people are (or are likely to be) 'open' to various transformational experiences, such as participating in international education. While Braskamp, Braskamp and Merrill's Gobal Perspective Inventory (GPI; 2007) provides an empirically-based understanding of the relationship between service participation and students' development of a global perspective, while providing an empirical roadmap for educators interested in a servicebased model of college development (Engberg, 2010).

These instruments were not adopted for the present study because the samples used in the studies were inappropriate for this study. Almost all of them were designed for undergraduate students. Others addressed concepts not exactly aligned with this study. Some of the instruments dealt exclusively with culture while others addressed knowledge values and attitudes relevant to their community at the time. Hence, they were considered irrelevant in today's enigmatic world where technology has shrunk the earth 
and changed the landscape of education. The instruments in question, in some cases, failed to recognize the advent of a knowledge society (World Bank, 2003), a knowledge

economy (Neef, 1999), and the skills required to be viable in the global workforce today, which must be redefined within the framework of globalization.

For all the reasons outlined above, it became apparent that it was necessary for this study to be undertaken in order to ask high school students their perspectives on their education in the field of the social sciences to shed more light on their preparedness to join the global workforce. To do so a new instrument was developed to provide answers to the following research questions.

\section{Research Questions}

1. Can acceptable validity and reliability estimates be established for an instrument developed to measure high school students' global awareness?

2. Can acceptable validity and reliability estimates be established for an instrument developed to measure high schools students' attitudes on global social issues?

3. What is the relationship between high school students' GPA, race/ethnicity, gender, socio-economic status, parents' education, getting the news, reading and listening habits, the number of classes taken in the social sciences, whether they speak a second language, and have experienced living in or visiting other countries, and their perception of global awareness and attitudes toward global social issues?

For this study global awareness is considered to be the "knowledge of the interrelatedness of local, global, international, and intercultural issues, trends, and systems" (Florida International University's Quality Enhancement Plan, 2010, p.23). 
Global awareness represents the "cognitive or knowledge aspect of students' perceptions" (Clarke, 2004, p.56). This study examines students' global awareness and attitudes within the framework of the constructs adopted for this study namely: global education, global citizenship, and global workforce. The stance taken for this study is that do students in high schools possess global awareness that is achieved through global education?

\section{Global Education}

What is global education? Even though scholars (Anderson, 1968; Becker, 1982; Case, 1993; Kirkwood, 2001; Kniep, 1986; Lamy, 1987; Pike \& Selby, 2000) have wrangled with its illusive definition since its initiation and throughout its evolution, the definition of global education still presents a "linguistic confusion" (Popkewitz, 1980, p. 303). Tye and Tye (1992) posit that global education involves learning about those problems and issues, "which cut across national boundaries, and the interconnectedness of cultural, environmental, economic, political and technological systems" (p. 87), while Osler and Vincent (2002) claim that "global education encompasses the strategies, policies and plans that prepare young people for living together in an interdependent world...." (p. 2). The latter add that global education includes the teaching of human rights and social justice as a means of encouraging critical thinking and responsible participation. All of these interpretations of global education include similar ideas but from a slightly different viewpoint.

As vague as the concept of global education might seem, there is a very categorical realization that those responsible for preparing students to become responsible citizens of their own country and of the world should be trained and willing to deal with difficult and complex global issues. "While the interactions and synergistic dynamics that 
constitute globalization are many" (Stromquist, 2002, p. xiii), its relevance to students and their future as well as to this study cannot be underestimated. Fullan (1993), a strong proponent for change in education maintains that "change mirrors life itself" (p. viii). His call for change is based on the claim that education has "a moral purpose which is to make a difference in the lives of students ... and to help produce citizens who can live and work productively in increasingly dynamically complex societies" (Fullan, 1993, p. 4). He makes a very strong argument when he identifies the business of schools, as "making improvements, and to make improvements in an ever changing world is to contend with and manage the forces of change on an ongoing basis" (p. 4). This study borrows some of the salient features from those definitions of global education such as: learning "cross-cultural awareness" (Hanvey, 1982. p. 162), and the study of "global problems and issues" (Kniep, 1986, p. 437). It also involves the possession of human beliefs and values (Merryfield, 1990), and the willingness to make the world a sustainable and more equitable place (Oxfam, 2006) while being trained to become lifelong learners.

\section{Changing Definitions of Literacy}

To explain the relevance of global literacy to the global workforce, it is necessary to explain the changing definitions of literacy. "Today even the definitions of what it means to be literate are shifting" (Sluys,Lewinson, \& Flint, 2006, p. 199). The definition of literacy has progressed from an exclusive focus on reading and writing to encompass a more inclusive and expansive perspective. Linguists, anthropologists, educators and social theorists no longer believe that literacy can be defined as a concrete list of skills that people merely manipulate and use. Rather, they argue that "becoming literate is 
about what people do with literacy" (Sluys et al., 2006, p. 199); in other words the functional aspect of literacy.

"Several forces have brought about and continue to influence transformations of literacy in the workplace. These intertwined economic, organizational, and technological forces have changed the nature of most work. Among these forces is participation in the global marketplace...this creates new literacy demands...." (Mikulecky \& Kirkley, 1998, p. 290). Dubin and Kuhlman (1992) discuss the changing meaning of literacy in their book, Cross-Cultural Literacy: Global Perspectives. They maintain that educators are cognizant of the fact that literacy, as the "simple definition of 'reading and writing' as we conceived of it in 1984" (Dubin \& Kuhlman, 1992, p.vi), has matured. Today most educators concede that change is necessary to cater to the demands of the knowledge society, and which requires a multitude of literacies such as: "digital literacy" (Labbo, Reinking, \& McKenna, 1998), "critical literacy" (Muspratt, Luke, \& Freebody, 1997), “global literacy” (Schuerholz-Lehr, 2007), "functional literacy” (Verhoeven, 1998), and political literacy" (Warren, 1992). According to Ruddell (1999), the definition of literacy, the perspectives, and the stances, with which research in literacy (as relevant to the global workforce today) is addressed, makes all the difference in the findings.

What is meant by global literacy was a question asked at a Building Global Literacy workshop of the Association of Universities and Colleges in Canada (AUCC). They met to discuss how "to provide students with an education that will prepare them for the increasingly complex world of the $21^{\text {st }}$ century" $(2001, \mathrm{p} 1)$. Among the many responses received were : students should gain a global perspective, cultural 
understanding, competitiveness, knowledge of languages, new courses emphasizing international issues, and finally "be able to thrive in the international environment" (p.2)

Mitchell (2006) joins the conversation on global literacy by offering several interpretations of the twin words - From the Prime Minister of Thailand, Shinawatra (2001) "I would like them (the students) to have global literacy, think well, be eager for lifelong learning and able to adapt to change" $\left(2^{\text {nd }}\right.$ para. $)$, from the Queensland University of Technology (2006) " students seeking employment in job markets that demand and value knowledge of trends....understanding of cultural diversity, knowledge of world regions, cultures and societies, and skills" ( $2^{\text {nd }}$ para.)." Mitchell adds, "in an era of globalization, there is the economic context where global literacy means knowledge, skills and practices" $\left(4^{\text {th }}\right.$ para. $)$ and be able to function effectively in a globalized market. The Summit of $21^{\text {st }}$ Century Literacy (2005) described global literacy as understanding the interdependence among people and nations and having the ability to interact and collaborate successfully across cultures.

As noted there is no single concise description of global literacy. However, this study favors the definition of global literacy as put forward by the Wisconsin Department of Public Instruction (2006). It embraces all of the dominant components of the interpretations of global literacy outlined earlier and which also includes some of the main tenets of global education and global citizenship. For them, job seekers who are globally literate should possess the five Cs: communication - be able to speak more than one language, culture - explore and experience the compassion and the curiosity about another culture, citizenship - understand global responsibility, community - understand current international issues, and careers - become lifelong-learners. This study considers 
global literacy the culmination of a global education in getting the students ready for global citizenship.

\section{Global Citizenship}

"As education has long been tied to citizenship, a global education provides the basis for world citizenship" (Adams \& Carfagna, 2006, p. 159). According to Tye and Tye (1992), such education engages students of all ages and in all subject matter in "the study of themselves as members of the human species, as inhabitants of planet earth, and as participants in the global social order" (p. xvii). To become world-citizens students must learn to make global connections. They will only be able to do that when they "begin to view themselves as global citizens in a rapidly changing world when they encounter, compare, experience, and adopt multiple perspectives" (Bacon \& Kischner, 2002, p. 48). They must learn to connect the dots of the contemporary world they live in - going from the local to the global, crisscrossing between other people, events, and issues in the complex web of today's world. Myers, (2006) argues that:

Scholarship on globalization suggests that new forms of democratic citizenship are emerging, yet the United States' educational system remains resistant to global perspectives in the curriculum and continues to favor national patriotism over learning about the world. (p.370)

Americans who wish to exercise effective citizenship in a democratic society within a nation-state or a "global village" (McLuhan, 1967, p. 63) in the 21st century will have to be knowledgeable about global issues. Education today needs to include establishing contacts with students in other nations, to help promote mutual understanding and problem solving (Engler \& Hunt, 2004). Heater (1999) strongly 
asserts that globalization is the foremost reason that global citizenship has become a viable concept today; and although the phrase "global citizens" is in circulation in educational circles there is little understanding of its far reaching implications for the present-day students. This study borrows from all of the above-mentioned proponents of global citizenship its foremost principle, which is: preparing young citizens through global education to play an active role in understanding global issues and problems and being able to offer solutions for a more equitable and sustainable world (Oxfam 2006).

Global citizenship is an intrinsic part of global education, and together they provide the requisites necessary for the students to participate in the global workforce. Global citizenship entails the willingness to apply the knowledge of interrelated global issues and multi-perspective analytical skills to local and global problem solving (Florida International University's Quality Enhancement Plan, 2010). Zembylas (2003) in his book review of Osler and Vincent's Citizenship and the Challenge of Global Education presents a rather clear relationship of global education, global citizenship and the global workforce when he writes:

They [Osler \& Vincent] explore educational responses to globalization such as efforts to create a skilled workforce to compete in a world job-market, and efforts to create cosmopolitan citizens ${ }^{1}$ capable of participating in democratic processes to resolve problems facing the global community. (p.388)

\section{Global Workforce}

Today because of globalization, multinational/transnational firms now have workforces that are spread across continents and countries, and that include an

\footnotetext{
1 "Global citizenship" used in the same article with the same connotation.
} 
increasingly complex blend of cultures, nationalities, and languages participating in a very competitive environment (Rosenzweig, 1998). William J. Clinton, the United States President in 2000 in a "Memorandum on International Education Policy" dated 19 April, stated, "To continue to compete successfully in the global economy and to maintain its role as a world leader, the United States needs to ensure its citizens develop a broad understanding of the world, proficiency in other languages, and knowledge of other cultures" (as cited in Hunter, 2004, p. 9). "The link between education and the economy drives other nations and must inspire us" (Rust, 2007, p. 131). Globalization has forever changed the education landscape. "We live in an interdependent economic universe... and economic success for any country depends on the educational attainment of its population...." (p.131), and the translation of that education is to get high school students ready for global citizenship and the global workforce. The key elements of that education can be found in a global education.

\section{Assumptions}

The basic assumptions of this study are as follows:

1. Students will have taken some social science classes or other subjects that dealt with concepts of global education and global citizenship, and that they will have some knowledge about current world issues, environmental problems, and cultural and religious intricacies to be able to answer questions in the survey.

2. The students who return parental permission forms are representative of students who do not return parental permission forms.

3. The students who participate will answer the questions conscientiously. 


\section{Significance of the Study}

There are two important issues addressed in this study. The first is gauging high school students' perceptions of global awareness and the second is measuring students' attitudes towards global issues. The history of education reform has always been to mandate other people to do things supposedly for the good of the students but in the “"hierarchical structure of education" (Levin, 2000, p. 155), the students are at the lowest rung. "Traditionally, students have been overlooked as valuable resources in the restructuring of schools" (Soo Hoo, 1993, p. 392; see also Ivey \& Broaddus, 2001; Vaughn, Schumm, Klingner, \& Saumell, 1995). Prior studies have generally focused on researchers' analyses and interpretations rather than students' perspectives (Jencks \& Phillips, 1998). "When adults do think of students, they think of them as potential beneficiaries of change. They rarely think of students as participants in a process of change and of organizational life" (Fullan, 2001, p. 151). This research is fueled by the recognition that students influence instruction and decision-making in the classroom (Wolfson \& Nash, 1968), and that their opinions are as valuable as those of teachers (Berliner, 1976). Phelan, Davidson and Cao (1992) argued that it is imperative to give more attention to "students' view of things that affect their learning, not so much to factors outside school, but to those in school that teachers and policy makers have some power to change" (p. 696).

The second segment of this research is the development of an instrument since no appropriate instrument was available for this study. The development of this instrument will: (a) help educators assess high school students' global awareness and their attitudes on global issues: (b) give students the rare opportunity to express themselves on their 
own education and its importance to their future in the careers they choose in the interdependent and interconnected world of today; (c) enable teachers to understand that students' voices are a tool they "have at their disposal to make themselves heard and to define themselves as active participants in the world" (McClaren, 2003, p. 245); (d) provide empirical evidence that realistically should precede the consideration of some reform in the improvement of curriculum; (e) add to the knowledge base of research done on students' opinions, voices, and perspectives; (f) identify the differences in the students' perspectives with the inclusion of demographic variables such as Grade Point Average (GPA), race/ethnicity, socio-economic status (SES), gender, speaking a second language, parents' education, having experienced living in or visiting other countries, reading and listening habits, and finally; (g) reiterate what other educators (Calvert, 1975; Cook-Sather ,2002; Myers, 1994) believed and wrote about, namely, that students are an integral and a very important beneficiary of the educational system;

In a letter to the community, Dr. Rudy Crew (2008), at the time, Superintendent of the Miami-Dade Public Schools system agreed with Friedman's (2005) thoughts in the comments he made about The World is Flat, when he remarked that, "Our schools must respond to these changes for two reasons: The first reason is simply because we live in an interconnected world and are continuously learning informally and adapting to it. The second, "and perhaps more importantly, our students will live in the flat world and we have a professional and moral obligation to prepare them". This mirrors the philosophy of John Dewey (1916) who wrote:

As a society becomes more enlightened, it realizes that it is responsible not to transmit and conserve the whole of its existing achievements, but only such as 
make for a better future society. The school is the chief agency for the accomplishment of this end. (p. 20)

\section{Delimitations of the Study}

1. The study has a sample which consists mostly of Hispanic students.

2. High school students in Miami-Dade County, Florida may not be representative of students in other counties such as Monroe County, Broward County, Collier County, and Palm Beach County within the South Florida area.

3. The study was done in high schools within the Miami-Dade County in the South Florida area which may not be representative of other schools in other parts of the state, or the country.

4. The sample was limited to schools that had principals willing to participate in the survey.

\section{Operational Definitions}

For the purpose of this study, the following terms convey the meaning as set out below. Other terms will be explained as they are introduced.

Attitudes. They reflect the affective evaluation of events and are frequently the consequence of learning. They are hypothetical constructs that are sometimes manifested in verbal reports.

Basic literacy. The definition used in this study in the one given in the Elementary Secondary Education Act, Title II, Basic Skills Improvement Program, that basic skills include reading, mathematics, and effective oral and written communication (cited in abstract, Jackson, 1980) 
Empirical. Unbiased, objective observations (Newman \& Newman, 2006, p. 228).

Functional literacy. A classic definition by Verhoeven (1998) of functional literacy is: "It involves cognitive, linguistic, educational, and social factors of literacy development" (p. 8).

Future. Pertaining to or connected with time to come (The American Heritage Dictionary of the English Language, 2006). However, for this study the word future will be used interchangeably with job opportunities for the students in the global workforce.

Globalization. "The international flow of ideas and knowledge, the sharing of cultures, global civil society, and the environmental movement" (Stiglitz, 2004, p. 4).

Global awareness. It is the "knowledge of the interrelatedness of local, global, international, and intercultural issues, trends, and systems" (Florida International University's Quality Enhancement Plan, 2010, p.23).

Global citizenship. Global citizenship entails the willingness to apply the knowledge learned through global education "of interrelated global issues and multiperspective analytical skills to local and global problem solving" (Florida International University’s Quality Enhancement Plan, 2010, p.58)

Global competency. The knowledge and skills that help students across disciplinary domains to comprehend global events and respond to them effectively (Reimers, 2009).

Global education. The process by which students are prepared to fulfill their civic responsibilities in a diverse and interconnected world (Hovland, 2006, as cited in Florida International University's Quality Enhancement Plan, 2010, p.58). 
Global literacy. Job seekers who are globally literate should possess the five Cs: communication - be able to speak more than one language, culture - explore and experience the compassion and the curiosity about another culture, citizenship understand global responsibility, community - understand current international issues, and careers - become lifelong-learners (The Wisconsin Department of Public Instruction, 2006).

Global perspective. Global perspective "includes a general recognition of human conditions within a socio-ecological framework, and considered a level of consciousness about the world which is developed in response to both formal and informal learning processes" (McCabe, 1994, p. 275). For this study a global perspective is looking at the world through the lens of a person who understands that no one lives in isolation and that interconnectedness affects the human race both positively and negatively.

Global workforce. Today because of globalization, multinational/transnational firms now have workforces that are spread across continents and countries, and that include an increasingly complex blend of cultures, nationalities, and languages participating in a very competitive environment (Rosenzweig, 1998).

Perspective. A subjective evaluation of relative significance and the ability to perceive things in their actual interrelation or comparative importance (The American Heritage Dictionary of the English Language, 2006).

Relevance. Saracevic (1975) and Harter (1992) consider relevance to be both objective and subjective. For this study the researcher will consider the subjective nature of relevance which according to them is concerned with the appropriateness and various 
degrees of intellectual interpretation (referring to perception, taking the user into consideration, p. 322) by humans.

Social science. For this study social science includes subjects such as history, geography, political science, sociology, psychology, economics, anthropology, and additionally, global studies, international studies, and social studies. The words social studies is sometimes used interchangeably with social science by certain educators, and accepted as such for this study..

\section{Summary}

The chapter addresses the need for changes in the school curriculum due to globalization. The concepts of global education and global citizenship are discussed within the context of changing definitions of literacies. The world has become a knowledge society with a knowledge economy (Hargreaves, 2003) and global literacy is important for students as they join the global workforce. High school students need to be taught how to become lifelong-learners (Haggerty, 1995) to stay productive in a global society. They need to understand interrelationships of people worldwide in preparation for their participation as global citizens. An important feature of the problem presented was the absence of consideration for students' opinions. The chapter continued with a narrative on several instruments used to investigate topics relating to global awareness. However, since no instrument was found suitable for this study a new instrument was developed. It helped measure high school students' global awareness and their attitudes towards global issues and the relevance of both to their future in the global workforce 


\section{Overview of the Study}

This study is presented in five chapters. Chapter 1 provides some background to the problem with education in high schools today as a result of globalization. A brief description on the importance of students joining the global workforce followed by the changing interpretations of literacy, some definitions of global education along with a brief discussion on global citizenship were outlined. The chapter also addressed the problem of students' perspectives being neglected. Additionally, a summation of a list of instruments, which were considered for the study, was presented, and a case made to develop an instrument. Chapter 2 includes a review of the literature pertaining to the myriad definitions of global education. It addresses students' perspectives and concerns about their school, curriculum, and related matters. It provides a detailed commentary on the importance of global citizenship. It establishes the justification for the development of an instrument to measure high school students' perspectives of global education and its relevance to their future in the global workforce and to global citizenship, along with a rationale for the choice of demographics. Chapter 3 contains a comprehensive description of the development of the instrument to measure high school students' perspectives, while supporting its reliability and validity. The chapter also describes the research design including the subjects, sampling and treatment procedures. The data analysis and findings of the study are presented in Chapter 4. Chapter 5 includes a discussion of the findings, conclusions drawn from the study, and recommendations for future research. 


\section{CHAPTER II}

\section{REVIEW OF THE LITERATURE}

This chapter presents an overview of globalization, and a plethora of definitions of global education and global citizenship that have continued to warrant a reform of the school curriculum. These definitions were reviewed in the context of their importance in developing a global awareness from the students' perspectives in identifying the relevance of global education and global citizenship to their future in the global workforce. The chapter continues with a review of the literature on the significance of student voices. The review centers around studies that elicited responses from students on their perceptions or perspectives on various educational features. These words (student voices, perceptions and perspectives) have been used interchangeably in some studies, and are accepted as such in this study. The chapter concludes with an analysis of the instruments used in research that have attempted to define and measure certain concepts of global education, listed here in chronological order: A Study of International Attitudes of High School Students (Neumann, 1926), World Citizenship Attitude Correlates (Lentz, 1950), A Scale to Measure World-minded Attitudes (Sampson-Smith, 1957), The Acceptance of the Global Education Scale (Bingham, 1979), Future World Perspective Values Scale (Silvernail, 1979), A Survey of Global Understanding (Barrows, 1981), New-mindedness (Ornstein \& Ehrlich (1989, p. 241), Global-mindedness Scale (GMS;Hett, 1993), the Intercultural Development Inventory (IDI;Hammer \& Bennett, 1998) the Beliefs, Events, Values Inventory (BEVI; Shealy, 2000), and finally the Global Perspective Inventory (GPI; Braskamp, Braskamp \& Merrill, 2007). Their appropriateness for this study or otherwise were discussed, and a case made for the 
development of a new instrument to study high school students' perspectives about their readiness to join the global workforce.

\section{The Repercussion of Globalization}

"Globalization, simply put, denotes the expanding scale, growing magnitude, speeding up and deepening impact of transcontinental flows and patterns of social interaction" (Held \& Mcgrew, 2002, p. 1). Even in its simplistic connotation “globalization engenders complexity” (Suarez-Orozco \& Qin-Hilliard, 2004, p. 5). It subsumes three crucial areas of the marketplace: (a) The economic world (Dunning, 2002) accelerated and dominated by modern technologies of transport and communication, (b) cultural globalization (Appadurai, 1996) which is a direct result of the media blitz causing the disappearance of local customs, norms and lifestyles (Huntington, 1996); and (c) the geopolitical side of globalization (Friedman, 2006) caused by the breaking down of nation-states (Wallerstein, 1979) and their interdependence (Kerr, 1979) together with the fluidity of national boundaries. The many faces of globalization are mirrored in: the economic practices of free trade; the cultural and social domain where it is reflected in the flow of people, goods and information, and a call for human rights; and in the political arena where it is evidenced in the breakdown of nation-states, and the beginnings of free elections.

From this perspective globalization looms rather overbearingly as a force to be contended with and it "necessitates a new paradigm for learning and teaching" (SuarezOrozco \& Qin-Hilliard, 2004, p. 5). Education can no longer entail only memorization of knowledge; rather it should give way to a new paradigm where cognitive thinking and problem-solving skills become the norm. Students must graduate with a cultural 
sophistication that enables them to work collaboratively in a diverse workplace (SuarezOrozco \& Qin-Hilliard, 2004). They must be ready to find their place in a knowledge society where being cognizant of how to become a lifelong learner is central to achieving success (Stiglitz, 2004). They can no longer depend on the current curriculum to qualify them for what lies ahead in their future. Rhoades and Slaughter (1991) observed that educational reform in the United States is being argued in terms of "being reshaped to meet the needs for a global market" (p. 208), while Green (1997) seems dubious about whether globalization processes will serve to effectively modify education. The common sense rationale is offered by Adams and Carfagna (2006) who maintain that, "To keep pace with the forces of globalization requires a global education" (p. 159).

It was imperative to include globalization as the springboard for this literature review because education for the future is so inextricably connected to the relentless advance of globalization. The late Ron Mofatt (2007), president of the National Association for Foreign Student Advisers (NAFSA) had this to say, "Competencies once considered essential for productive professions within a regional or national economy are no longer the coin of the realm in a market place without borders" ( $1^{\text {st }}$ para.). He added, "Global systems generate global issues that can only be addressed with global competencies" ( $1^{\text {st }}$ para. $)$, and global competencies can only be achieved through global education.

\section{Defining Global Education}

Many scholars have attempted to define global education. Most of these attempts evolved in the1970s; each decade heralded new educators with a vision for reform in education and innovative educational insights into the transformation occurring in the 
world because of globalization. They were apprehensive about the breaking down of the rigid borders of nations which was causing changes in the community. Communities continue to become knowledge societies demanding knowledge workers who have the competence of lifelong learners (Hargreaves, 2003). With the advent of the technological era, knowledge had suddenly acquired a very short shelf life. The above-mentioned circumstances became fundamental in the advocacy for some adjustment of the curriculum in schools which is generally referred to as global education and considered important for students joining the global workforce, and one addressed very persuasively by Wagner (2008) in his book, The Global Achievement Gap. His thesis is that only the most innovative schools in the world provide students with the skills that will enable them to compete in a global workforce. In the United States, "students are graduating from both high schools and colleges unprepared for the world of work" (p. xx). This was based on a survey of 400 employers.

There are a few issues that are central to all of the definitions, namely interconnectedness and interdependence, multiculturalism, and sustainable development. The educators seemed to follow a "borrow and add approach in developing the definitions" (Gaudelli, 2003, p. 6). Hanvey's (1982) model is still considered the yardstick for global educators who are trying to introduce global education into the curriculum in schools today. His seminal five dimensions of a global perspective are: perspective consciousness, "state of the planet" awareness, cross-cultural awareness, knowledge of global dynamics, and awareness of human choices (p. 162). Others have emulated his main ideas in their definitions, while subscribing to their individual concepts, thereby making their expositions more definitive or more ambiguous. 
For Kniep (1986) there were four elements crucial to global education: "the study of human values, the study of global systems, the study of global problems and issues, and the study of the history of contacts and the interdependence among peoples, cultures and nations" (p. 437). Lamy (1983) took a more critical approach and suggested that a curriculum with a global perspective must attempt to "encourage students to find workable solutions in socioeconomic, military-security, and ecological problems which challenge the leaders and citizens of this world" (p. 18).

Case (1993) admitted to there being a need to postulate even more, so as to further clarify the true meaning of global education. He offered two interrelated dimensions of a global perspective: the substantive dimension, which refers to knowledge of various features of the world and how it works; and the perceptual dimension, which is an orientation or an outlook. Used in this context, according to Case, global perspective refers to seeing the whole picture, a concept he shares with Pike and Selby (1988) who subscribed to a holistic paradigm. Swift (1980) did not extend us a definition but he had expressed some very germane features of global education. He believed that reading and writing could not be the ultimate goal of education but it had to be used to "turn children on to life, furthermore, to a life of global participation and responsibility" (p. 46). He also believed in a very important tenet of global education namely, that it is "a natural and holistic bridge to many disciplines" (Swift, 1980, p. 46).

Merryfield (1990, 1991, 1994) and Merryfield, Jarchow and Pickert (1997) addressed global education as a teacher-problem, as in teacher education, both in preservice training and in-service training (Merryfield, 1998) and in the area of mentoring. This is evidenced by her prolific writing on the topic. She combined the 
elements advanced by global scholars into what constitutes an all-inclusive global education definition, creating the most up-to-date framework in the field today. She included eight elements: human beliefs and values, global systems, global issues and problems, cross-cultural understanding, awareness of human choices, global history, acquisition of indigenous knowledge, and development of analytical, evaluative and participatory skills.

O' Sullivan (1999) is another one of the numerous global educators (Case, 1993; Hanvey, 1982; Kniep, 1986; Merryfield, 1998) who has added to the meaning of global education. O'Sullivan's definition is a general summation of the other definitions. He argues:

To prepare students for the global challenges of the new century, excellence in education should be defined as meeting the requirements of both paradigms (global economic competitiveness and global interdependence), and as including the study of all major global change-economic and technological-as well as the study of all world cultures, policies, ecology, and humanitarian issues. (p. 311)

His definition is inclusive of economic competitiveness which this study considers an important component of global education.

With so many educators advocating global education the important question is: Are schools heeding the advice and taking the necessary steps to incorporate or implement global education into the curricula? To answer that question an exhaustive search in the data bases (when research was started in 2008) such as JSTOR, Omni File Full Text Mega, Academic One File, ProQuest, and PsycINFO was conducted but 
produced very little empirical evidence of studies that were done to indicate that schools were attempting to adapt to accommodate the changing need of their students in the classroom today. Most of the information on schools that promoted global education or were beginning to incorporate the tenets of global education in teaching methods and curriculum came from websites like Global Ed, Global Net, American Forum for Global Education, CHOICES for the $21^{\text {st }}$ Century, Global Citizens for Change. Key words like global education in data bases such as OmniFile Full Text Mega (2009) brought up 359 articles. The number dropped to 86 when schools was added as a descriptor to the same data base. JSTOR (2009) brought up 459 articles when global education and schools were used as keywords appearing in full text. The time-frame for most of the articles coincides with the period when global educators were engaging in an active discourse about the subject namely, the 1980s-1990s.

If the word teacher was introduced as a keyword the articles increased phenomenally but decreased in the same amount when the word student was introduced. This was true in all data bases. Most of the articles dealt with teacher training and methods to be used in classrooms to teach global education, and interestingly the majority were within the time-frame from 1980 to 1993. Student opinion as key words and education as subjects brought up a mere 9 articles in OmniFile Full Text Mega (2009). Substituting the word perspective revealed 35 relevant articles. When student opinion was used as the key word and education and high school as descriptors were used in the ERIC data base a mere 15 studies came up. An entry of global education as key word and high school as descriptors resulted in 13 articles. 
This meager number of empirical findings in the literature that schools are attempting to integrate global education or some kind of reform to bring about change also underscored the rather sparse number of articles on students' opinions. There is plenty of literature or material available on advocating teachers in content and methodology about teaching global education, but few when where there is empirical evidence of such enactments. The few surveys conducted in the field or related to global education were done at a different time and addressed different attitudes of mostly college students. This study is more about getting high school students' global awareness about the diverse, dynamic, and interdependent world they live in. It is about their attitudes toward global social issues and the knowledge and skills they are developing with a global education in preparation for their entry into the global workforce.

\section{Relevance of Global Education to the Global Workforce}

"Preparing global-ready students requires schools to rethink their mission, priorities and objectives... Students should develop perspectives and skills to mitigate the growing cascade of challenges resulting from globalization's ubiquitous reach" were Mofatt's words while chairing a National Association for Foreign Student Affairs (NAFSA) meeting in 2007.The most important question in education today that educators, researchers, and policymakers must ask is: What do we want students to learn that will facilitate their entry into a geocultural and geopolitical world? A follow-up inquiry would be to find out the existing opinions of the high school students about their current curriculum. Do they believe they need a global education to advance themselves in the global workforce? Do they understand they will become part of a global workforce because "seismic demographic changes are transforming the workforce across the world" 
(Hewitt Associates Survey, 2004)? According to demographic projections, soon the workforce will look dramatically different than what is seen today" (Hewitt Associates Survey, 2004). It will be: an aging workforce (in 2010, $14 \%$ increase in $65+$ age group), a shrinking workforce (52 million jobs to be filled, 29 million people available), a more diverse workforce (34\% will be non-white), and a globalized workforce (the West will produce only $3 \%$ of the labor force) (Statistics from U.S. Bureau of Labor Statistics, Census Bureau, and the International Labor organization World Employment Report as cited by Hewitt, 2004).

These changing demographics in the population, especially the diminishing population of young adults, it is expected that this country will need a larger portion of them to be "well prepared educationally to meet the future needs of the nation" Cole (1990, p. 2). According to her and so many other global educators (Anderson, 1968; Becker, 1982; Case, 1993; Kirkwood, 2001; Kniep, 1986; Lamy, 1987; Selby \& Pike, 2000), students will face increasingly complex roles in a diverse workforce as adults both as citizens and workers, "and if all children are to develop advanced intellectual capabilities through their schooling, then we must understand and act upon the nature of this desired achievement" (Cole, 1990, p. 2). To stay competitive and learn to become lifelong learners, they will need global education.

"Students must know how to cope in a pluralistic society and how to relate to diversity" (Hendrix, 1998, p.305). In fact, he adds this process of training students to participate in a multicultural society should become a matter of conscience. Kniep (1986) appends to that thought when he admits, "Global education has not yet reached a place of prominence on the curriculum. It is the exception rather than the rule to find 
programs that include global educational content" (p. 437). Today, twenty-four years later, Kniep's assessment is still true. It is important for administrators, policy makers, and teachers to realize that, "to educate from the global perspective is to solidify the transcultural human forces that live within people" (Guillory \& Guillory, 1989, p. 58), and that, "the scope of the global education curriculum must be determined by the philosophy of an evolving world, and analysis of the current realities in which students live" (Hendrix, 1998, p. 307). According to many global educators (Case, 1993; Kniep, 1986; Selby \& Pike, 2000), who advocate global education and global citizenship, all of these concepts must be woven into the curriculum from an interdisciplinary point of view, together with an understanding of the obligations of world citizenship in the twenty-first century.

Most global teachers in the early 1970s looked at social studies as the vehicle to develop the main tenets of global education. Thuermer (1993) in her dissertation wanted to ascertain whether global education was really the answer to five persistent questions in the social studies curriculum. They were summed up as: (a) Should the social studies and social science courses be fused or federated? (b) What should the scope and sequence of the curriculum be? (c) Should social studies be learned in depth or through broad coverage? (d) What kinds of qualities should the social studies curriculum develop in students? (e) How can students be prepared through the social studies to be ready for the future?" (Thuermer, 1993, abstract). She drew the conclusion that while global education could contribute somewhat to the discussions surrounding the first three issues it was of most importance to the last two issues. Thuermer (1993) examined the qualities that the social studies curriculum should develop in students and if those qualities prepared them 
for the future. She drew the conclusion that while global education could contribute somewhat to the discussions surrounding the first three issues, it was of most importance to the last two issues. She decided that global education could provide students with the tools to begin to engage in a new kind of cognition, helping them take patterns of history that is the past and apply them to patterns of the present to be able to predict the blueprints for the future. This is true especially today, "when the most intractable problems are global rather than local, and when national boundaries and affiliations become less important or helpful in solving them" (Thuermer, 1993, abstract). In spite of this and other empirical evidence there has been a feeble attempt to really reform the social studies curriculum or any other curriculum because the worldwide movement (Tye, 2003) as global education is sometimes called, faded away when accountability appeared on the horizon.

It is worthy to note, nevertheless, that there is a gradual resurgence of global thinking since the beginning of the $21^{\text {st }}$ century (Fujikane, 2003; Marshall, 2003). The sole reason being the realization that it is an interrelated world we live in, and that for the United States to maintain its status quo as a leader in economic dominance in the world, education in this country must change now. There is also a broad agreement that the influence of the nation-states has diminished. According to Fujikane (2003) who looked at global education in the United States, Japan and the United Kingdom identified three reasons for this shift in worldviews, which should relate to the revised educational imperatives. He emphasized a strong focus on: (a) the intensity of interdependence in all aspects of human life which is best explained using the analogy of a spider's web; (b) 
Falk $(1994)^{2}$ envisages global citizenship as "based on social responsibility, solidarity, a feeling for equity, and for nature" (p. 7); (c) "The growing moral sense of "oneness" transcending national borders" (Fujikane, 2003, p. 143). In this context the instruction we provide in schools today is apparently not exactly in accordance with the prescribed educational suggestions offered by Fujikane (2003). Students need to learn and get educated within the confines of these world views to be able to become functionally literate (Verhoeven, 1998). In order to optimize the acquisition of global literacies and to prepare for a global workforce, that will grow increasingly interconnected and crosscultural, high school students need to have global education.

Wing-Wah (2004) shares similar ideas in her study. For her, the world has witnessed three important international trends in the past two decades: (a) an increase in the number of democratic states, (b) economic globalization, and (c) educational reforms in light of the challenges of the new millennium. "A great deal of research has addressed educational change in relation to either globalization or democratization but little has been said about the complex interactions among all three processes" (p. 497). Her study examined the local educational policy in Hong Kong and Taiwan. She observed the inadequacy of the educational systems to prepare students for the new millennium and how the urgent need for change was addressed. Wing-Wah argued that economic globalization provided an opportunity for both governments to reposition their economies and reorient their education systems. They demonstrated their insight by accommodating global imperatives in education and curriculum reforms, particularly the emphasis on

\footnotetext{
${ }^{2}$ He borrows this one from Steenbergen (1994) who summarizes Falk's discussion on global citizenship in a chapter in the book, The Condition of Citizenship.
} 
learning English as second language, and information and communication technology (ICT) as transnational skills. This is an example of how other countries are addressing some of the problems that this researcher is attempting to posit: Are the students in our schools ready to be the workers of tomorrow and take their place proudly in a globalized world?

While less cataclysmic, the brisk pace of globalization over the past 20 years, driven by the profound technological changes described by Thomas Friedman (2005) in The World Is Flat, by the economic explosion of third world countries like China, and India, and the accelerating pace of innovations, has produced a whole new world. Yet somewhat ironically, educational discourse has remained placid, framed by issues and standards set decades before the widespread use of the personal computer, the Internet, and free trade agreements (Fullan, 2001). Isolation is no longer an option educationally or economically. Other countries such as China, Russia, India, South Africa, Chile, and Brazil, to mention a few are moving quickly to restructure while reexamining their current educational systems. They are "making fundamental reforms in response to changed political conditions and demographic shifts and in order to prepare their students to be successful in the knowledge-intensive, high-tech, and globalized economy" (Stewart \& Kagan, 2005, p. 241). Those countries have realized the relevance of global education for their respective students, and it is expedient the United States follows suit. "In this knowledge-based society, the United States urgently needs to reaffirm a consensus about the role and purposes of public education in a democracy-and the prime importance of learning in meeting those purposes" (National Commission on Teaching and America's Future, 1996, p. 11). 


\section{Defining Global Citizenship}

Just as global education has had an evolving etymological development so has global citizenship. There is a profusion of literature on cosmopolitanism (Nussbaum, 2002), global governances (Rosenau, 1995), world-citizens (Parker, Ninomiya, \& Cogan, 1999), futurists (Silvernail, 1979), and even "planetary citizenship with an ecological interpretation" (Carter, 2001, p. 3) in the academic world. Each of these concepts has a very precise connotation and interpretation of why and how in a globalized world we belong to more than one community, society, or country.

While examining the literature and gleaning the most relevant concepts of global citizenship was arduous, it contributed to the realization that citizenship is an impassioned topic. It is intensely debated by both its proponents (Oxfam, 2006; Merryfield, 1998), and its critics (Heater, 2004; Miller, 1993 and others (Lynch, 1989; Pike, 1998; Tarrow, 1992; Wheatley \& Kellner-Roger, 1996) who interrogate the pros and cons of every level of citizenship. Nevertheless, it is undeniable that nationalism and globalism coexist in this interdependent world, and it is fundamental that global citizenship be discussed in the context of its relevance to the students' future in a global workforce.

Piaget was writing about "overcoming the egocentric attitude" as early as 1951. According to him faculty had to be trained to teach the child for cognitive and affective integration because the cognitive functions determined the "pattern" of behavior and the affective functions provided its "dynamism" (p. 563). It is important for educators to remember this concept because in his observations Piaget noticed, at what he called stage II, children revealed that, "their ideas of other countries have developed in exactly the 
same way as those concerning their own, but frequently with an antagonism between the two types of affective ideas or reactions" (p. 569). In his final conclusion, and the one relevant to this study, Piaget stated: "the child's discovery of his homeland and understanding of other countries is a process of transition from egocentricity to reciprocity" (p. 578).

Global citizenship gained recognition at the end of the $20^{\text {th }}$ century when the economic, technological and cultural trends became summed up by the word "globalization". The concept of global citizenship has, however, met with a good deal of skepticism. One basic objection, and it is a compelling one, is that the global conditions for citizenship do not exist and therefore it is at best, metaphorical. The second is that it tends to be elitist used frequently by jetsetters for whom global citizenship is an entitlement to economic trends. Global citizenship has its opponents to its most rigorous definition, namely that of belonging to a "fully established federal world government" (Carter (2001, p. 6) which in itself may seem to be utopian. Yet, it is still a concept about which all educational discourse must be cognizant.

In his 1964 classic, Class, Citizenship, and Social Development, Marshall asserted that citizenship in the nation-state involved three components: the civil, the political, and the social. According to him, " the civil element is composed of the rights necessary for individual freedom - liberty of the person, freedom of speech, thought and faith, the right to own property" (p. 211) among other things. The political aspect referred to participation in the process of government, and finally the societal feature alluded to the ability to have access to society's resources and enjoy social mobility. Global citizenship is more difficult to define because there is no global government or global 
laws and yet the twin words have begun to assume a certain magnitude that is both misunderstood and debatable.

In this study, global citizenship is examined from two viewpoints; one of them being Noddings' (2005) whose understanding of the subject addresses itself more to the adult population, and the other offered by Oxfam (2006) whose portrayal of global citizenship is more from the vantage point of the classroom, engaging both teacher and student.

Noddings (2005) elucidated that global citizenship most predominantly is defined in terms of economics which includes free trade and a global citizen "is one who can live and work effectively anywhere in the world" (p. 3). However, with the tremendous economic growth the environment continues to be threatened and this leads to the concerns of the destruction of Planet Earth. The economic order continues to influence globalization and global citizenship, and one cannot ignore its continued dependence and interconnectedness within the global village and its sustained effect on culture. Some people view this phenomenon as "the homogeneity of societies, whereas others see it as increasing the hybridization of cultures and diversity" (Torres, 2002, p. 365). For Noddings (2005) "peace is a precondition of global citizenship" (p. 4), adding that a global citizen must see war as contrary to all the aspects of global citizenship.

Oxfam (2006) defines citizenship education with children in mind and how global citizenship must be taught through curriculum within a teacher-student relationship. Education for global citizenship should encourage children to care about the planet and those who share it. It should give them the opportunity to develop critical perspectives about global issues and enable them to express their own values, beliefs and opinions 
while listening to and respecting other people's points of view. When they grow up and become global citizens they should have "a sense of their own role as world citizens, respect and value diversity... be outraged by social injustice, and are willing to make the world more equitable...." (Oxfam, 2006, p. 3). Global education has similar tenets and therefore global education and global citizenship are not mutually exclusive.

"Citizenship has always been associated with the constitution and operation of the modern nation-state" (Torres, 1998, p. 86) and therefore until recently has been part of the core curriculum because it is one of the mandates of any democratic society. Heater (1999) added to the same thought that, "For two hundred years citizenship and nationality have been political Siamese terms" (p. 95). However, others have indicated that "in the face of globalization, that it (relationship of education and national citizenship) is no longer a position that can be maintained" (Davies, Evans, \& Reid, 2005, p. 68). Torres (2002) quotes Ohmae, a respected Japanese business strategist who advances this thesis in his work The End of the Nation State, "that the nation state is economically sclerotic" (p. 366). According to Ohmae (1995), "nation-states have become inescapably vulnerable to the discipline imposed by economic choices made elsewhere by people....” (p. 12). And while the deliberation on the controversy of citizenship education continues, the world has moved on and the argument has entered a new stage of global citizenship, and even includes citizenship of Planet Earth which, "embodies a new sense of the universal political subject beyond the context of the nation-state, and a refreshed awareness of our shared dependence on nature" (Stewart, 1991, p. 23). The debatable question is: Is the nation-state and citizenship withering away with the advent of globalization? The rhetorical question is: Do schools have to learn to adapt to a new world view and prepare 
their students for global citizenship instead? The dilemma for education is how to come to grips with the changing nature of citizenship in a globalizing world.

Global citizenship has received some attention in international research that investigates teachers' perceptions of citizenship (Hahn, 1998., Torney-Purta, Schwille, \& Amadeo, 1999), while discussing the changing context of citizenship (Torres, 1998) especially for students in school (Pike \& Selby, 1988). According to Davies, Evans, and Reid (2005) citizenship education stresses three key features: social and moral responsibility, community involvement, and political literacy. While the general consensus among educators is that global education and citizenship education seem to be closely aligned, Davies et al. (2005) draw a distinction between global education and citizenship education: the former (global education) has wider parameters and is more "affective" (p. 84) while citizenship education is more of a "classroom-based cognitive development". Yet, Davies et al. (2005) agree that "with the declining power of the welfare state and the rise of globalization means that there is a need for greater integration between the two areas" (p. 85). There is no better way to make this happen than by "transnational movements in support not only of peace, but also of human rights, preservation of the global environment or greater economic equality which are often seen as vehicles for global citizenship...."(Carter, 2001, p. 7). While it is generally agreed that we are in a globalized world, the concept, that we belong to one world and need to respect other cultures and citizens, is still a dubious one. Although the idea of "oneness" has been mirrored in the media, international organizations, conferences, and treaties, the gravity of the situation has still to be realized in schools. The schools need to be aware 
their students need to understand global citizenship as being a crucial ingredient of belonging to the global workforce.

\section{Relevance of Global Citizenship to the Global Workforce}

Andrzejewski and Alessio (1999) ask the same relevant question as this study

does: Are we educating students for competitive employment in the global marketplace?

Are we educating global citizens who can respond creatively to the enormous and

pressing issues facing humankind in the twenty-first century?” (p. 4). Banks (2008)

seems to have the answers to those questions when he argues that "students need to

develop the knowledge, attitudes, and skills that will enable them to function in a global

society" (p. 132). Banks (2008) offers an explanation for that statement by adding,

"Worldwide migration has increased diversity in most nation-states and is forcing nations

to rethink citizenship and citizenship education" (p.132). In the wake of those statements

and others by concerned global citizens (Noddings, 2005; Nussbaum, 2002; Maira,

2004), it is vital to discuss why global citizenship is as relevant as global education is to

the future of the students in the global workforce.

Why is global citizenship essential for the $21^{\text {st }}$ century? The answer may be found in the words of The Summary Report of the National Commission on Teaching and America's Future (NCTAF) (1996) entitled, What Matters Most: Teaching for America's Future, "If every citizen is to be prepared for a democratic society whose major product is knowledge... every community must be focused on preparing students to become competent citizens and workers in a pluralistic, technological society" (p.3).In a fast-changing and interdependent world, education can, and should help young people to meet the challenges they will confront, now and in the future. 
All children should be taught to become less self-serving and more altruistic, and more so in the era of globalization; Oxfam (2006) elaborates on that thought: The lives of young people in the workforce are increasingly shaped by what happens in other parts of the world. Education for global citizenship gives them the knowledge, understanding, skills and values that they need if they are to participate in contributing locally and globally. Education is a powerful tool for changing the world because tomorrow's adults are the children and young people we are educating today. Education for global citizenship encourages children and young people to care about the planet they share. It will help develop critical thinking about many contemporary global problems. Children must learn that they can "become world citizens without losing their roots and while continuing to play an active part in the life of their nation and their local community" (Delors, 1996, p. 17).

Education for global citizenship encourages children and young people to explore, develop and express their own values and opinions, whilst listening to and respecting other people's points of view. This is important for children and young adults making informed choices as to how they exercise their own rights and their responsibilities to others especially when they join the global workforce. The scope of Education for Global Citizenship and Social Responsibility, according to Andrzejewski \& Alessio (1999), is wider than a single subject, it is in fact interdisciplinary. It is safe to conclude with a very pragmatic statement from Spring (2004), "I am persuaded we need schools that educate for active global citizenship within the biosphere paradigm" (p. 167). 


\section{A Discussion on Research Done on Students' Attitudes and Opinions.}

The review of how students' perceive their education will include a conversation on the reason their opinions are so vital in bringing about change. The stance taken on the following discussion of students' perspectives is to conclude that whenever students' opinions are sought the ensuing policy, reform or/and improvement has been beneficial to both policy makers and the student themselves. Here in the United States much of the classroom research in the last 26 years has focused on teachers or teacher-student relationships (Brophy, 1982). In fact, the National Commission on Teaching and America's Future (1996) very clearly includes students in its decision-making process when it addresses them stating, "students may think they have no role to play in implementing the recommendations... but students are America's future...think about how you can contribute to your learning and that of others" (p. 129).

The potential benefits of student consultation lies not only in what students say about their experiences in school but also what they say about their aspirations. Yet, students' perspectives continue to be under-represented as a source of valuable data in reforming schools and education at large. This study is an attempt not only to obtain beneficial data about students' perspectives on the relevance of their education for job opportunities and success in an interdependent and interconnected world, but it is also anticipated that it will serve to achieve a focused dialogue about some change in curriculum.

The absence of literature on student perspectives on curriculum is especially conspicuous; a view reiterated by Atula (1998) who in an earlier study maintained that the emphasis on global education in the extant scholarly literature had been mostly on 
teachers and curriculum but without the students' opinions. Using keywords such as student opinions and descriptors as education in schools displayed 204 articles in the JSTOR data base but there were even fewer studies that actually had research on what students believed was academically functional for their future careers. In defense of the copious number of studies, it must be stated that researchers have investigated students' perceptions about a multitude of topics relevant to their education in school, such as assessment (Earl \& Torrance, 2000 ; Terenzini, 1989), accountability (Mulvenon, Connors, \& Lenares, 2001) quality of education (Witte \& Rigdon, 1993), and a myriad of investigations on classroom management (Good, 1999) and school climate (Buckley, Storino, \& Sebastián, 2003), school safety (Kitsantas, Ware, \& Martinez-Arias, 2004), even blogging in the classroom (Ellison \& Wu, 2008), and cyber-bullying. All these studies collectively led to initiatives taken by both the schools and the community to improve the schools and their academic environment. In many cases reforms were introduced taking into consideration the limited data gleaned from those studies on student voices, or conclusions derived solely from sources that reflected the teachers' perspectives. Yet, others used the findings that manifested student opinions, even though they were not in tandem with those of policy makers and educators, which was notable.

Nixon, Martin, McKeown, \& Ranson recognized that, "fostering dialogue at the classroom level, enabling pupil's voices to be heard and valued, has the potential not only to improve relationships but to enhance the learning and achievement which policy makers seek" (as cited in Flutter \& Ruddock, 2004, p.23). Students' participation takes the usually descriptive analysis of classroom discourse, more commonly used in research on teaching and learning, a step further. "Students' perspectives indicate that the agenda 
for improvement may need to be set within a broader context" (Flutter \& Ruddock, 2004, p. 132).

Calvert (1975) argues that, "Education is supposed to be for the pupil" (p. 2), who according to her is the principal beneficiary from the educational process. "The educational process is supposed to accrue to the pupil and not to the teacher or the administrator or any person in society" (Calvert, 1975, p. 2). The students have very little choice, and "they occupy this position by virtue of their age" (p. 3). Wiggan (2007) on the other hand believes that there is a lot of research on student achievement and its related components but more is needed "to develop studies around students' perspectives, in which rather than being passive subjects, students are knowers and are given a voice...." (p. 325). Though educators see the significance "of choice in relation to student behavior and classroom management, there is little evidence that we have considered choice in relation to educational programs" (Rice, 2005, p. 40), such as making provisions for them to choose courses that would better educate them to become citizens in a globalized environment.

Cook-Sather (2002) is suspect of student exclusion in the discourse about curriculum and its effectiveness for their future, when she asserted, "We as educators and educational researchers must seriously question the assumption that we know more than the young people of today" (p. 3), especially about what they need to learn in preparation for the years ahead. For her, "it is time that we count students among those with the authority to participate both in the critique and in the reform of education (p. 3)". CookSather agrees with Calvert when she emphasizes, "there is something fundamentally 
amiss about building and rebuilding an entire system without consulting at any point those it is ostensibly designed to serve" (p. 3).

Studies of at-risk student populations include those by King (1977) and Howard (2003). The former looked at students' perceptions about vocational and technical programs, and added that, "in order to enable public education to initiate social, cultural, and economic growth, educators should have a broad perspective of the perceptions of these students toward traditional education programs" (p. 430). When Howard (2003) did his study he realized how little research had explicitly addressed African American students' own perspectives of their college ambitions and the manner in which they constructed their college potential and academic identities; his findings coming almost 32 years later after King (1977). Howard (2003) concluded that it was "imperative that future research take into account students' viewpoints" (p. 14). It was important for practitioners and researchers to provide viable spaces to gain insights into the day-to-day realities of young people and create schools and other learning spaces that responded to the needs of high school students. Not only are the lives of young people, and their potential to become productive members of society dependent upon it, but our future as a society is reliant on it as well.

A similar study was one done by De la Ossa (2005) who looked at an at-risk student population - those who attended alternative schools in the Eight Puget Sound area in Washington State. She considered the study partially because alternative school enrollments were on the increase and had the endorsement of the proponents of educational reform, correction workers and other interested parties. But the real reason for the study was to find out "how do alternative high school students perceive their 
educational experience? And, how do alternative high schools approach meeting the needs of the students?" (p.24). De La Ossa sought to get answers as to the viability of alternative schools from the students and although this study was limited in scope, the overall recurring themes represented voices that wanted to be heard. Most of the students thought the school was an outdated system and was not working. Students spoke about recommendations for future high schools and to some extent action was taken but not without some resistance from the concerned authorities.

Another example of how student voices are incongruous with those of administrators is Triplett and Barksdale's (2005) research which examined elementary students' perceptions of high-stakes testing through the use of drawings and writings. On the day after students completed their high-stakes tests in the spring, 225 students were asked to "draw a picture about your recent testing experience" (p. 241). The researchers examined the prevailing negativity in students' responses and suggested ways to decrease students' overall test-anxiety- including making changes in the overall testing culture and changing the role teachers play in test preparation. The findings in the studies mentioned were conclusive that students' insights were meaningful. In Donald and Denison's (2001) investigation into students' perceptions of quality criteria they noted, "that the importance students accord to particular goals shapes the activities in which they engage and the degree of effort they expend in those activities" (p. 481), led to conclusions that were in agreement with other educators (Cantor \& Langston, 1989; Volet, 1997; Volet \& Lawrence, 1990).

According to Torney-Purta (1989) "research is needed to explore how global and international goals may be achieved" (abstract). There is a dearth of research, that 
explores the nature of the students' global perspectives and international understanding, and specifically, their perception of the highly contested term of globalization used to describe the new world system for which they are being educated. Maira (2004) asserted that studies in globalization pertaining to youth culture "have much less focus directly on youth per se, and particularly on the ways young people themselves understand or grapple with globalization" (p. 205). Scholarship concerning globalization and relevant education has tended to focus less on students themselves and more on educational systems and policies. Brown (2006) explains in her dissertation that in her review of the literature "pertaining to globalization, international education and specially the International Baccalaureate Organization (IB) I found not one particular study that assessed how IB students perceive globalization or any other population of students perceive it, for that matter" (p. 9).

Additionally, Trice and Dey (1997) express their growing concerns about the increasing divergence in the educational goals of faculty and students. Faculty teaching, while considering students' 'intellectual development as more important than students' future goals or ambitions" (p. 531), had remained relatively stable over the past two decades. However, their study which covered a 24-year period identified that students' educational goals had changed during that time and those goals needed to be addressed. The data clearly indicated that the views of faculty and students were at variance with each other and more research was needed to make teacher-student goals more compatible. Their study manifested the importance of students' opinions for establishing successful goals. 
Allen (1986) believed that classroom management was very important because it established an environment conducive to both instruction and learning (Duke, 1979). This was a major concern of both the educators and the community (Gallup, 1985). Given that teacher-student interactions are central to classroom management, studies of students' and teachers' perspectives of their classroom interactions contribute significantly to the success of classroom management. Allen's study (1986) underscored that statement in his conclusion "classroom management must not be seen only from a teacher's perspective...but also from a student's perspective...." (p. 457).

An understanding of the teachers' perspective on classroom management is always being developed according to Brophy (1983), but unfortunately, very often without an understanding of the students' perspectives (Alschuler, 1980; Rogers, 1977). Johnston and Ochoa (1993) are an example of that negligence in their paper written on teacher education and global perspectives. Not once was the student perspective considered except as a follow-up to teacher-teaching and student-learning. This oversight on the part of researchers could eventually lead to negative encounters between students and teachers which will continue to affect classroom management negatively and even reverse learning.

Pyne, Nernes, Magnusson and Poulsen (2002) designed a Comprehensive Career Needs Survey to assess the career needs of junior and senior high school students in southern Alberta. This study brought together two important components namely student voices and global education. The questionnaire explored career needs from the perspective of students, teachers, parents, counselors, and administrators. An important aspect of the research was to examine how adolescents perceived the terms "career" and 
"occupations". It also helped determine how those perceptions evolved over time, and helped investigate their views on policies and practices to internationalize the curriculum. Their opinions on the following questions were explored: Why should schools develop an internationalized curriculum? What should an internationalized curriculum include? What teaching and learning strategies does your school use to engage young people in developing the skills they need now and in their future lives in an internationalized world? Results suggested, "that many individuals did not distinguish between the terms 'occupation' and 'career', students of different ages tended to consider these terms in somewhat different ways" (p. 5). But, interestingly and very important to this study, there was a consensus view among students and teachers interviewed that the internationalization of the curriculum and development of intercultural understanding should be a priority, and schools need to do more to tackle this issue.

Another study by Code, Bernes, Gunn, and Bardick (2006) used the same Comprehensive Career Needs Survey to investigate how high school students perceived career concerns. The question was very similar to the one in the previous study by Pynes et al. (2002), "what discourages you when you think about your career?" The majority of senior high students' responses fell into seven themes - the one relative to this study was training and education concerns. According to Code et al. (2006), the secondary students, "felt unprepared for their post-high school transition" (p. 172). They had specific concerns, one of them being "the right training and education for a job" (p. 167). The conclusions were that by “involving adolescents' own perceptions of their career concerns, the career planning process may become more relevant and students may receive better preparation" for their future (p. 173). 
That student perspectives are vital for educational reform, is a theme that resonates through educational discourse. Fullan (2001), a persistent advocate of school and curriculum reform argues, "that the moral purpose of schools is to make a difference in the lives of students and that making a difference is literally to make changes that matter" (p.16), and these changes should be to include students' opinions. In another study, Harris (1994) presented data suggesting that in two important dimensions of schooling there had been little change over time in the extent to which students had some control: The first dimension was their time, space, and movement and the second dimension revealed that students had little or no control over their learning. In his words, "student voice remains peripheral - they are essentially observers rather than participants in their own development" (p. 63). "What tomorrow needs is not masses of intellectuals but masses of educated men- educated to feel and to act as well as to think" (Farley, 1981, p. 179).

School students of all ages have their own opinions on everything from music and fashion to genetic modification and digital expertise. Educators are remiss in neglecting students' perspectives on their own education. The absence of student experience from current educational discourse seems to be a consequence of systematic silencing of the student voice. According to Erickson and Shultz (1992) this poor representation of "student opinion and voice from current educational discourse limits the insight of educators" (p. 482). They add, "Somehow the perspectives and voices of students themselves need to appear more prominently in research on teaching, learning, and curriculum....” (p. 481). 


\section{Review of Some Instruments Considered for This Study}

In the broad range of research studies that were reviewed there were several scales, surveys, instruments, questionnaires that were encountered. They were used to measure varying constructs such as: global understanding (Barrows, 1981), acceptance of global education (Bingham, 1979), global-mindedness (Hett, 1993), worldism (Lentz (1950), attitudes of high school pupils toward international questions (Neumann, 1927), student interests, knowledge, attitudes, and perceptions (Pike \& Barrows, 1979), worldmindedness (Sampson \& Smith, 1957), and future world perspective values (Silvernail, 1979). Intercultural Competence (Hammer \& Bennett, 1998), Beliefs, Events, Values inventory (Shealy, 2000), and the three major dimensions of the Global Perspective Inventory - cognitive, intrapersonal, and interpersonal ( Braskamp, Braskamp \& Merrill, 2007) are more recent inventories, and all of them had different operational definitions than the ones considered for this study. However, the central thread of commonality among them was learning to develop a tolerance for another culture and other people, or having a sense of social justice, recognizing human rights, and recognizing the need to save our planet. Knowing, understanding and caring were central to all of the surveys.

Since they all addressed nuances of multiculturalism, human rights, and sustainable development which are important components of global education and global citizenship, the instruments were reviewed in the context of their usefulness and their relevance, if any, to this study. There is a conspicuous absence of an emphasis on the interconnectedness and interdependence of the world due to technology, which almost seem to exclude the innovation, competitiveness, and lifelong learning components of global education. The most relevant ones will be discussed. The associated details, 
findings, and conclusions that will be mentioned may be not representative of the entire study undertaken, but definitely related to this study.

The earliest study found was done in 1927 by Neumann entitled very simply The Attitudes of High-School Pupils toward International Questions. The "expert" advice in this study was derived from "five of the most important books" (p. 795) at the time about the topic, and a list of 109 items was compiled and classified under 12 headings. The 12 headings were as follows: (a) racialism, (b) nationalism, (c) imperialism, (d) militarism, (e) desire for economic prosperity, (f) tendency toward proletariat cooperation for the establishment of the world state, (g) attitudes regarding public opinion, (h) tendency toward recognition of rights of other nations and peoples, (i) appreciation of their worth, (j) attitudes towards international cooperation, (k) attitudes of international good will, and (1) humanitarian attitudes (p. 795). The study was conducted to discover how various concepts about international issues existed in the minds of high-school pupils and an "attitude indicator" was used for this purpose. A five-point scale was designed to indicate the direction and relative strength of the attitudes. It was administered to 1,110 high school pupils in 15 high schools in six different states.

The results indicated that high school pupils had definite, conservative attitudes among other findings. Neumann (1927) suggested that those definite international attitudes were often based on prejudices rather than on facts, a conclusion true even today. Neumann's (1927) recommendations based on those findings were that those tendencies "are in need of redirection" (p. 796), and that they should be of interest and value to educators. The study is almost a period study as indicated by the choice of the headings; however, it is interesting to note that the same subject matter is being studied 
under different descriptive words and maybe different overtones, even today. Educational reform in the United States is still trying to get students to develop global perspectives. It is the impassioned desire of every global educator to enable students to develop empathy, and learn to live in a world that is so much more interrelated and mutually dependent than 82 years ago (Case, 1993; Hanvey, 1982; Kniep, 1986; Merryfield, 1998).

Lentz (1950) who founded the Character Research Institute at Washington University began by circulating questionnaires to measure conservative to radical political opinion and moved on to Attitude Research. This is about a study he called the Youth Expressionaire. It was given to a volunteer test population of 763 with a median age of 23 in 1936. This earlier study had a "3000 item exercise” (p. 207), however, since Lentz (1950) had no references the earlier study could not be located. That was followed by a 1946 study which was a four-page, 158-item questionnaire given to under-graduate students (However, it must be noted - only 66 items were included in the article describing the study). The sample size was 514 . He chose 200 world citizens and 150 national citizens from the test population on the basis of consistent reaction on the same two key items: (a) I would prefer to be a citizen of the world rather than a citizen of one country, and (b) Should world patriotism be second to national patriotism? Twenty-three test questions dealt with the United Nations, the atomic bomb, national disarmament, and national patriotism. The next ten items related to race and the remaining dealt with measurement of conservatism-radicalism. Again, the choice of topics was relevant to that generation.

Lentz (1950) concluded that the world citizen seemed to be not only more international but more democratic, tolerant and social-minded; these are some 
characteristics expected of global citizens today as well. However, he was intrigued as to what caused this kind of an individual to be this magnanimous. He published several books most of them related to humanitarianism and peace. Although he was later known as the father of peace research, his work is not discussed in the literature. This brief tribute to his work is relevant because of his contribution to the arena of peace and what is now almost synonymous with the concept of global citizenship which is directly related to this study. He expressed his disappointment when he remarked, "So much for this brief and somewhat incomplete report of a very incomplete study" (p. 213), and he hoped other educators and peace loving people like himself would continue to do more research in this area.

It was only in 1957 that the World-mindedness scale of Sampson and Smith gave educators the first definition of the concept of world-mindedness. For Sampson and Smith a world-minded individual possessed a value orientation, or frame of reference (world-mindedness) apart from knowledge about or interest (international-mindedness). They conferred that the two concepts need not correlate at all. Their example of a world citizen was a very simplistic one: "one who favors a world view of the problems of humanity, whose primary reference group is mankind rather than American, Chinese, English etc.” (p. 99). This scale was also administered to college students. It contained 60 items which were then reduced to 32; half of them were pro-world-minded items and the other half anti-world-minded items. It was a Likert-type scale. The items dealt with religion, immigration, government, economics, patriotism, race, education and war. There was no mention of how they arrived at the above-mentioned eight dimensions. A critique that could be directed to some of the questions is that some of them might seem 
inappropriate in today's geo-political and geo-cultural world. The odd-even reliability of .93 (corrected) and test-retest reliability of .93 indicated that the scale could be reliably used for measuring individual attitudes. The scale yielded several types of empirical evidence of validity - one of them being a high correlation with another scale whose validity had been independently established and whose content was similar to that of the World-mindedness Scale items, but, Sampson and Smith neglected to identify the "other scale".

There were many studies that used either the original World-mindedness scale or versions of it in conjunction with other scales either for dissertations or just independent research by corporations. Hull (1972) used the scale in a cross-cultural sensitivity group exercise involving foreign and American students and found that American students showed a significant increase in world-mindedness after participating in a sensitivity group also attended by students from other cultures. Using the same scale Dotson, Tashakori, and Courbois (1988) found that students' world- minded attitudes were improved as a result of the involvement in a summer study abroad program. Singer (1965) saw a steadily increasing number of reports regarding the manner in which the educational system was preparing Americans to assume effective and responsible role in world affairs. He felt a distinction needed to be made between matters of knowledge and matters of belief. He used a modified version of the World-mindedness scale (Sampson \& Smith, 1957) and the cosmopolitanism scale (Levinson, 1957). The modified version was administered to the students of four undergraduate courses in foreign and international relations. "The major purpose was to ascertain the changes that might accompany participation in foreign policy on international relations courses on the 
students' attitudinal predispositions toward the outside world" (p. 332). All three of the studies (Hull, 1972; Dotson et al., 1988; \& Singer, 1965) indicated there was a significant improvement in their world-mindedness attitude after taking courses or sharing spaces with people from other cultures.

A modified version of the Sampson and Smith instrument was also used by Wiseman, Hammer, and Nishida (1989, p. 357). It was a brief six-item version of the World-mindedness scale: (a) Our country is probably no better than many others; (b) It would be better to be a citizen of the world than any particular nation; (c) Our responsibility to people of other races ought to be as great as our responsibility to people of our own area; (d) Any healthy individual regardless of race or religion should be allowed to live wherever they want; (e) Our schools should teach history of the world rather than our own nation; and (f) Our country should permit the immigration of foreign peoples even if it lowers our standard of living. They used two other scales in the study Negative Stereotypes, and Attitude Toward Other Cultures.

A Likert-type scale was used; the higher the score the more favorable the worldminded response. The sample was drawn from students in a university in Japan, and from three universities in the United States. The general conclusion was that the Japanese knew more about the Americans and the Americans knew less about the Japanese. Wiseman et al. (1989) had this to say based on their findings: "By studying another culture, speaking its language, or visiting its nation, one learns the boundaries of one's own culture and discovers new cultural perspectives" (p. 364). This finding is included as demographics in this study to validate the same results. 
The following study is discussed for two reasons; first, the sample population was not students, second it introduced some of the personal demographics that this study would use. Garnham (1975) also used the World-mindedness scale (Sampson \& Smith, 1957) to explore some dimensions of Foreign Service elitism, and he tested the hypothesis that Foreign Service Officers' attitudes are related to personal background characteristics. This hypothesis was examined in the context of four explanatory variables: (a) regional background, (b) socioeconomic background, (c) religion, and (d) education. There were three dependent variables: (a) world- mindedness (Sampson \& Smith, 1957) (b) psychological flexibility, and (c) career satisfaction. His findings indicated that the knowledge of the officers' regional, socioeconomic, educational, and religious background did not improve the ability to predict their probable worldmindedness. This was an interesting result since other studies with almost the same variables had different results.

Khishtan's (1990) study also used the Sampson and Smith's scale (1957). His sample was faculty members. The purpose of the study was to examine whether selected demographic data and life experiences such as: travel abroad, study abroad, employment in foreign countries, participation in international conferences, educational background, teaching experience, and age, are related to attitudes toward world-mindedness. Major findings included the following: A majority of the respondents who demonstrated a high degree of world-mindedness had international experience, such as study or travel abroad, $80 \%$ believed that living in Washington, D.C, attending overseas conferences and using material in class that stimulated world- mindedness, were beneficial 
Silvernail's (1979) study validated teachers' global perspectives using the Future World Perspective Value scale. The twin purposes of his study were to test the reliability and validity of the instrument and to collect descriptive data of teachers' and students' present values. Interestingly, the study referred to global educators or proponents of global education as futurists. He built his study around four constructs: economic growth, technological development, international relations, and world economic justice. The sample size consisted of a total of 672 including preservice teachers, inservice teachers, and students, who had the smallest representation. A major limitation of the study was the lack of demographic information. The validity and reliability were not significant but the findings indicated in a small measure that both teachers and students accepted transformational world perspective values.

The following study is included here because its sample is different and provided unexpected and interesting findings. Rigby, Metzer and Dietz (1990) wanted "to replicate the Australian findings (Rigby, 1987) among subjects in a number of countries in different parts of the world, despite varying political or social circumstances" (p. 323). He wanted to verify whether the findings of the study such as: supporters of nuclear disarmament tended to be relatively world-minded, they were more opposed than others to institutional authority and more likely to express anxiety about the existence of nuclear weapons in both Australia and in the world (Rigby et al., 1990, p. 322), or were these results peculiar to Australia?

The countries chosen for the replication studies were: United States, Netherlands and West Germany. The questionnaires included a modified version of the Worldmindedness scale using a 19-item scale selected from a 32-item measure developed by 
Der-Karabetian (1983), based upon earlier work by Sampson and Smith (1957) and Silvernail (1979). Items tapping world-mindedness related to a wide variety of social issues, namely, race, religion, immigration, government, economics, education and ecology, or the lack of some or all of the world-mindedness attitudes which in turn indicated anti-world-mindedness. The five independent variables listed were: worldmindedness, attitude to authority, nuclear stress, age, and sex (p. 325). Age and gender were non-significant predictors. On the world-mindedness survey the results seem to indicate that "world-mindedness was the antithesis of patriotism" (p. 326). It was one of the conclusions that certainly could not be overlooked in the context of global citizenship. Bingham (1979) designed "The Acceptance of Global Education Scale” (AGES) to measure the attitude of secondary social studies teachers toward goal statements for the social studies curriculum that reflect a global perspective. "The scale incorporated current perceptions of global education identified from the literature into 10 goal statements for each of the world order tenets: (a) reduction of violence, (b) economic equality, (c) ecological balance, (d) social justice, and (e) political participation” (Bingham, 1979, p. 3). The scale also contained ten non-global statements. Both the global and the nonglobal statements were identified by experts in global education. It used a 6-point Likerttype scale. The questionnaire had 60 questions but the article did not contain any information about the study or its administration. In the review of the literature there were brief references to Bingham's AGES but nothing of any consequence.

There was a single study identified that had used the scale in conjunction with the World-mindedness scale (Sampson \& Smith, 1957), and that was in a dissertation by Hosseinali (1995). According to Hosseinali, the World-mindedness scale (Sampson \& 
Smith, 1957) measured value-oriented attitudes in people, whereas the Globalmindedness scale (Bingham, 1979) measured attitudes, beliefs, and knowledge about international affairs. He found that gender, teaching experience abroad, and living outside the United States were all significant predictors for world- mindedness. These findings appear to be similar to Khishtan's conclusions.

In 1979, Pike, Barrows, Mahoney and Jungeblut conducted an extensive study, taking in 102 schools at grades 4,8 , and 12 . For the purpose of this study only the information gained from the study of grade 12 will be discussed. Four survey instruments were developed: "a background and interest questionnaire, a knowledge test, and separate measures of attitudes toward and perceptions of other nations and peoples" (p. 2). The study was designed having a potential value as a stimulus to help educators everywhere to become more self-conscious about other nations. It was anticipated that it would help strengthen and close critical gaps in international understanding, and would help policy makers prioritize curriculum planning and stimulate more research on international education. The study was based on a "survey of 1728 students in 206 schools of $4^{\text {th }}, 8^{\text {th }}$, and $12^{\text {th }}$ grades across 27 states" (p. iv). "The final participation rate of selected schools was $59 \%$, a very satisfactory rate given the time-consuming requirements of the study....” (p. 9). The survey examined the students' knowledge of other countries and measured their attitudes and perceptions towards them.

The study provided some powerful examples of the extent of student illiteracy in world affairs, on the positive side it showed that when schools cared the results were reversed. The findings indicated: low level knowledge of other countries, a relationship between foreign language usage and formal study of language in schools. The research 
demonstrated a relationship between students' interest in visiting other countries and their attitudes and perceptions of those countries. Ethnocentrism seemed to diminish with age. The recommendations were that "what was needed was a sense of the importance of the international dimensions of education" (p. xii).

The Clarke (2004) study drew its inspiration from the Pike, Barrows, Mahoney and Jungeblut (1079) research. Clarke's study used 701 students from a diverse college population that represented departments of business, liberal arts, science, and teacher education. Global awareness was measured by: (a) academic study of at least one year of a foreign language, (b) number of visits to a foreign country, (c) degree of exposure to the media through television, magazines, and journals; (d) study of a course in non-Western civilizations, and (e) personal involvement with someone from another country or culture. The study investigated both the knowledge base and activism of students, described as global awareness, and the affective construct called Internationalism. The findings revealed that those students who gained exposure to a foreign language, got acquainted with another culture, and/or participated in a media that dealt with foreign countries - all had a positive global awareness attitude. These findings were similar to the findings of Khishtan (1990) and Hossenali (1995). The question of whether the culture of the United States was superior to that of other countries was generally agreed on, since the majority ( $71 \%$ ) of the respondents answered in the affirmative. Descriptive data showed that generally global awareness was associated with holding international attitudes.

Barrows, in collaboration with Ager, Bennett, Braun, Clark, Harris, and Klein (1981) under advisement from the ETS designed and administered the Global Understanding Survey (GUS). The survey (GUS) adapted 64 items from 10 existing 
scales: "the World-mindedness Scale, the Pacificism Scale, the Internationalism Scale, the Hostility in International Relations Scale, the Nationalism Scale, the InternationalismNationalism Scale, the Patriotism Scale, the Attitudes toward Patriotism Scale, the Peterson War Scale, and the Attitudes toward World Affairs Scale" (Barrows et al., 1981, p. 7). However, the final instrument contained 113 items and was administered to a probability sample from a two-stage stratified design. The first stage was determined according to three factors: "school type, location, and estimated mean student ability" (p.40). The second stage consisted of a selection of freshmen or seniors within four-year colleges and universities and all students from two-year colleges for a total of 3014 students. The findings indicated that "each of the three groups surveyed fell short of achieving the criteria that were explicit or implicit in the survey's instruments "(p. 135) which were designed to test knowledge necessary to global understanding. Another notable finding was that there was no appreciable relationship between global knowledge as tested and either foreign language proficiency of some formal or informal study of the language. Another major conclusion noted was the significant relationship "of the ways in which students acquired information with the knowledge and affect components of global understanding" (p. 136).

Torney-Purta (1982) looked critically at the findings of the Global Understanding Survey that Barrows et al. (1981) administered to 3014 college students. She wanted to answer the question "why education major students lagged behind other type of students" (p. 200). She had prospective teachers who were taking education courses take the Global Awareness Survey which was an adaptation of the Global Understanding Survey. She chose 28 of the easier items from the knowledge test of the Global Awareness Scale and 
administered it along with the 10 -item Global Concern Scale to approximately 1,500 secondary school students in nine states. " The following variables were significant predictors of the knowledge score among high school students: school grades, reading international news in the paper, gender (boys performed better), number of years of social studies, foreign travel, and watching television news" (Cogan, Torney-Purta, \& Anderson, 1988, p. 284).

In Torney-Purta's conclusions she forewarned that if one is attempting to improve the preparation of students at the undergraduate level to become teachers, one must be clear as to what one's aim is in the area of global understanding. If it is increased awareness and knowledge of global problems based on the findings, a general suggestion is to recruit intellectually more capable students into the education major. Her second critique was that more attention should be given to the formal curriculum. "Building an international perspective into a variety of courses taken by large numbers of students appears to be important” (p. 204). But this can be a cumbersome task especially since Karp (1981) had already found that "the textbook in American government that adequately presents America's place in the world from a global perspective - permeating the entire text - has yet to be written" (p. 7).

It seemed a logical process that since her last study indicated that global awareness is not part of the curriculum at the time that Cogan, Torney-Purta, and Anderson (1988) decided to learn from others. So, as a prelude to their study advanced the accepted wisdom that to enhance understanding of one's educational system it might be a good idea to compare it to a similar one or maybe a better one. With this in mind and the growing Japanese economic boom at the time, the Japanese educational system seemed 
an obvious choice for comparison. Again, they used the Global Understanding Survey (Barrows et al., 1981) and Torney-Purta's own study of 1982 as a springboard for the new comparative study. A stratified random sample was drawn from the total population of national universities in Japan involved in the training of teachers. The survey was translated into Japanese. The Japanese students answered the same test given by Barrows et al. in 1981 . All United States' data came from the Barrow's study which must be noted had a sample that consisted of students enrolled in different majors including education. The findings showed the Japanese answered more items correctly than the American counterparts. The Japanese did better on reading graphs and items that dealt with international trade, nuclear issues and international organizations - a reflection of their status in the world at the time. The findings suggested that the American students enhanced their global awareness and general knowledge skill during the four-year course at the university while the Japanese student seemed to stagnate during that same period. Both studies indicated that "internationalization" of education is a must if both countries have to meet the challenging needs of the $21 \mathrm{sr}$ century

As globalization was becoming a reality with the dynamics of the market place changing the boundaries of nation-states, and putting the identities of their populations in jeopardy, Hett (1993) understood that "the leaders of the $21^{\text {st }}$ century would need remarkable insight into other cultures and peoples and unprecedented concern for the well being of the world community" (abstract). To this end she developed an instrument to measure global-mindedness. The sample was drawn from a population of undergraduate students. Hett arrived at her item pool through interviewing 14 participants from a variety of professional backgrounds. That was the qualitative part of 
her research and it helped provide depth to the empirical data. She was able to identify five main dimensions through her literature review and the interviews, namely: interconnectedness of humanity, cultural pluralist, caring, futurist orientation, and global minded behaviors. Her instrument had 64 items that mirrored those five dimensions mentioned earlier. Her instrument has been the most popular instrument mentioned, modified or used in several research studies (Duckworth, Levy, \& Levy 2005; Golay, 2006; Kehl, 2006; Zhai \& Scheer, 2004; Zong, 1999). Her final 30-item global mindedness scale contained five factors under which the 30 items are subsumed responsibility, cultural pluralism, efficacy, global centrism, and inter-connectedness. Three hundred and ninety six students in San Diego were found to score significantly higher if they were female, if they were registered at a college with exposure to an international curriculum, if they had enrolled in five or more international courses, if they had participated in international activities and possessed an interest in politics with a liberal outlook, if they had friends from other cultures and/or had lived or studied abroad.

A study undertaken by Duckworth et al. (2005) appeared to contradict some of Khishtan's (1990) findings mentioned earlier. These authors studied 93 pre-and inservice international school teachers who participated in a professional development program. The questionnaire included a segment from the Global Mindedness Scale developed by Hett (1993) to measure global-mindedness. Duckworth et al. (2005) found that there was no significant correlation between scores on the Global-mindedness scale and the following variables: gender, age, ethnicity, length of stay outside the United States, birth place, and languages spoken. "One possible explanation is that most of these categories measure quantity...." (p. 298), and their study did have a qualitative 
component. The qualitative results indicated mixed levels of international mindedness for the participants. These findings were interesting since they contradicted all previous findings from other studies (Hett, 1993; Hosseinali, 1995; \& Khishtan, 1990).

After a critical review of the earlier instruments (Neumann, 1927; Lentz, 1950; Sampson \& Smith, 1957) it became clear they reflected a different time-frame and hence were ruled out. Bingham's AGES (1979) was never validated and was directed towards teachers. Silvernail's (1979) instrument had a very small sample of students. His four constructs were limited in their scope. Barrows et al. (1981) had a very complete instrument however it was administered to undergraduate college students and tested for the political, cultural and economic knowledge of the world. Hett's (1993) instrument again was very well received by the academic community. Hett's study sought to define global-mindedness while developing an instrument by expanding on already existing instruments. Hett defined global-mindedness as a world view that makes one feel connected to the world community and feel responsible for its members (p. 143), while this study seeks to define global education and global citizenship from a high school student's perspective as relevant to their future in the global workforce. The three most recent studies, IDI, GPI, and BEVI, all have a cultural bias with a focus on college students while this study explored high school students' perspectives of their education in the social sciences and analyzed their responses in the context of whether they are being prepared to join a global workforce.

A decisive effort was made to look at examples of studies undertaken in a variety of subjects and disciplines using instruments that measured global-mindedness or worldmindedness, but the geographic spread of research in this area is limited. It was mostly 
confined to Canada (Mehdi, 2006; Brooks, 2006), and the United States (some of which were discussed). Relevant empirical work undertaken by doctoral students, as well as by educational practitioners, academics and educators in general was included in the review. The time period was never given a consideration because it was necessary to probe thoroughly for an instrument that could be used for this study. In spite of a conscientious search none was found, but having located some of the older literature proved useful as a partial basis for this research.

\section{Choice of Demographics}

The research done with the instruments discussed also provided a framework for the selection of the demographics used for this study. Ethnicity was an important choice especially in the South Florida area where most students are Hispanic. Studies reviewed differentiated between the Hispanic groups. Schmidt in his article Academe's Hispanic Future (2010) acknowledges that Hispanic parents expect their children to go to college, adding that Cuban-Americans ages 18-24 are slightly more likely than white students their age to be enrolled in college. This is important for this study especially since it was carried out in the Miami-Dade County where the majority of Hispanic students are Cuban-American or Cuban immigrants. Adding to the same results, other researchers (Pedraza-Bailey 1985) have found that Cuban and Latin American descent students do better in U. S. schools than those of Mexican or Puerto Rican descent.

Earlier, Weissman, Bulakowski and Jumisko (1998) jfound that motivational factors for Hispanic students could be arranged in a hierarchy with knowledge at the top. They added that Hispanic students described the importance of succeeding because they were the first in their families to go to college. Interestingly both studies align with the 
influence of parents. Hispanic parents are motivated to have their children succeed which relates to the findings in this study namely that both ethnicity and parents' education are significant for factor one (self-perceptions of global awareness). Kao (2004) found that immigrant parents tend to engage more in a conversation with their children about college while Rong and Grant (1992) argue that Hispanic attainment improves with successive generations of residence in the United States. This also helped with the inclusion of parent's education as a demographic variable for this study.

The findings from some of these studies clearly indicated that "higher level of parental education led to higher levels of optimistic educational aspirations or educational attainment...." (Dubow, Boxer, \& Huesmann, 2009, p. 241). However, other studies have found that parents' education can be affected by ethnicity (as described), SES, and most importantly parenting styles which can be moderating factors (Darling \& Steinberg, 1993). Dubow et al. (2009) agreed that, "parental educational level is an important predictor of children's educational and behavioral outcomes" (p. 225). This was also validated by others (Dearing, McCartney, \& Taylor, 2001; Davis-Kean, 2005). These findings also support the argument that "immigrant parents are more likely to talk about college" (Kao, 2004, p. 427). "Children who have parents with higher education and a longer stay in the United States showed higher school achievement than children who have parents with lower education...." (Moon, Kang, \& An, 2009, p. 285).

Gender is the most commonly used demographic variable and it would be remiss to ignore especially in the discussion of students' perspectives and attitudes. There is an inherent psychological difference in gender approach to social studies as discussed in the finding of Wolters and Pintrich (1998). This study investigated contextual differences in 
motivation and self-regulated learning in three different subject areas: English, math, and social studies. In particular, they 'found differences in students' reported value and interest for academic tasks, self-efficacy, and test anxiety across the academic subject areas of mathematics, English, and social studies" (p. 41). However, each of these differences in the three motivational constructs was moderated by gender.

Colon and Sanchez (2010) concluded that "female participants reported higher levels of economic value of education and had higher grade point averages (GPAs) than male participants" (abstract). Qin (2006) also makes a contribution to these findings. Her research endorses previous findings that girls outperform boys academically. Van Houtte (2004) explains why girls achieve more and have more favorable attitudes toward school and education, among the obvious - spending more time doing homework, they have "higher expectation of themselves and are more enthusiastic about continuing their studies" (p. 160).

Socioeconomic status (SES) was chosen as a demographic variable because having a large immigrant population in South Florida it was almost obligatory to include. However, due to the constraints of time, and in the interests of cost and intrusiveness of some of the measures used to ascertain SES such as household income and home resources checklist, free/reduced lunch was used instead. Although Harwell and LeBeau (2010) argue that SES "is difficult to defend conceptually, empirically, or methodologically" (p.121), the measure used to define SES for this study was considered adequate since federal poverty guidelines are used in determining student eligibility for free or reduced lunch programs. 
The choice of subjects taken in the social science curriculum as a variable was integral to the realization whether they affected the students' global awareness and attitudes toward social issues including their future in the global workforce (Fernandez, Massey, \& Dornbusch, 1976; Farman, Natriello, \& Dornbusch, 1978; Pellegrini, 1982). Each of the subjects (history, economics, social studies, global studies, international studies) was chosen because a preliminary inquiry suggested these were some of the subjects offered in the MDCPS. History and economics was the most commonly offered subjects. A few researchers even discussed that they should be taught together (Duff, 1971; Main, 1978). Most research delineated the importance of both history and economics in the life of the students present and future including transfer effects of cognitive skills (Chizmar, McCarney, Halinski, \& Racich, 1985; Short, 1994).

The copious research done on the value of study-abroad programs validated the use of living/visiting other countries as a demographic variable. Wang, Peywandi and Moghaddam (2009) in their study found that even a two-week living abroad has significant positive attitudes towards diversity and other social issues. Doyle (2009) adds to the experience of studying abroad by arguing that is a holistic experience.

The inclusion of listening to music as an independent variable seemed important especially with the advent of technology, and sheer observation of high school students' obsession with i-Pods and MP3 players. However, although most research studies reviewed for this study did not use it as a variable, the researcher believed listening to music could pervade the students' perspective of global awareness or even their attitude toward certain social issues. . The major choice was between pop music and hip-hop. It 
must be noted that research on both genres of music has been interesting, more so on hiphop music, but none directly relating to their influence in the global awareness arena.

Reading habits with teenagers was necessary since reading from a book or newspapers is considered an outdated mode for them. Therefore, it was necessary to have the students indicate their preference in getting their news and information. It was expected to showcase if the students' global awareness, attitudes, and perspectives were influenced by where they did their reading or getting their news.

Although GPA is a widely used demographic variable its reliability as a predictor is skeptical especially if they are self-reported (Kuncel, Crede, \& Thomas, 2005). Therefore, self-reported grades must be used and interpreted with caution. Bacon and Bean (2006) argue that GPA is not widely used because it is poorly understood on account of grade inflation, greater use of objective testing or other means of grading. They added emphasizing that "self-reports of GPA and GPAs reported from the registrar have been found to correlate as high as .97” (p. 40). For this study GPA was used as a demographic variable to determine if it would be a correlate to the factors that emerged from the regression analysis.

\section{Summary}

The chapter opened with a discussion on globalization followed by a discourse of several definitions of global education and global citizenship. The subject matter that was reviewed, deliberated, and included in the narrative was to determine the relevance of the subject matter in getting high school students prepared for the global workforce. A few studies were chosen purposefully to support the statements and arguments on the importance of high school students' attitudes, perspectives, and global awareness. 
A chronological review of some appropriate instruments used to measure the attribute of world-mindedness or similar concepts were explored. Most of them mirrored their respective social, political, economic, cultural and societal communities. However, some general themes about empathy, global issues and problems, cross-cultural understanding, and social justice emerged from the studies analyzed over the last 81 years. They were: respect for another culture, caring for other human beings and the planet, behaving responsibly in the community, and the world at large. In spite of the recurring general themes none of them were considered because this study was not about attitudes but more about students' perspectives on the relevance of their education (social sciences) getting them ready for their the global workforce.

The review of the literature decidedly indicated that education had to change to accommodate the evolving dynamics of globalization. The chapter chronicled several viable reasons why global education and global citizenship should become part of the high school students' curriculum at school. Schell and Solomon (1997) offer yet another conclusive rationale for this study. In a series of arguments, they explain why students must become globally astute (p. 4), and one of the justifications was that "we now find ourselves rushing with great speed into global competition" (p. 5). The rhetorical question they ask and one that all educators should ask of our students is "are we prepared for this contest?” (p.5). This study is about finding out if high school students believe they are ready or being prepared for entry into the global workforce. 


\section{CHAPTER III}

\section{METHODS}

This chapter describes the research methods used in this study. It reviews the research questions in reference to the psychometric measures that were used. It includes: the research design, instrument development procedures to answer the research questions, the dependent (DV) and independent variables (IV), description of the sample, data collection, statistical treatment, and finally the limitations of the study. Prior to all these decisions an approval from the Institutional Review Board at FIU was received to conduct research on human subjects (see Appendix A)

"The selection of a research design is based on the nature of the research problem or issue being addressed, the researcher's personal experiences, and the audiences for the study" (Creswell, 2009, p. 3). Since this study would develop an instrument, the overarching choice was made to use inferential statistics and some descriptive statistics for the demographics using PASW (SPSS) 18. This decision was informed by the procedures of inquiry, and specific methods of data collection, analyses and interpretation that would be used to develop validity and reliability estimates for the instrument.

\section{Research Questions}

1. Can acceptable validity and reliability estimates be established for an instrument developed to measure high school students' global awareness?

2. Can acceptable validity and reliability estimates be established for an instrument developed to measure high schools students' attitudes toward global social issues?

3. What is the relationship between high school students' GPA, race/ethnicity, gender, socio-economic status, parents' education, getting the news, reading and 
listening habits, the number of classes taken in the social sciences, whether they speak a second language, and have experienced living in or visiting other countries, and their perception of global awareness and attitudes toward global social issues?

\section{Research Design}

The study was an ex post facto research design because the treatment had occurred naturally and the researcher had no control over assignment of participants to treatments. Ex post facto, “....is generally a term that describes research which is initiated after the independent variable (the variable of interest) has already occurred and cannot be manipulated...." (Newman \& Newman, 2006, p.119). For this study the variable of interest was the education the high school students had already received. "The researcher starts by specifying a dependent variable and tries to identify possible reasons for its occurrence as well as alternative explanations" (Diem, 2002, p. 3). It is commonly used in real-world situations when the investigation happens after the fact. In this study education has taken place, and the researcher evaluated whether high school students agreed or disagreed with their learning experiences as they related to global education and global citizenship.

"The researcher does not have control over the independent variables and therefore cannot make any causal conclusions - no matter what statistical analyses are conducted" (Newman \& McNeil, 1998, p. 56). The three major weaknesses in conducting an ex post facto study according to Newman, Benz, Weis, and McNeil (1997, p. 38) are: "the inability to manipulate the independent variables, the lack of ability to randomize, 
and the risk of improper interpretation due to lack of manipulation," all of which were duly noted.

For this study there were three constructs: global education, global citizenship, and global workforce. Nunnally (1970) states that when a variable is abstract rather than concrete, it is labeled a construct. "Such a variable is literally a construct in that it is something that the scientist puts together from his own imagination, something that does not exist as an isolated, observable dimension of behavior" (p. 139). He continues, “A construct represents a hypothesis (usually only half formed) that a variety of behaviors will correlate with one another in studies of individual differences...." (p.139). Creswell (2009) reiterates Nunnally's (1970) definition of a construct. For Creswell (2009) a construct is "an attribute or a characteristic expressed in an abstract, general way" (p. 130). Nunnally (1970) further explains that if the constructs are considered a vital part of the scientific activity then, "there are three major aspects of the process (i.e., developing and validating the measures):

1. Specifying the domain of observables

2. Determining to what extent all, or some, of those observables correlate with one another ....

3. Determining whether or not one, some, or all measures of such variables act as though they measured the construct (p.141).

In this study, all three of the above-mentioned processes were given consideration in the statistical treatments.

Independent/predictor and dependent/criterion variables are the two among the many labeled variables. For Creswell (2009) "independent variables are those that cause, 
influence, or affect outcomes" (p.50). The independent variables, henceforth referred to as predictor variables, considered for this study were demographics such as: grade point average (GPA), race/ethnicity, gender, socio-economic status (SES), speaking a second language, parents' education, having the experience of visiting/living in other countries, the number of classes taken in the social sciences, reading and listening habits. It was estimated that these independent variables were characteristics or attributes that could influence or affect the outcomes of this study.

The interpretation and coding of the demographic variables are as follows:

GPA (Grade Point Average) - the students entered grade point average on a scale from 1 to 6 (weighted) depending on the classes taken such as: Dual Enrollment, Advanced Placement classes, International Baccalaureate, or honors classes).

Race/ethnicity - the classification of White, Black, American Indian, Asian/Pacific Islander, Hispanic were adopted from the Miami-Dade County Public Schools websites (Hispanic coded 1, and others coded 0).

SES - socio-economic status was determined using students' feedback on whether they were the recipients of free and reduced lunch $($ yes $=1$, no $=0$, $)$.

Gender $-($ female $=1$, male $=0)$

Schools $-($ public $=1$, private $=0)$

Reading habits - the students classified their choices in reading material: books, magazines, Internet, and newspapers (dummy coded variables)

Listening habits - the students identified the type of music they listened to: hip hop, pop, jazz, and other (dummy coded variables) 
Parents' education - the students reported the highest education either parent had received: no formal education, high school, college, and graduate school (did not complete high school $=0$, high school $=1$, college $=2$, graduate school $=3$ ).

"Dependent variables are those that depend on the independent variables....." (Creswell, 2009, p.50). For this study, the dependent variables henceforth referred to as criterion variables were the students' perceptions about global awareness and attitudes towards global issues.

\section{Description of the Sample}

Participants in this study were high school students from the Miami-Dade County, Florida area. They were drawn from a sample of 66 high schools including charter schools (not including eight alternative high schools) and five parochial and private schools. A total of 14 schools participated resulting in a total sample size of 704 high school students. There were students from two charter schools, two parochial schools and one private school. The rest were public high school students. The sample size of 704 exceeded the recommended minimum needed to carry out a factor analysis, which according to Nunnally (1970) "is to have at ten times as many subjects as items....five subjects per item should be considered the minimum to be tolerated" (p. 214). Comrey and Lee (1992) give us a general rule of thumb as to sample sizes: 50 as very poor, 100 as poor, 200 as fair, 300 as good, and 500 as very good (taking into consideration the number of variables). So this study satisfied the rule for having a very good sample size.

. The sampling method was a non-probability sampling. The high school students were chosen from the $11^{\text {th }}$ grade and $12^{\text {th }}$ grade because they would definitely have just finished taking a class in social studies (sometimes labeled global or world or 
international studies). They were also chosen because they were on the threshold of making decisions for their future and might have better perspectives and attitudes about their current education in the social sciences.

A letter (see Appendix B) explaining the nature of the study, and detailing the commitment on the part of the school, teachers and students, if they chose to participate, was mailed to all 66 high schools within the Miami-Dade County area. The principals were advised that the survey would be administered during the social science period. It was anticipated that the response level would be low and hence all schools responding would be selected. The $11^{\text {th }}$ and $12^{\text {th }}$ grade high school students in schools that agreed to participate were asked to sign assent forms (see Appendix C), and their parents were also given consent forms (see Appendix D) to be signed. Their participation was contingent upon the parental consent forms and their own assents being returned duly signed.

Using the guidelines suggested by Nunnally (1978) that there be a ratio of 10 participants for each item in a factor analysis that is discussed later; this study required a sample from 300 to 400 high school students based on the 36 items estimated to make up the instrument. Thorndike (1982) advocated twice as many statements in the initial pool as the number to be retained in the final test. Lester and Bishop (2000) would like it to be three or four times the number of the required items for the final instrument. Although Mundfrom, Shaw and Ke (2005) made this point about sample size: "when the variablesto-factors ratio exceeds 6 , the minimum sample size begins to stabilize regardless of the number of factors or the level of communality" (p.159), the researcher chose the larger ratio for the factor analysis notwithstanding the recommendation from Mundfrom, Shaw and $\operatorname{Ke}(2005)$. 
The participants' ethnicity in this sample was multicultural coming from multigenerational immigrant families, who have settled in the South Florida area. The majority were Hispanic given the general demographics of Miami-Dade County. They also included students from Cuba, Brazil, Columbia, Honduras, Nicaragua and other Latin American countries. They also included students from the Caribbean Basin, namely: Jamaica, Haiti, Trinidad and Guyana. It also comprised few EuropeanAmerican, Native American, and African American students together with those from Asian countries.

\section{Instrumentation}

The following data collection instruments were used. The process of test development, outlined in the Standards for Educational and Pyschological Testing (1999), was used and combined with Dillman's (2000) Tailored Design Method, which is made up of the four stages of pretesting. Figure 2 summarizes the adapted framework that was used to develop the test

\section{Step 1 - Purpose of the Instrument}

The first step as identified by the Standards (1999) is to describe "the extent of the domain or scope of the constructs to be measured" (p. 37). For this study the three constructs of global education, global citizenship, and global workforce derived their scope from some of the studies examined in the review of the literature, and from the items of the instruments that were perused for this study. The purpose of this instrument was to measure the high school students' perspectives and attitudes concerning these three domains 


\section{Step 2 - Test Specifications}

The second step was to design the instrument by identifying test specifications. "The test specifications delineate the format of items, tasks, or questions; the response format or conditions for responding; and the type of scoring procedures" (Standards, 1999, p. 38). This study only included Likert-type survey questions. It used a 4-point response format ranging from strongly agree to strongly disagree, because Doyle (1975) makes a convincing argument for the choice: "The absence of a neutral point will often force a little more thought and result in ratings that are correspondingly more precise" (p.

23) from the respondents.

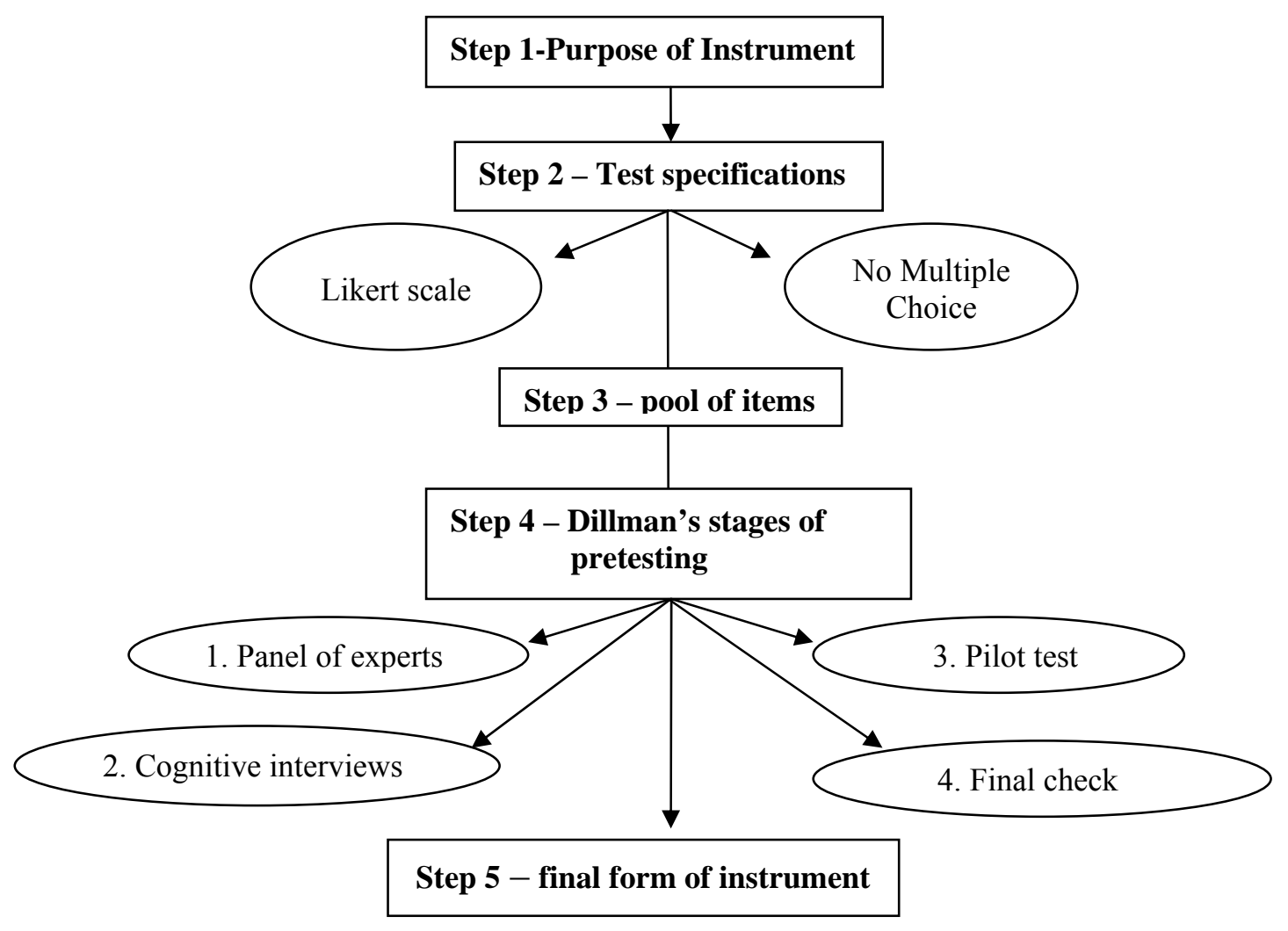

Figure 1. Instrument Design Framework (Chaney, Eddy, Dorman, Glessner, Green \& Lara-Alecio, 2007) 


\section{Step 3 - Development of a Pool of Items}

The process of measurement began with the identification of constructs: global education, global citizenship, and global workforce. The various definitions of the three constructs were established from a thorough review of the literature. It assisted in articulating the detailed meaning of the constructs and helped establish the defining components of the constructs which eventually resulted in the development of the item pool. The item pool was selected from the universe of content accumulated from the extensive and systematic literature review from the PsycINFO, JSTOR, ERIC, Omni File Full Text Mega, Academic One File, and ProQuest. An informative selection of dissertations on relevant topics to this study including a vast array of Internet sites such as Google Scholar, Global Ed, Global Net, American Forum for Global Education, CHOICES for the $21^{\text {st }}$ Century, Global Citizens for Change, and other related global education Internet sites were also read and included in the selective process for the item pool.

Additionally, various instruments that dealt with related topics were also examined, but were deemed inappropriate for this study. However, they did provide some concepts that are valid and necessary even today, Hence some of the items from the pool did contain certain elements from the following instruments: International Questions (Neumann, 1927), Worldism (Lentz (1950), Worldmindedness (SampsonSmith, 1957), Global Perspectives (Bingham, 1979), International Relations (Silvernail, 1979), Global Understanding (Barrows, 1981), New-mindedness (Ornstein \& Ehrlich (1989) and The Global Mindedness Scale (Hett, 1993). The Intercultural Development Inventory (IDI; Hammer \& Bennett, 1998), The Beliefs, Events, Values Inventory (BEVI; 
Shealy, 2000), and The Global Perspective Inventory (GPI; Braskamp, Braskamp \& Merrill, 2007) were also reviewed but did not make a contribution toward the item pool.

These items were created to serve as stimuli to the content, perspective, or construct to be measured. Special precautions were taken in the selecting, writing, and designing of the items and in considering the following: First, a frame of reference and item format - the frame of reference was to provide the research evidence that would indicate perceptual selectivity or as Van de Ven and Ferry (1980) called it "cognitive filters". Smith, Kendall, and Hulin (1969) argued, "When two individuals with different frames of reference are exposed to the same object of stimulus, they select different aspects and provide different summary evaluations of the situation" (as cited in Lester \& Bishop, 2000, p.11). Therefore, this study considered: GPA, ethnicity, gender, speaking a second language, visiting other countries, reading and listening habits, SES and parents' education as variables that could affect the students' perspectives of global education and global citizenship and their relevance to their future in the global workforce.

Second, content and population specificity implies that the words chosen will be specific to the particular population or sample. Additionally, descriptive and evaluative items were distinguished during test construction. Van de Ven and Ferry (1980) consider descriptive items to be positive and value-free, focusing on facts, while evaluative items are normative, value-laden, and involve an opinion about the strengths or weaknesses of the item that involves behaviors. Fry's (1968) readability formula was also taken into account to confirm proper comprehension of the items.

Finally, items were made "clear, concise, as unambiguous as possible, and simple as opposed to compound statements" (Lester \& Bishop, 2000, p. 11). Most items were 
worded mildly positive or mildly negative since more extreme items tend to create less variance (Mueller, 1986).

\section{Step 4 - Dillman's Four Stages of Pretesting}

Following the Institutional Review Board's approval, the items were subjected to four stages of pretesting as identified by Dillman (2000).

- Stage 1 - Review by experts

This step proved most frustrating since the researcher found it impossible to get the cooperation of the experts approached. There were 15 experts who were contacted in the United States, Australia, United Kingdom, and Canada. Since the topic was global education it was only appropriate to have experts not necessarily confined to the United States. Hence, Julie Dyer from Australia, an associate professor from the Deakin University, David Selby of the United Kingdom, Graham Pike of Canada and Chris Hart founder of the Global Studies Foundation in the United States were contacted to act as experts. However, repeated requests received no response. Other global educators such as William Gaudelli, Kenneth Tye, and Toni Kirkwood from the United States were contacted, too; but all declined the offer for various professional and personal reasons.

All requests were either denied or the recommendations were perfunctory and could not be used to establish content validity. An attempt was made to request faculty within Florida International University, and that failed as well. Another effort to get a focus group from the faculty at the College of Education proved unsuccessful, with only one professor, Dr. Ilon and my chair, Dr. Farouk in attendance. Since it was becoming increasingly difficult to get the cooperation of the experts the researcher chose to develop the items from the in-depth literature review done for this study. 
The main goal of content validity is "to finalize the substantive content of the questionnaire so that the construction process can be undertaken" (Dillman, 2000, p. 141). Content validity "sometimes referred to as subject validity, is primarily a judgmental process" (Lester \& Bishop, 2000, p. 12), and crucial to this study. "Content validity is established by showing that the test items are a sample of a universe in which the investigator is interested" (Cronbach \& Meehl, 1955, p. 281). According to Rubio, Berg-Weber, Tebb, Lee, Rauch, "Researchers can receive invaluable information by conducting a content validity study. Using a panel of experts provides constructive feedback about the quality of the newly developed measure and the objective criteria with which to evaluate each item" (2003, p.95). "Content validity does not provide a numerical number, just an indication of general agreement by experts in the content area" (Newman \& McNeil, 1998, p.40). In effect, according to Mueller "there is no statistical index of content validity. The process must simply be documented" (1986, p. 63).

With almost no expert contribution to content validity, the researcher developed the items. The items were most representative of the universe of content reviewed in the literature. The researcher paid careful attention to determine if voids in statements existed, if new items had to be included, and if items should be discarded or rewritten. Since the definitions of the three constructs were the underpinning for the development of the item pool, it was necessary to establish the logical clustering of items to each dimension, for example: items that clustered around multiculturalism, a concept included in global education, or items that clustered around sustainable development a concept of global citizenship. After much scrutiny thirty-six items were chosen to make up the item pool (see Appendix E). 
- Stage 2 -Interviews to evaluate cognitive and motivational qualities

According to Dillman (2000), the interviewer "probes the respondents to get an understanding of how each question is being interpreted and whether the intent of each question is being realized" (p. 142). It was anticipated that obtaining permission from the schools to interview the students was going to be complicated and stall the progress of this study. Therefore the researcher decided to skip this stage in the interest of time.

- $\quad$ Stage 3-Pilot test

According to Lester and Bishop (2000), and Dillman (2000), a pilot study should be conducted with the items selected from the those used to estimate content validity for the purpose of performing some initial item analyses, and they "should emulate procedures to be used in follow-up studies" (Chaney et al., 2007, p. 151). The resulting 36 items selected were carefully scrutinized for their content, clarity of expression, reading difficulty level (Fry, 1968), and double-barreled nuances prior to their inclusion into the pilot survey. A pilot survey was administered to 46 high school students.

- Stage 4-Final check

There were only two minor misinterpretations of the items on the demographic part of the survey. The two items (10 and 12) were explained to the students in the pilot study. They were also clarified in subsequent administrations of the survey to the sample. They were advised as to what the researcher was looking for, and there were no further problems.

\section{Procedures for Survey Administration}

A written approval from the office of Program Evaluation from the Miami-Dade County Public Schools (MDCPS) was secured. A formal letter explaining the 
significance and relevance of the study to the current educational environment with details on the administration of the survey, the format of the survey, the time-limit for the survey, and the supervision for the administration of the survey was mailed to all the principals of the 66 high schools in the Miami-Dade County area. This was accompanied by a brief form letter asking them to indicate their willingness or unwillingness to participate in the study. There was no response from any of the principals except one. This was followed by emails containing the same letter with attachments of the approval from MDCPS. A copy of both the student and parent consent form was also sent via email. On three occasions a brief meeting with the principal was set up to further encourage participation in the survey. The researcher visited each school that was willing to participate to distribute the forms (assent and consent) to the teachers to have them signed by students and parents prior to the administration of the survey. The teachers were informed about the event mostly through their principals, or sometimes, I was sent the name of the teacher I should contact for further instructions on scheduling etc.

The students were duly notified by their respective teachers about the upcoming administration of the survey. The researcher was informed about the return of the signed forms and the scheduled date and time for the survey. The survey was conducted during regular school hours and did not disrupt classroom procedures in the schools that participated. The survey took between $20-30$ minutes. The survey was administered by the researcher in an effort to comply with the proper administration of the survey. The surveys were collected in a timely and non-disruptive manner. A formal letter thanking the principal, teachers and students for cooperating in this endeavor was mailed shortly thereafter. 


\section{Statistical Treatment}

A model for the construction of a survey instrument was developed based on the literature and in accordance with some of the DeVellis' (1991) recommendations on scale development. However, the survey required some very important psychometric considerations, and those, according to Newman and McNeil (1998) are, "validity, reliability and usability” (p. 39). This required empirical investigation. Determining validity - refers to the accuracy of the scale, and that it really measures what it is purported to measure. The most important purpose of test validation is to determine how well the test measures all parameters that are confined to the construct in question. "The nature of the evidence required depends on the type of validity" (Nunnally, 1978, p. 88).

\section{Validity}

The two types of validity estimated were content validity and construct validity. Content validity has been discussed earlier in the chapter. Construct validity was the most important statistical technique for the refinement of this instrument. "It focuses on the extent that a measure (scale or subscales within a larger instrument) performs in accordance with the theoretical expectations" (Lester \& Bishop, 2000, p. 16). Creswell (2009) advocates construct validity to estimate whether "items measure hypothetical constructs or concepts" (p. 149), and factor analysis is often used as a statistical procedure for this purpose. Therefore, factor analysis was used to estimate construct validity for this instrument and to have a data-reduction technique, since it reduces a large number of overlapping measured variables to a smaller set of factors,. For this study it was vital to find out if items loaded on the factors that reflected the three constructs. It 
was also important to identify a factor structure, if possible, so that it can be replicated on a new sample before finalizing items in the survey.

Factor analysis requires two stages - factor extraction and factor rotation. The first stage was important to make the initial decision about the number of factors underlying a set of measured variables. That was established using Kaiser's (1958) eigenvalue rule which retains factors that have an eigenvalue of 1 or more. This method helped in the choice of the number of factors and the total variance of the items they accounted for. Cattell's (1966) scree plot was also used to corroborate the number of factors that were meaningful and would affect validity.

The second stage was to geometrically manipulate (rotate) the factors to make them more interpretable and to make final decisions on the underlying factors. Factor rotation helps redefine the factors in order to make sharper distinctions in their meanings. Varimax, an orthogonal rotation, and principal component analysis was used for the factor analysis. "For smaller sample sizes, a factor loading with an absolute value of .40 or greater" (Sheskin, 2004, p. 1022) is considered meaningful, and that was the value used to confirm the final selection of the factors.

\section{Reliability}

The reliability of a set of items is affected by several factors. According to Gable and Wolf (1993) these are: "the characteristics of the sample, the homogeneity of the item content, the number of items, and the response format" (p. 212). The selection of the sample is critical. The goal is to select a sample that exhibits the same level of variability as the target population (Gable \& Wolf, 1993). 
Special attention was given to the item content as relevant to the three constructs. All this was done for the sole purpose of estimating internal consistency using a Cronbach's alpha (1951) of .80 or higher. Also, duly noted is the fact that the more items on a scale the greater the potential for adequate sampling of the content universe and the development of variability in the resulting scores.

Nunnally (1959) warned, "A careful distinction should be made between test validity and test reliability" (p. 95). For a test to have high validity it must have high reliability; however high reliability is a necessary but not sufficient condition for high validity.

According to Nunnally (1978), the Likert scales have been used frequently since they are relatively easy to construct, can be highly reliable and have been successfully adapted to measure many types of affective characteristics, therefore, the Likert scales were used for this study. Research questions \#1 and \#2 (Can acceptable validity and reliability estimates be established for an instrument developed to measure high school students' global awareness? Can acceptable validity and reliability estimates be established for an instrument developed to measure high schools students' attitudes toward global social issues?) were addressed using factor analysis to determine construct validity and Cronbach's alpha to estimate internal consistency for the instrument.

For research question \#3 a correlation was run to determine if any relationship existed between the criterion and the predictor variables. Additionally, hierarchical linear regression was chosen because the independent variables could be entered into the equation/model in an order that the researcher could control the entry of the predictor variables of interest. With hierarchical linear regression, one can write the models that 
reflect the specific research question being asked and the researcher can assign "order of entry of variables according to logical or theoretical consideration" (Tabachnick \& Fidell, 2007, p.138).

The .05 level of significance was used because the consequences of rejecting a true null hypothesis were not serious enough to warrant a more stringent confidence level. A hierarchical multiple regression was used to further analyze the relationship of the criterion and predictor variables. The $F$ test was also used to test the statistical significance of the proposed relationships in the research questions because it is very robust. The model summary, ANOVA and the regression coefficients were all interpreted to determine any statistical significance between the predictor and criterion variables.

A power analysis was conducted to figure out the probability of rejecting a false null hypothesis. A Type II error is related to the power of the test. The power of a test is defined as the "the ability of a test to detect a difference when a difference exists" (Newman \& Newman, 2006, p.236).

\section{Summary}

The chapter detailed the research design followed by a discussion of the variables relevant to the research questions. This was followed by a brief review of the sample. The instrument design framework was used to delineate each step in the development of the instrument. The importance of the validity and reliability of the instrument was outlined. A detailed description on the statistical methods used to estimate validity and reliability were discussed. The relevance of the choice of those methods to this study was also identified. 


\section{CHAPTER IV}

\section{FINDINGS AND ANALYSIS OF DATA}

The primary purpose of this study was the development of an instrument to measure high school students' perceptions of global awareness and attitudes toward global issues which included global citizenship and becoming a viable member of the global workforce. It also explored whether acceptable validity and reliability estimates can be established for such an instrument. This study also sought to establish a relationship, if any, between certain demographics and the three constructs: global education, global citizenship, and global workforce. However, since the results of the factor analyses were different, and two unrelated factors emerged: self-perceptions of global awareness and attitudes toward global social issues, the relationship between the demographics and the two new factors were investigated instead.

This chapter provides details on the findings of this study, including a description of the survey pilot study, the responses from Miami-Dade County high school students, and the demographics of the respondents. It identifies the factor structure of the survey, and reliability and validity estimates for the instrument being developed. Factor analysis was used for construct validity and Cronbach's alpha for internal consistency. A hierarchical multiple regression analysis was run to determine relationships, if any, in the scores based on demographic data. Independent Samples $t$ Tests were done for certain dichotomous variables.

\section{Description of Participants}

The survey of 36 items (see Appendix E) was first administered to 46 students as a pilot study to identify problems with comprehension of text and the presence of other 
errors. This was done only after confirmation of the receipt of the required forms (parent consent and student assent). The two items in the demographics that needed clarification were parents' education (item 10) and subjects taken in the social science classes (item 12). The students were confused whether it had to be both parents, or either one; therefore, they were told that parents' education should reflect the highest education level in the household. The question about classes taken in social science directed students to circle only one, however, a few students had taken more than one, and they were told to circle all classes taken in social science. After addressing the two items that needed clarification, the survey was administered to the rest of the sample totaling 658 students. The total sample size was 704 which included those in the pilot study.

A numerical description of the sample and the geographical distribution of the schools are presented in Appendix F. Even though it was a nonprobability sample, the schools were sort of proportionately distributed over Miami-Dade County. They represented public, charter, parochial, and private schools. Several demographic characteristics were used to describe the sample of the students who participated in the study. These included GPA, race/ethnicity, gender, socio-economic status, parents' education, getting the news, reading and listening habits, the number of classes taken in the social sciences, whether they speak a second language, and have experienced living in or visiting other countries. Descriptive statistics were used to describe the sample.

\section{Estimates of Construct Validity}

An exploratory factor analysis was performed using principal component analysis with varimax rotation because "in exploratory factor analysis one seeks to describe and summarize data by grouping together variables that are correlated' (Tabachnick \& Fidell, 
2007, p.609). It was applied to all 36 items of the survey. This analysis was done to estimate the number of factors as they related to the three constructs: global education, global citizenship, and global workforce; and to estimate construct validity. The exploratory factor analysis revealed an 11 -factor solution accounting for $55 \%$ of the variance with an eigenvalue of 1 or more (see Appendix G).

There is a broad consensus in the literature that finding eigenvalues is among the least accurate methods for selecting the number of factors to retain (Velicer \& Jackson, 1990. All 36 items of the survey were entered into the procedure. Costello and Osborne (2005) suggest that the number of useful factors obtained from a principal component analysis can be determined using the scree plot developed by Cattell (1966). The concept of "the scree plot involves examining the graph of eigenvalues and looking for the natural bend or break point in the data where the curve flattens out" (p. 3). Therefore the scree plot was examined. It indicated two factors that could be extracted, possible three.

The researcher decided on two factors since the third factor only added $4 \%$ to the variance (see Appendix G). The two-factor choice accounted for $25.09 \%$ of the variance in the items. An orthogonal rotation was done using varimax with a two-factor extraction suppressing all coefficient values below .4. Only items with factor loadings of .4 or greater were retained (see Appendix H). Although Kline (1993) and others have argued that "loadings greater than .3 can be regarded as significant [meaningful]" (p.141), the researcher adopted the more stringent measure to improve the construct validity. The concept that defined the first factor reflected the first research question about high school students' perceptions on global awareness. This global awareness could have developed 
either from their curriculum, their teachers, and/or their school. Hence factor 1 was labeled self-perceptions of global awareness.

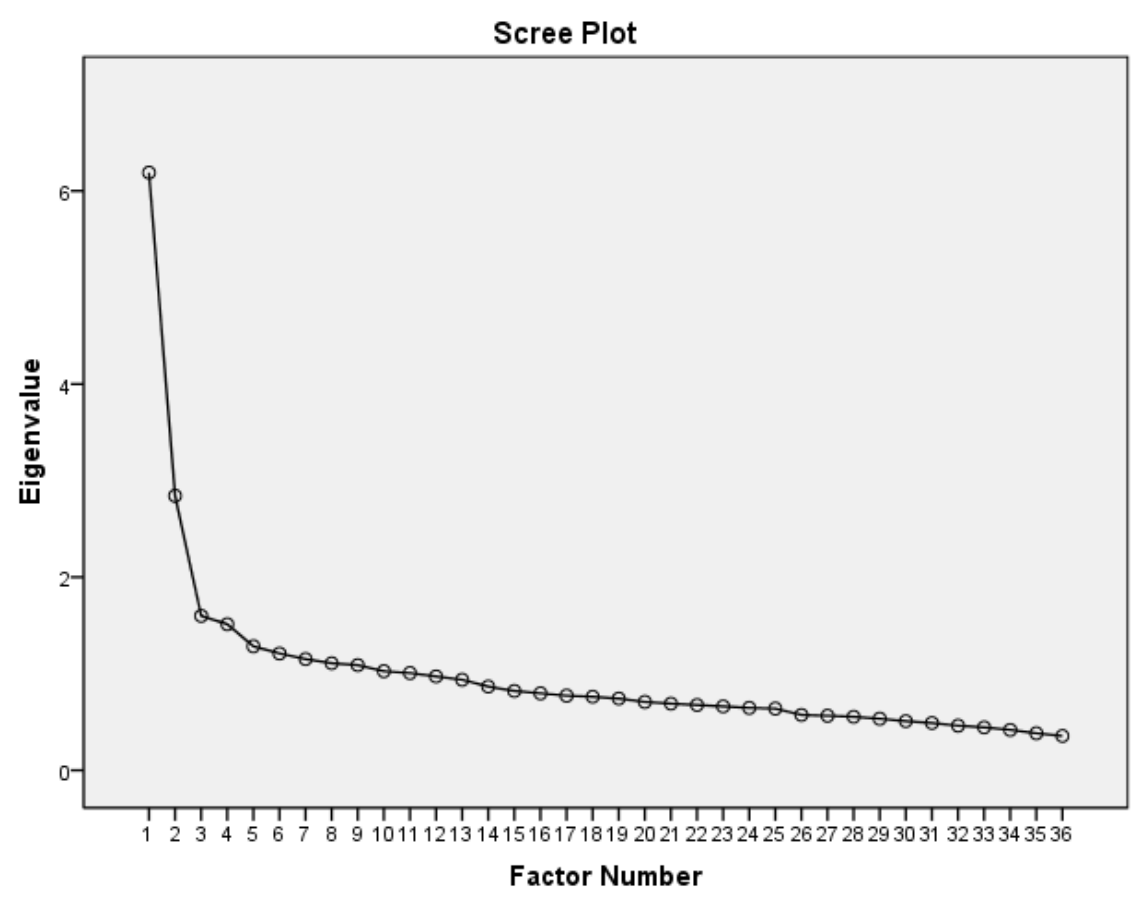

Figure 2. Scree plot indicating number of factors.

The second factor, attitudes toward global social issues, was more difficult to label. The items that loaded on factor 2 broadly expressed the high school students' values and attitudes toward global social issues. The items that loaded highly on this factor were concerned with students' attitudes about the value of global social issues. After much scrutiny a central theme emerged and the factor, attitudes toward global social issues seemed to best describe the factor loadings.

The two factors, self-perceptions of global awareness and attitudes toward global social issues were the new dependent variables. The computation for the means of the factor scores included the sum of the scores of the items in the survey that comprised each factor divided by the number of items. 


\section{Estimates of Reliability}

The reliability of the instrument was estimated using Cronbach's alpha for internal consistency. A review of the column that read "if item deleted" provided no improvement in the alpha of self-perceptions of global awareness (factor 1), which stood

at .825 (see Appendix I). Attitudes toward global social issues (factor 2) could be improved from .723 to .742 if item 8 (reverse scored) was removed but the improvement was considered minimal and the item was retained (see Appendix J). These are acceptable levels of internal consistency (George \& Malley, 2003). Looking at the item-total correlation, using 0.33 as the criterion $(\mathrm{Ho}, 2006)$ it was decided to keep all 23 items that had factor loadings of .4 or higher on either factors.

From these findings it can be concluded that for research question \#1 acceptable validity and reliability estimates can be established for an instrument developed to measure high school students' global awareness. The construct validity was estimated using exploratory factor analysis. The internal consistency of factor 1 (self-perceptions of global awareness) was identified using Cronbach's alpha with .825 for the 14 items that loaded on the factor.

Factor 2 labeled attitudes toward global social issues answered research question \# 2 which indicated that acceptable validity and reliability estimates can be established for an instrument developed to measure high schools students' attitudes and values concerning global social issues. Factor 2 accounted for approximately $8 \%$ of the variance on the entire instrument as indicated by the eigenvalue resulting from the factor analysis. The internal consistency for factor 2 using Cronbach's alpha was .723, which is acceptable (George \& Malley, 2003) to estimate reliability. 


\section{Descriptive Statistics}

\section{Frequencies}

Demographic data were used in this study as a means of describing the sample, and to determine if the sample's demographics were related to their perspectives on global awareness and attitudes toward global social issues. Student participants were described in terms of their GPA, race/ethnicity, gender, socio-economic status, parents' education, reading and listening habits, the number of classes taken in the social sciences, whether they speak a second language, and have experienced living in or visiting other countries, and their perception of global awareness and attitudes toward global issues. The ethnicity of the respondents was overwhelmingly Hispanic (65.2\%), and 84.2\% spoke a second language. The gender distribution was almost equal, $43.4 \%$ male to $56.6 \%$ female. Public schools provided $59.2 \%$ of the student sample while private schools made up the balance of $40.8 \%$. For all students, academic achievement as indicated by their GPAs was impressive; $73.8 \%$ had a 3.00 or higher. Almost half the students $(44 \%)$ had taken more than one course in the social sciences.

\section{Correlations}

Ethnicity and pop music were significant for factor 1(self-perceptions of global awareness) at the $p<.01$ level. Parents' education and gender were also significant for factor 1 at the $p<.05$ level. More demographic variables correlated to factor 2 (attitudes toward global social issues). Gender, ethnicity, reading books, reading news on the Internet, taking social studies, history, economics, and living in other countries were all highly correlated at the $p<.01$ level for factor 2. SES and taking international studies were significant at the $p<.05$ level. These correlations helped determine the choice of 
variables to be entered into the models and the sequence with which they were entered into the regression equation.

\section{Multiple Regression Analysis}

Two hierarchical linear regression analyses were conducted to determine if any of the demographics of the high school students were predictors of selfperceptions of global awareness (factor 1) and the attitudes toward global social issues (factor 2). In the hierarchical regression the predictor variables - GPA, ethnicity, parents' education, SES, and gender were entered in the first step. The remaining 18 variables namely: getting the news, reading habits, classes taken in the social sciences, visiting and/or living in other countries, knowledge of a second language, and music listened to were entered into step 2 as moderating variables. (For coding of all variables see p. 76). The underlying assumptions for linear regression considered for this study were:

- Linearity (scatterplot)

- Multicollinearity (Variance Inflation Factor or Tolerance)

- Homoscedasticity (outliers)

- The variables are normally distributed (test of normality).

This study checked for linearity. Multicollinearity was not present because the tolerance values were more than 0.1 . An analysis of the residuals indicated they met the criteria for homoscedasticity for perceptions of global awareness (factor 1) and indicated one outlier for attitudes toward global social issues (factor 2) but this was discounted because of the large sample size (704). 


\section{Hierarchical Regression Analysis for Self-Perceptions of Global Awareness (Factor}

\section{1)}

The demographic variables in step one minimally predicted self-perceptions of global awareness (factor 1$), R^{2}=.03, R_{a d j}^{2}=.02, F(5,604)=3.60, p<.05$. The standardized coefficients specified that two variables, ethnicity, $\beta=.132$, $t(586)=3.19, p=.001$, and parents' education $\beta=.101, t(586)=2.37, p=.018$ in model 1 were significant. The demographic variables accounted for only $3 \%$ of the variance of factor 1 . The significant betas indicated that the beta is probably non-zero in the population and that the variables, ethnicity and parents' education, accounted for more than zero percent of the variance of the criterion variable, self-perceptions of global awareness. A positive $t$ value $(t=3.677$, $\mathrm{p} \leq=.009$ ) for ethnicity indicated that the Hispanic students scored significantly higher than non-Hispanics and accounted for significant amounts of variance in factor 1 independent of the other variables in the model. (For all coding of variables see page 75) Adding the moderating variables in step two resulted in a statistically significant overall model for self-perceptions of global awareness, $R^{2}=.08, F(23,586)=2.11, p<$ .05. The moderating variables accounted for 5\% more of the variance in perceptions of global awareness, $\Delta R^{2}=.05, F(18,586)=2.11, p<.05$. 
Table 1

Regression Coefficients Self-Perceptions of Global Awareness - Factor 1

\begin{tabular}{|c|c|c|c|}
\hline \multirow[b]{2}{*}{ Variable } & \multirow[b]{2}{*}{ Model $1 B$} & \multicolumn{2}{|c|}{ Model 2} \\
\hline & & $B$ & $95 \% \mathrm{CI}$ \\
\hline Constant & $2.698 * *$ & $2.414 * *$ & $(2.02,2.79)$ \\
\hline GPA & 0.01 & -0.00 & $(-0.05,0.04)$ \\
\hline Ethnicity & $0.12 * *$ & 0.08 & $(-0.00,0.17)$ \\
\hline Gender & 0.04 & -0.01 & $(-0.09,0.06)$ \\
\hline SES (recoded) & -0.03 & -0.02 & $(-0.11,0.06)$ \\
\hline Parents' education & $0.05^{*}$ & 0.05 & $(0.00,0.09)$ \\
\hline News from radio & & $0.23 *$ & $(0.00,0.46)$ \\
\hline News from TV & & $0.26^{* *}$ & $(0.07,0.44)$ \\
\hline News from internet & & $0.27 * *$ & $(0.08,0.45)$ \\
\hline Reading the newspapers & & 0.15 & $(-0.19,0.50)$ \\
\hline Reading magazines & & 0.05 & $(-0.23,0.34)$ \\
\hline Reading books & & 0.11 & $(-0.17,0.39)$ \\
\hline Reading the internet & & 0.02 & $(0.25,0.30)$ \\
\hline Taken class in social studies & & -0.01 & $(-0.10,0.06)$ \\
\hline Taken class in global studies & & -0.01 & $(-0.14,0.11)$ \\
\hline Taken class in history & & 0.08 & $(0.01,0.18)$ \\
\hline Taken class in international studies & & 0.04 & $(-0.17,0.17)$ \\
\hline Taken class in economics & & 0.08 & $(0.00,0.16)$ \\
\hline Speaking a second language & & 0.05 & $(-0.07,0.17)$ \\
\hline Living in other countries & & 0.00 & $(-0.07,0.09)$ \\
\hline
\end{tabular}




\begin{tabular}{|c|c|c|c|}
\hline \multirow[b]{2}{*}{ Variable } & \multirow[b]{2}{*}{ Model $1 B$} & \multicolumn{2}{|c|}{ Model 2} \\
\hline & & $B$ & $95 \% \mathrm{CI}$ \\
\hline Visiting other countries & & -0.05 & $(-0.16,0.05)$ \\
\hline Listening to pop music & & $0.18^{* *}$ & $(0.05,0.31)$ \\
\hline Listening to other music & & -0.02 & $(0.00,0.05)$ \\
\hline Attending public schools & & 0.00 & $(0.00,0.08)$ \\
\hline$R^{2}$ & .03 & .08 & \\
\hline$F$ & $3.60 * *$ & $2.11 * *$ & \\
\hline$\Delta R^{2}$ & & .05 & \\
\hline$\Delta F$ & & 1.68 & \\
\hline
\end{tabular}

Note. $N=610 .{ }^{*} p<.05 .{ }^{* *} p<.01 . \mathrm{CI}=$ confidence interval

See p.76 for coding of variables

\section{Hierarchical Regression Analysis for Attitudes Toward Global Social Issues (Factor}

2)

The demographics variables of ethnicity, gender, GPA, parents' education, and SES entered in model 1 accounted for significant proportions of the variance of factor 2 (attitudes toward global social issues), $R^{2}=.06, R_{\text {adj }}^{2}=.05, F(5,604)=7.168, p<.001$. Gender and SES accounted for significant amounts of unique variance independent of the other variables in the model, $\beta=.174, t(586)=4.35, p<.001, \beta=.090, t(586)=4.35, p$ $<.001$ respectively. An Independent Sample $t$-Test $(t=5.126, p=\leq .009)$ confirmed that female high school students had higher attitude toward global social issues scores than males, and students who had free or reduced lunches had higher scores on the attitudes toward global social issues factor than those who did not have free/reduced lunch. 
Adding the moderating variables in step two resulted in a statistically significant overall model for attitudes toward global social issues, $R^{2}=.186, F(23,586)=5.81, p<$ .001 . The moderating variables accounted for $13 \%$ more of the variance in attitudes toward global social issues, $\Delta R^{2}=.130, F(18,586)=5.18, p<.001$. Taking classes in history and economics were statistically significant, $\beta=.111, t(586)=2.86, p=.004$ and $\beta=.67, t(586)=3.91, p \leq .009$ respectively (see Table 5). High school students who took classes in history and economics had higher scores on the attitudes toward global social issues while controlling for the other demographic variables. This indicated that students who took these subjects developed stronger value judgments on global social issues and joining the global workforce. Living in other countries was also significant, $\beta$ $=.102, t(586)=2.43, p=.016$ indicating the exposure to other cultures and people is a strong predictor of the attitudes toward global social issues. Of the interacting variables, attending public schools was related to the attitudes toward global social issues, $\beta=-.226$, $t(586)=-4.85, p \leq .009$, indicating that those who attended public schools had high scores on the attitudes toward global social issues while controlling for all other variables. Table 2 Regression Coefficients (Attitudes Toward Global Social Issues - Factor 2)

\begin{tabular}{|c|c|c|c|}
\hline \multirow[b]{2}{*}{ Variable } & \multirow[b]{2}{*}{ Model $1 B$} & \multicolumn{2}{|c|}{ Model 2} \\
\hline & & $B$ & $95 \% \mathrm{CI}$ \\
\hline Constant & $3.241 * *$ & $3.433 * *$ & $(3.09,3.76)$ \\
\hline GPA & 0.03 & 0.01 & $(-0.03,0.05)$ \\
\hline Ethnicity & 0.07 & 0.06 & $(-0.02,0.14)$ \\
\hline
\end{tabular}


Table 2 (continued)

\begin{tabular}{|c|c|c|c|}
\hline \multirow[b]{2}{*}{ Variable } & \multirow[b]{2}{*}{ Model $1 B$} & \multicolumn{2}{|c|}{ Model 2} \\
\hline & & $B$ & $95 \% \mathrm{CI}$ \\
\hline Gender & $0.15 * *$ & 0.11 & $(0.04,0.18)$ \\
\hline SES (recoded) & $0.07 *$ & 0.01 & $(-0.06,0.09)$ \\
\hline Parents' education & -0.01 & 0.00 & $(-0.03,0.04)$ \\
\hline News from radio & & -0.06 & $(-0.26,0.13)$ \\
\hline News from TV & & -0.04 & $(-0.02,0.11)$ \\
\hline News from internet & & $0.04 *$ & $(-0.11,0.20)$ \\
\hline Reading the newspapers & & -0.23 & $(-0.53,0.07)$ \\
\hline Reading magazines & & -0.24 & $(-0.50,0.00)$ \\
\hline Reading books & & -0.10 & $(-0.35,0.13)$ \\
\hline Reading the internet & & -0.19 & $(-0.43,0.04)$ \\
\hline Taken class in social studies & & 0.03 & $(-0.04,0.10)$ \\
\hline Taken class in global studies & & -0.03 & $(-0.15,0.07)$ \\
\hline Taken class in history & & $0.12 * *$ & $(0.03,0.20)$ \\
\hline Taken class in international studies & & 0.07 & $(-0.03,0.18)$ \\
\hline Taken class in economics & & $0.14 * *$ & $(0.07,0.21)$ \\
\hline Speaking a second language & & -0.08 & $(-0.19,0.01)$ \\
\hline Living in other countries & & $0.09 *$ & $(0.01,0.16)$ \\
\hline Visiting other countries & & 0.00 & $(-0.09,0.10)$ \\
\hline Listening to pop music & & 0.06 & $(-0.04,0.17)$ \\
\hline
\end{tabular}


Table 2 (continued)

\begin{tabular}{lccc}
\hline \multirow{2}{*}{ Variable } & Model 1 $B$ & \multicolumn{2}{c}{ Model 2 } \\
\cline { 3 - 4 } & & $B$ & $95 \% \mathrm{CI}$ \\
\hline Listening to pop music & & 0.06 & $(-0.04,0.17)$ \\
Listening to other music & & 0.04 & $(-0.02,0.11)$ \\
Attending public schools & & $0.19^{* *}$ & $(0.27,0.11)$ \\
$R^{2}$ & .06 & .19 & \\
$F$ & $7.17^{* * *}$ & $5.81^{* *}$ & \\
$\Delta R^{2}$ & & .13 & \\
$\Delta F$ & & 5.18 & \\
\hline
\end{tabular}

Note. $N=610 .{ }^{*} p<.05 .{ }^{* *} p<.01 . \mathrm{CI}=$ confidence interval

See p.76 for coding of variables

Research question \#3 sought to determine if any relationship existed between certain demographics (GPA, race/ethnicity, gender, having experienced living or visiting other countries, reading and listening habits, socio-economic status, speaking a second language, and parents' education) and high school students' global awareness, and their attitudes towards global issues. The findings from the correlation analysis conducted indicated a relationship between ethnicity $(\mathrm{r}=0.138, p<.01)$, parents' education $(0.085$, $p<.05$, gender $(\mathrm{r}=0.078, p<.05)$ pop music $(\mathrm{r}=0.141, p<.01)$ and factor 1 (selfperceptions of global awareness). There were more demographic variables that correlated to factor 2 (attitudes toward global social issues) - gender $(\mathrm{r}=0.194, p<.01)$, ethnicity $(\mathrm{r}=$ $.128, p<.01)$, social studies, international studies courses, history, economics, SES, listening to hip hop music, public schools, getting news on the Internet, reading books, 
and living in other countries - all had improved relationships to factor 2 in the correlation.

The hierarchical regression, which was conducted to estimate predictability between the predictor and criterion variables, confirmed some of the preliminary findings in the correlation analyses. Ethnicity and parents' education were both significant in the first step model for factor 1 (self-perceptions of global awareness). Pop music and listening to news (TV, Internet and radio) were significant in the step 2 model. Gender ( $p$ $<.01)$ and SES $(p<.01)$ were significant in the correlation analyses as well as in the regression for factor 2 in the step 1 model. Having taken courses in history and economics, living in other countries, and attending public schools were all significant in the step 2 model.

Onwuegbuzie and Leech (2004) recommend a post hoc power analysis for studies with non-significant findings; but he also strongly advocates its use for studies that will be replicated. According to Newman and Newman (1977) the power of a test is defined as the probability of detecting a difference when one exists. It is highly unlikely there is a Type II error in a powerful test. Therefore a post hoc power analysis was conducted using an effect size of .18 ( $\mathrm{R}$ squared), sample size $(\mathrm{N}=610)$, alpha $=.05$, and number of predictors (23) which resulted in a power analysis of a Gpower $=.99$. Ideally, power should be at least 0.80 to reduce the incidence of Type II error.

\section{Summary}

The chapter presented the findings of the study in two parts. The first part of the chapter discussed the findings related to the validity and reliability of the instrument. The second part of the chapter presented the findings of the multiple regression analysis 
conducted to establish the relationship of the predictor variables with the criterion variables (self-perceptions of global awareness and attitude toward global social issues).

The instrumentation and the research design were discussed. The development of 36 survey items was done from a detailed examination of the literature review. The sequence that followed was sending out letters to school principals, and then emails. The contact with the schools having been established, the assent and consent forms were distributed to the participant schools. The pilot study of 46 students was followed by the administration of the study to 658 other students after having addressed the two problems encountered in the pilot test.

The data were entered and the predictor variables were appropriately coded and labeled. A factor analysis followed. Eigenvalues and a scree plot were used to determine the number of factors. An exploratory orthogonal varimax analysis revealed an 11-factor solution accounting for $55 \%$ of the variance. The factor structure was presented and discussed. A close examination of the findings from the factor analysis facilitated the decision to retain just two factors with a variance of 25.09. An item analysis helped determine Cronbach's alpha (.825 for factor 1 and .723 for factor 2 ) to estimate the reliability of the instrument. The result was a 23 -item instrument.

These analyses helped answer the two primary questions of the research namely: Can acceptable validity and reliability estimates be established for an instrument developed to measure high school students' perceptions of global awareness? And, can acceptable validity and reliability estimates be established for an instrument developed to measure high schools students' attitudes toward global issues? 
The third research question entailed establishing a relationship between the demographics and the two factors. The preliminary correlation study indicated ethnicity and gender were significant for both factor 1 and 2 . Whether the students listened to pop music, and parents' education were significant for factor 1 while living in other countries, classes taken in history, international studies, economics, social studies, and listening to news on the Internet were all significant for factor 2. Two hierarchical multiple regression analyses were conducted to better understand the relationship of the 23 predictor variables with the 2 criterion variables. The demographic variables - ethnicity and parents' education in step one significantly predicted perceptions of global awareness (factor 1), and gender together with SES significantly predicted attitudes toward global social issues (factor 2). A discussion of these findings is presented in Chapter 5 along with recommendations for further research. 


\section{CHAPTER V}

\section{SUMMARY, DISCUSSION, AND CONCLUSION}

The final chapter of this dissertation looks critically at the research questions, summarizes the results, and evaluates the methods used in the study. A discussion of the findings within the scope of the research questions, and the variables, both dependent and independent, are presented. Implications for theory and practice are outlined. The chapter concludes with the limitations of the study in several areas and a recommendation for further research.

\section{Summary of the Study}

This researcher did a very exhaustive review of the existing literature which revealed very limited research in global education. This meager research was due partially to the strong emphasis on testing and accountability in math and science. Students need to acquire new $21^{\text {st }}$ century skills such as having empathy, innovativeness, competitiveness, and developing different literacy skills. The world continues to become more interdependent and interconnected with each global event; case in point - the economic crisis of 2008. We cannot choose to ignore the fact that we are becoming part of a global citizenry when we, not as nation, but as community of nations, come together to deliberate and sign an agreement on the reduction of nuclear weapons. The consolidated effort of nations coming together to help the people of Haiti during the tragic earthquake is another evidence of belonging to more than just a nation-state. These are events that should be clearly indicative that global citizenship is becoming a reality, even though it may be limited in its scope. Therefore, it was necessary to determine what students' perspectives of their current education were, and if it included some global 
education that also incorporated global citizenship, and if together global awareness and knowledge of global issues would facilitate their entry into the global workforce.

A related problem is the minimal inclusion of students in a discussion about their curriculum. In a democratic society such as the United States, it is incomprehensible why students' perspectives are ignored. They are the most important beneficiaries of education yet their opinions are not considered at all or considered redundant. Therefore, this researcher felt compelled to study high school students' perspectives and to make them a part of the conversation on how they perceived their readiness for entry into the global workforce.

This study sought to answer three research questions:

1. Can acceptable validity and reliability estimates be established for an instrument developed to measure high school students' global awareness?

2. Can acceptable validity and reliability estimates be established for an instrument developed to measure high school students' attitudes toward global social issues?

3. What is the relationship between high school students' GPA, race/ethnicity, gender, socio-economic status, parents' education, getting the news, reading and listening habits, the number of classes taken in the social sciences, whether they speak a second language, and have experienced living in or visiting other countries, and their perception of global awareness and attitudes toward global social issues?

The participants $(\mathrm{N}=704)$ in this study were students from 14 high schools (public, charter, parochial, and private) from Miami-Dade County, Florida. Descriptive statistics were used for the demographic items (independent variables) in this study to 
describe the basic features of the data and to provide simple summaries. This study used an ex post facto design. A factor analysis helped determine the factors and the items that would make up the final instrument. A hierarchical linear regression was conducted both to predict and explain which of the 23 independent variables were important influences on the two dependent variables, self-perceptions of global awareness and attitudes toward global social issues.

\section{Findings and Interpretation}

\section{Factor Analysis}

Since there was no instrument available, one had to be developed to address the first two questions. The instrument was developed using exploratory factor analysis with orthogonal varimax rotation. Two factors emerged with 23 items as the final instrument. The two factors, self-perceptions of global awareness and the attitudes toward global social issues answered the first two primary research questions.

Through the use of a principal component exploratory factor analysis with varimax rotation resulted in two factor solution when using an eigenvalue of 1 as a cut off as well as a scree plot criterion for determining factor cut offs. These two factors cumulatively accounted for only $25.09 \%$ of the variance. The rotated solution yielded two interpretable factors, self-perceptions of global awareness and attitudes toward global social issues. The self-perceptions of global awareness factor accounted for $17.19 \%$ of the item variance, and the attitudes toward global social issues accounted for $7.9 \%$ of the item variance. The factor loadings selected were .4 and above for all 23 items.

The content validity of the instrument was decided upon by the researcher using the extensive review of the literature. The construct validity was estimated using 
Cronbach's alpha for internal consistency (.825 - factor 1 and .723 - factor 2$)$ and Spearman-Brown's alpha (.835 using split-half method). Both alphas are acceptable for this study.

These were important findings since they aligned with the first two research questions. The self-perceptions of global awareness factor answered the question: Can acceptable validity and reliability estimates be established for an instrument developed to measure high school students' global awareness? The attitudes toward global social issues factor addressed the second question: Can acceptable validity and reliability estimates be established for an instrument developed to measure high schools students' attitudes on global issues?

The very meaningful finding from the responses on the items of the survey was that although they did not align directly with the three constructs, they did identify two very important features of the instrument: (a) High school students' self-perceptions of global awareness, (b) Their attitudes on global social issues. Also, the loading of the factors indicated that the global education and global citizenship were interdisciplinary in nature and were holistic. The items were designed to cluster around the main tenets of the three constructs; instead they clustered around two new factors indicating that the students understood the constructs differently from what the literature revealed.

\section{Correlation}

A correlation study was done to estimate some exploratory data to determine the type of regression to be used. It also helped to identify a bivariate linear relationship, if any, between self-perceptions of global awareness and the attitudes toward global social 
issues and the 23 independent variables, keeping in mind the dictum that correlation does not imply causation.

For the self-perceptions of global awareness factor the independent variables that had a meaningful relationship were pop music, ethnicity, parents' education, and gender (female). Ethnicity and pop music were significant at $p<.01$ level. The sample had a 65 $\%$ representation of Hispanics. Hispanics had better perspectives of global awareness than other ethnic groups of students (Independent-samples T test). The correlation between pop music and the self-perceptions global awareness factor was positive and statistically significant $(\mathrm{r}=0.141, p<.01)$. Important for this study was the inclusion of parents' education as an independent variable and its correlation to factor $1(\mathrm{r}=0.085, p$ $<.05)$. The higher the parents' education the higher the students scored on factor $1.70 \%$ of the parents had attended college or had a graduate degree. Female students (57\%) had more positive perspectives of global awareness.

For the attitudes toward social issues factor, ethnicity, the study of economics and social studies, reading books, and gender showed significant relationships $(p<.001)$. Attending public schools correlated positively $(p<.001)$ with attitudes toward global social issues factor. This finding is very significant for this study since the case was made earlier that the students were denied the opportunity of expressing their opinion on their own education. This confirms the earlier claim made in the literature (Calvert. 1975; Cook-Sather, 2002) that students can make a valid contribution to the discourse on change in curriculum including the social sciences. The following independent variables: living in other countries, the study of history, reading news on the internet, were all positive $(p<.01)$ and international studies and SES at the $p<.05$ level. Again, taking 
classes in history and international studies coupled with reading the news on the Internet were related to factor 2. The students' responses identified the need for more emphasis on the subject matter of the social science curriculum to become successful in the global workforce. This is evidence that the neglect of social sciences is a mistake. All the social science classes conjointly, not just a history or a social studies class, help the students understand there is more to be learned to develop global literacy and global competency skills. The explanation for the positive relationship of SES $(\mathrm{yes}=1, \mathrm{no}=0)$ with factor 1 (attitudes towards global social issues) is ambiguous.

Ethnicity and gender were significant for both factors, self-perceptions of global awareness and attitudes toward global social issues, although understandably gender (female) was more significant for the attitudes toward global social issues factor (female $=1$, male $=0$ ) which corroborates with other studies in the literature (Corbin, 1994; Wolters \& Pintrich, 1998). Females in general are more devoted to learning at school (Glickman, 1976). Since $65 \%$ of the sample was Hispanic (Hispanic $=1$, other $=2$ ), they had either lived or visited their homeland and were probably more exposed to more than one culture. Also, being immigrant and the desire to succeed may be a contributor to both their self-perceptions of global awareness and their attitudes toward global social issues

\section{Hierarchical Linear Regression}

Since a preliminary multiple regression indicated that some of the independent variables that were significant in the correlation analysis were also significant in the multiple regression, it was decided to run a hierarchical regression analysis. This particular format for the regression enabled the researcher to sort the independent variables that accounted for a unique variance of each factor while controlling for all 
other variables in a 2-model solution. This was done to help develop a prediction model to determine the type of students who possessed some global awareness and had favorable attitudes on global social issues. The predictor variables entered in model 1 for self-perceptions of global awareness and the attitudes toward global social issues factor were: GPA, SES, ethnicity, gender, and parents' education (this was done because ethnicity, gender, SES, and parent's education were significant in the correlation analyses for the two factors: self-perceptions of global awareness and the attitudes toward global social issues).

Factor 1 Model 1. In model 1 for factor 1 (self-perceptions of global awareness) ethnicity and parents' education were statistically significant, $R^{2}=.03, F(5,606)=3.349$, $p<.01$, and they each accounted for a unique variance. Therefore they could be predictors of self-perceived global awareness of high schools students in the South Florida area. The significance of ethnicity in these findings is important especially since other researchers such as Pedraza-Bailey (1985) found citizenship an important priority with Cuban Americans who have a $65 \%$ presence in the South Florida area. They also wanted to maintain their social class which resulted in the keen desire to educate themselves. "Cubans in contrast to Puerto Ricans and Mexicans have been recognized for their distinct economic success" (Zuniga, 1998, p. 212), which translates into getting an education and developing an understanding about certain global concerns. Additionally, this also adds to the findings of Schmidt (2010) that Cuban-American parents (as opposed to other Hispanic groups in the United States) value education and are more likely have a college degree and want the same for their children. 
Parents' education is frequently overlooked as an independent variable in the literature but the researcher believed it plays an important role in developing a student's principles and philosophies of life. Parents' education accounted for a unique variance for the self-perceptions of global awareness factor which was a valuable finding. It serves to delineate the role of educated parents in the student-life of their children (Dubow, Boxer, \& Huesmann, 2009). However, GPA and SES were not significant in model 1 for the self- perceptions of global awareness factor.

Factor 1 Model 2. In model 2 for factor 1 (self-perceptions of global awareness) the independent variables that accounted for a unique variance were, $R^{2}=.075, F(18,588)$ $=1.668, p<.05$, were listening to pop music, and getting the news from either radio. $\mathrm{TV}$, or the Internet. This informed the researcher that in the age of technological communications students kept in touch with the news using electronic media. This evidently influenced their perception of global awareness. The two main choices in listening to music, among others, were pop and hip-hop and surprisingly pop music was significant. The explanation for this significance is difficult to determine at this juncture since there is some literature on pop music but none of it makes a contribution to its influence on students' global awareness. It is a variable that may need further investigation especially since hip-hop music was not significant.

Factor 2 Model 1. In model 1 for factor 2 (attitudes toward global social issues) factor, gender is statistically significant $(p<.001)$ which indicates that female students (since they were coded 1) are more motivated (Parker, 2007) toward learning global social issues or they were more interested in social studies. This made them achieve more (Corbin, 1994) and also helped develop their attitudes toward global social issues. Socio- 
economic status is also significant $(p<.05)$ for the attitudes toward global social issues factor which suggests that income can affect the high schools students' attitudes toward global social issues. This study revealed that students with free and/or reduced lunches had more positive attitudes toward global issues. Landorf (2005) in a study done in the Miami-Dade County Public Schools found similar results, namely that students on free/reduced lunches responded affirmatively to questions concerning global social issues.

Factor 2 Model 2. Taking classes in economics within the social science field was significant for factor $2(\mathrm{p}<.001)$. A class in economics probably provided the basis for realizing that the world economy is important and that it is the environment that they must work in as members of a global workforce. Various researchers have found economics as a subject in social studies to be stimulating to the overall educational process - gaining cognitive skills (Chizmar, McCarney, Halinski, \& Racich,1985) with such positive effect that it should be taught from kindergarten through $12^{\text {th }}$ grade (Schur, 1970) not just as an elective.

Taking classes in both history and economics are statistically significant, and a very important finding for this study. These findings mirror similar findings by Hunter, White, and Godbey (2006) in their study, What Does It Mean To Be Globally Competent. The Stanley Foundation and the American Council on International Intercultural Education's (ACIIE, 1996) third stage of global competence development requires the learner to develop an extended awareness of history especially as it relates to politics, economy and geography. This is especially true because the researcher makes the case in Chapter 1 that social studies has been relegated to the back-burner (Barber, 2002; Hicks, 
2003; Merryfield, 1997; \& Pike \& Selby, 2000; see also Burroughs, Groce, \& Webeck, 2005). The findings are evidence that those who take social science classes are more likely to develop positive attitudes toward global social issues.

In model 2 , living in other countries $(p<.05)$ accounted for a unique variance of attitudes toward global social issues. Students who have spent some time living elsewhere are more open to global problems and more likely to develop empathy, understanding, and global citizenship. This concurs with earlier studies done on study abroad programs (Rogers \& Kochunny, 1994). The students are better able to understand that we are truly interconnected and interdependent. The final independent variable that is significant $(\mathrm{p}<.001)$ is attending public schools in MDCPS as opposed to private schools. This may be explained by the fact that the social science curriculum in the public schools is infused with global perspectives starting in the sixth grade geography, seventh grade civics, eight grade U.S. History, ninth grade world history, $11^{\text {th }}$ grade American history, and finally $12^{\text {th }}$ grade American government (MDCPS Competency Based Curriculum). At each grade level the global perspectives are very clearly delineated for each subject. The responses to classes taken in the social sciences indicate that the majority of the students in public schools have taken history (84\%), economics (46\%), and social studies $(54 \%)$.

\section{Limitations of the Study}

The limitations of the study are as follows:

1. Not all of the students from the classes in question participated, and no analyses were available to suggest the difference between the participants and nonparticipants. 
2. Since the study employed a non-probability sampling technique the sample may not be representative of the population.

3. The responses to the questions may not be answered with the desired conscientiousness.

4. These findings cannot be generalized to any other population.

Additionally, there were some difficulties experienced in getting content validity for this study due to the reluctance of experts to participate in the study. Getting the schools to participate in this study was a gargantuan task, as well. Many of the administrators did not wish the students to be interrupted or distracted by any "outside sources"

\section{Implications for Theory and Practice}

The implications for theory evolved from the conceptual framework of the fourdimensional method (Pike \& Selby, 1985) reviewed for this study which advocated a holistic approach. A key conclusion from the responses to the survey is that the subject matter for the three constructs - global education, global citizenship, and global workforce is interdisciplinary in nature. The students perceived the survey items in a holistic manner. Although they were designed to cluster up on the three constructs: global education, global citizenship, and global workforce, they clustered up very differently to give the study two new constructs: self-perceptions of global awareness and the attitudes toward global social issues.

The findings of this study shift the focus of dealing with at least the two constructs - global education and global citizenship in a holistic rather than an exclusive manner. Many scholars in education have embraced each of the constructs and deal with 
them in a specific way - global education (Merryfield, 1992), global citizenship (Davies, Evans \& Reid, 2005, Oxfam, 2000), and global workforce (Spring, 2008, Nordgren, 2002). Others have opted for the comprehensive approach in defining global literacy (Schuerholz-Lehr, 2007), global competency (Reimers, 2009), and 21 ${ }^{\text {st }}$ century skills (Trilling \& Fadel, 2009) to embody all three constructs, which may also be the acceptable approach for curriculum today.

The statistical significance of the findings from the hierarchical regression analysis implied that there is some evidence that having more social studies classes infused with global perspectives helps the students acquire better attitudes toward global social issues. Since the loading of the factors was different from the expectation of the researcher in that they did not load on the three intended constructs, maybe from the students' perspectives the three constructs are related and interdisciplinary. Perhaps global awareness and global education is best taught as an interdisciplinary subject. Strong advocates of global education have introduced the method in pre-service teacher training; conceivably more needs to done.

The findings also have an implication for curriculum development in the social sciences. None of the social science subjects were significant for factor 1 (selfperceptions of global awareness) which could lead to the speculation that the content in the subjects is not conducive to learning global awareness, or , the right methods are not being used to instruct the students. Yocum (1992) found that global education, even though it was being taught in the schools in his study, did nothing for an increase in the global-mindedness of the students. However, those students who were allowed full participation developed more global-mindedness in those classes which is reflective of 
the method of teaching. Since both history and economics classes were significant for factor 2 (attitudes toward global social issues) the subject matter in both history and economics could be reviewed to possibly include subject matter that would help in the development of global awareness.

Few studies have been conducted to study students' perceptions about their own education; the conclusions from this research suggest that such studies do provide noteworthy and valuable information. The most significant implication for teachers and administrators is to recognize the fact that students have had the opportunity to express their perspectives. In this study the students have provided evidence that the literature on teaching separate courses for global education and/or global citizenship may be incorrect. Educators rarely get the opportunity to assess high school students' global awareness, and these findings provide some information that can be used constructively. The survey could be used as a pre-test and post-test to find out if high schools students' global awareness and attitudes on global social issues have changed after taking certain social science classes or after having received instruction that has been interdisciplinary in nature

Making students an important part of the discussion (Calvert, 1975) on curriculum is a democratic process and one very important to the teaching of democratic principles especially in preparation for national and global citizenship. Research has indicated that soliciting students' feedback on policy changes is vital for the success of those policies (Howard, 2003; King, 1977). Current reform in education has indicated that sometimes students' are dissatisfied with certain administrative and curriculum changes, but decisions are usually made unanimously by administrators and educators (De la Ossa 
(2005). The findings in this study indicate that students can provide academia very responsible and intuitive answers about their perspectives and attitudes towards curriculum (Atula, 1997; Cook-Sather, 2002; Wiggan, 2007) if they are included in the discussion; and that is a valuable finding.

\section{Recommendations for Further Research}

This study supplements the existing literature on global education by introducing an instrument that has valid and reliable estimates. However, this instrument should be administered to various other samples within the population of Florida and then, maybe in other states. Administering the survey in a different cultural environment would perhaps give it better validity and reliability estimates. Since Miami is a large urban area, its replication in rural areas may provide important findings to add to the current validity and reliability estimates of this instrument.

I recommend that if this research is replicated that there be cognitive interviews, as recommended by Dillman (2000) to get a better understanding on the interpretation of the questions. This qualitative process could add a new dimension to the validity and reliability estimates of the instrument.

It is recommended that a couple of multiple choice questions be included to summarize the students' perspectives on the three constructs. It may help the students focus on the three constructs more definitively. More items could be added that would strengthen the argument that students do need global education to develop global competency to join the global workforce.

The predictability of the demographics to the criterion variables could be made more significant by the addition or deletion of some of the independent variables, for 
example: SES and ethnicity could be more clearly defined to elicit more meaningful and valuable responses. For the variable SES, students could be asked to identify not only free/reduced lunch but additionally household income, parents' occupation, etc. Ethnicity could be made more specific to include Cuban-American, Mexican, Puerto Rican, and others to provide more insightful differences concerning survey responses.

Also, the difference in the findings of students listening to pop music (positive relationship) versus hip hop (negative relationship) to self-perceptions to global awareness seems to warrant more study since music plays such a major role in the listening habits of high school students. The variable, listening to a type of music, definitely needs more research. According to Green (1997), "we do not hear music without some delineation or other...it is an integral element of our listening experience" (p.7). Powell adds that, "rap music provides a significant form of informal education for adolescents" (p.245). Much more information about students' behavior patterns and thought processes can be gleaned from students' listening habits (Greer, Dorow, Wachhaus, White, 1973), and therefore it warrants more study.

\section{Conclusion}

The researcher initiated this study with the understanding that students provide us with valuable information when questioned. The findings did provide the researcher with some modest knowledge about students' self-perceptions of global awareness and their attitudes toward global social issues in general. It is the hope of this researcher that in some small measure this study has made a contribution to the body of knowledge that students' voices are important and that teachers and administrators should understand and 
recognize that fact. If that is the only outcome of this study, then this has been a successful endeavor in research. 


\section{REFERENCES}

Adams, J. M., \& Carfagna, A. (2006). Coming of age in a globalized world: The next generation. Bloomfield, CT: Kumariam Press.

ACIIE/Stanley Foundation. (1996). Education for the global community: A framework for community colleges. Muscatine, IA: Stanley Foundation Publications.

Allen, J. D. (1986). Classroom management: Students' perspectives, goals, and strategies. American Educational Research Journal, 23(3), 437-459.

Alschuler, A. (1980). School discipline: A socially literate solution. New York, NY: McGraw-Hill.

American Educational Research Association (AERA), American Psychological Association (APA), and National Council on Measurement in Education (NCME). (1999). The standards for educational and psychological testing (1999). Washington, DC: Author.

American Heritage ${ }^{\circledR}$ Dictionary of the English Language. (2006), (4 ${ }^{\text {th }}$ ed.). Retrieved from Dictionary.com website: http://dictionary.reference.com/browse/perspective

Anderson, L. F. (1968). An examination of the structure and objectives of international education. Social Education, 35, 639-652.

Andrzejewski, J. \& Alessio, J. (1999). Education for global citizenship and social responsibility. Progressive Perspectives. 1(2). Retrieved from http://www.uvm.edu/ dewey/monographs/glomono.html\#Education\%20for\%20G lobal\%20Citizenship\%20and\%20Social

Appadurai, A. (1996). Modernity at large: Cultural dimension of globalization. Minneapolis, MN: University of Minneapolis Press.

Association of Universities and Colleges of Canada. (2002). Building Global Literacy. A report on a workshop organized by AUCC. Retrieved from www.aucc.ca/_pdf/english/reports/2002/Global_Literacy_e.pdf

Atula, J. (1998).Implementing a global education curriculum: Case studies of two teachers. Unpublished master's thesis. Memorial University of Newfoundland, Canada.

Bacon, D. R. \& Bean, B. (2006). GPA in research studies: An invaluable but neglected opportunity. Journal of Marketing Education, 28, 35 - 42. doi: $10.1177 / 0273475305284638$ 
Bacon, C. M., \& Kischener, G.A. (2002). Shaping the global classrooms. Educational Leadership, 60(2), 48-51

Banks, J. A. (2008). Diversity, group identity, and citizenship education in a global age. Educational Researcher, 37(3), 129-139.

Barber, B. R. (1995). Jihad vs McWorld: How globalism and tribalism are reshaping the world. New York, NY: Random House.

Barber, B. R. (2002). The educated student: Global citizen or global consumer? Liberal Education, 88(2), 22-28.

Barrows, T.S., Ager, S.M., Bennett, M.F., Braun, H. I., Clark, J.L.D., Harris, L.G., \& Klein, S. F. (1981). College students' knowledge and beliefs: A survey of global understanding. Princeton, NJ: Change Magazine Press.

Becker, J. M. (1982). Goals for global education. Theory into Practice, 21(3), 228-233.

Berliner, D.C.(1976). Impediments to the study of teacher effectiveness. Journal of Teacher Education, 27, 5-13

Bingham, J. (1979). The acceptance of global education scale. (Retrieved from ERIC database. (ED180857)

Braskamp, L. A., Braskamp, D. C., \& Merrill, K. C. (2007). Global perspectives inventory. Chicago, IL: Global Perspective Institute

Brooks, B. (2006). Educating for a culture of peace through holistic education: A case study of the Robert Muller School of Fairview. (Doctoral dissertation, McGill University, 2006), Dissertation Abstracts International, 68.

Brophy, J. E. (1982). Two reaction papers. The Elementary School Journal, 82(5), 519533.

Brophy, J.E. (1983). Classroom organization and management. The Elementary School Journal, 83(4), 265-284.

Brown, J. G. (2006).High school students' perceptions of and attitudes toward globalization: An analysis of international baccalaureate students in Estado de Mexico, Mexico, and Texas, United States of America, Texas. (Doctoral dissertation, Texas A \& M University, 2006). Dissertation Abstracts International, 67. 
Buckley, M. A., Storino, M., \& Sebastián, A. M., (2003). The impact of school climate: Variation by ethnicity and gender. Paper presented at the Annual Conference of the American Psychological Association, Toronto, Canada. Retrieved from ERIC database. (ED481671)

Burroughs, S. A., Groce, E. \& Webeck, M. (2005). Social studies education in the age of testing and accountability. Educational Measurement: Issues and Practice, 24, 13-20.

Calvert, B. (1975). The role of the pupil. Boston, MA: Routledge \& Kegan Paul.

Cantor, N., \& Langston, C. A. (1989). Ups and downs of life tasks in a life transition. In L. A. Pervin (Ed.). Goal concepts in personality and social psychology (pp. 127167). Hillsdale, NJ: Lawrence Erlbaum Associates.

Carter, A. (2001). The political theory of global citizenship. London, England: Routledge.

Case, R. (1993). Key elements of a global perspective. Social Education, 57(6), 318-325.

Cattell, R. B. (1966). The scree test for the number of factors. Multivariate Behavioral Research, 1, 245-276

Chaney, B. H., Eddy, J. M., Dorman, S. M., Glessner, L., Gree, B. L., \& Lara-Alecio, R. (2007). Development of an instrument to assess student opinions of the quality of distance education courses. The American Journal of Distance Learning, 21(3), 145-164.

Chizmar, J. F., McCarmey, B. J., Halinski, R. S.., Racich, M.J. (1985). "Give and take," economics achievement, and basic skills development. The Journal of Economic Education, 16(2), 99-110

Clarke, V. (2004). Students' global awareness and attitudes tointernationalism in a world of cultural convergence. Journal of Research in in International Education, 3(1), 51-70.

Code, M. N., Bernes, K B, Gunn, T. M., \& Bardick, A. D. (2006). Adolescents' perceptions of career concern: Student discouragement in career development. Canadian Journal of Counselling, 40(3), 160-174.

Cogan, J., Torney-Purta, J. Anderson, D. (1988). Knowledge and attitudes toward global issues: Students in Japan and the United States. Comparative Education Review, 32(3), 282-297.

Cole, N. S. (1990). Conceptions of Educational Achievement. Educational Researcher, 19(3), 2-7. 
Colon, Y., Sanchez, B. (2010). Explaining the Gender Disparity in Latino Youth's Education: Acculturation and Economic Value of Education. Urban Education, 45(3), 252-273. doi: 10.1177/0042085908322688

Comrey, A. L., \& Lee, H. B. (1992). A first course in factor analysis. ( $2^{\text {nd }}$ ed.). Hillsdale, NJ: Lawrence Erlbaum Associates.

Cook-Sather, A. (2002). Authorizing students' perspectives toward trust, dialogue and change in education. Educational Researcher, 31(4), 3-14.

Corbin, S. S. (1994). Lessons from the classroom: Male and female high school attitudes toward and achievement in social studies. (Retrieved from ERIC database. (ED393777)

Costello, Anna B., \& Jason Osborne (2005). Best practices in exploratory factor analysis: Four recommendations for getting the most from your analysis. Practical Assessment Research \& Evaluation, 10(7) 1-9.

Creswell, J. W. (2009). Research design: Qualitative, quantitative, and mixed methods approaches. $\left(3^{\text {rd }}\right.$ ed.). Thousand Oaks, CA: Sage Publications

Crew, R. (2008). Schools for a flat world. Retrieved from http://www.dadeschools.net/superintendent/crew/articles/schoolsFlat.htm

Cronbach, L . J. (1951). Coefficient alpha and the internal structure of tests. Psyschometrika, 16, 297 - 334.

Cronbach L. J., \& Meehl, P. E (1955). Construct validity in psychological tests. Psychological Bulletin, 52, 281- 302

Darling, N., Steinberg, L. (1993). Parenting style as context: An integrative model. Psychological Bulletin, 113(3), 487-496.

Davies, I., Evans, M., \& Reid, A. (2005). Globalizing citizenship education: A critique of global education and citizenship education. British Journal of Educational Studies, 53(1), 66-89.

Davis-Kean, P. E. (2005). The influence of parent education and family income on child achievement: The indirect role of parental expectations and the home environment. Journal of Family Psychology, 19(2), 294-304. doi: 10.1037/08933200.19.2.294.

Dearing, E., McCartney, K., Taylor, B. A. (2001). Change in family income matters more for children with less. Child Development, 72(6), 1779-1793. doi: 10.1111/14678624.00378 
De la Ossa, P. (2005). "Hear my voice": Alternative high schools students' perceptions and implications for school change. American Secondary Education, 34(1), 24-39.

Delors, J. (1996). Education: The necessary utopia. In UNESCO's Learning: The treasures within: A report to UNESCO of the international commission on education for the twenty-first century. Paris, France: UNESCO Publishing

Der-Karabetian, A. (1983). Nationalism and worldmindedness: Japanese versus American comparison. Paper presented at the Western Social Science Conference, Albuquerque, New Mexico. Retrieved from ERIC database. (ED236104).

DeVellis, R. F. (1991). Scale development: Theory and applications. Newbury Park, CA: Sage Publications.

Dewey, J. (1916). Democracy and education. New York, NY: The Macmillan Company.

Diem, K. G. (2002). Using research methods to evaluate your extension program. Journal of Extension, 40(6). Retrieved from (http://www.joe.org/joe/2002december/a1.php.

Dillman, D.A. (2000). Mail and internet surveys: The tailored design method. New York, NY: Wiley.

Donald, J. G., \& Denison, D. B. (2001). Quality assessment of university students: Student perceptions of quality criteria. The Journal of Higher Education, 72(4), 478-502.

Dotson, M., Tashakkori, A., \& Courbois, J. (1988). The impact of study abroad on world minded attitudes of business students. In R.L. Kind (Ed.), Proceedings of the 1988 conference (pp. 206-208). United States Southeast Region: Academy of International Business.

Doyle, K. O.(1975). Student evaluation of instruction. Toronto, Canada: Lexington Books.

Doyle, D. (2009). Holistic Assessment and the Study Abroad Experience Frontiers: The Interdisciplinary Journal of Study Abroad, 18, 143-155. Retrieved from www.frontiersjournal.com/documents/FrontiersXVIII-Fall09DDoyle.pdf

Dubin, F., \& Kuhlman, N. A. (1992). The dimensions of cross-cultural literacy. In F. Dubin \& N. A. Kuhlman (Eds.). Cross-cultural literacy: Global perspectives on reading and writing. Englewood Cliffs, NJ: Regents/Prentice Hall. 
Dubow, E. F., Boxer, P., \& L. Rowell Huesmann, L. R. (2009). Long-term effects of parents' education on children's educational and occupational success: mediation by family interactions, child aggression, and teenage aspirations. Merrill-Palmer Quarterly, 55(3), 224-250

Duckworth, R, L., Levy, L. W., \& Levy, J. (2005). Present and future teachers of the world's children: How internationally-minded are they. Journal of Research in International Education, 4(3), 279- 311.

Duff, T. B. (1971). Basic economic concepts in the high school curriculum. The Journal of Economic Education, 3(1), 5-10. Retrieved from http://www.jstor.org/stable/1182077 .

Duke, D. L. (Ed.). (1979). Classroom management: The seventy-eighth yearbook of the NSSE (part II). Chicago, IL: University of Chicago Press.

Dunning, J. H. (Ed.). (2002). Regions, globalization, and the knowledge-based economy. Oxford, England: Oxford University Press

Earl, L., \& Torrance, N. (2000). Embedding Accountability and Improvement into LargeScale Assessment: What Difference Does It Make? Peabody Journal of Education, 75(4), 114-141.

Ellison, N., \& Wu, Y. (2008). Blogging in the classroom: A preliminary exploration of student attitudes and impact on comprehension. Journal of Educational Multimedia and Hypermedia, 17(1), 99-122.

Enberg, M. (2009). Service participation and the development of a global perspective. Presentation at annual meeting of American Educational Research Association. Denver, $\mathrm{CO}$.

Engler, J., \& Hunt Jr. J. B., (2004). Preparing Our Students for Work and Citizenship in the Global Age. Phi Delta Kappan. 86(3), 197.

Erickson, F., \& Shultz, J. (1992). Students experience of curriculum. In P. W. Jackson (Ed.). In The Handbook of Research on Curriculum. New York, NY: Macmillan.

Falk, R.A. 1994. The making of global citizenship. In B. Steenbergen (Ed.). The Condition of Citizenship (pp. 32-39). London, England: Sage.

Farley, J. (1981). Perceiving the student: Enriching the social studies through the affective domain. Theory into Practice, 20(3), 179-186. 
Farman, G., Natriello, G., Dornbusch, S. M. (2978). Social studies and motivation: High school students perceptions of the articulation of social studies to work, family and community. Theory and Research in Social Education, 6(3), 27-39.

Fernandez, S. M., Massey, G. C., \& Dornbusch (1976). High school students' perceptions of social studies. Social Studies, 67(2), 51-57.

Florida International University's Quality Enhancement Plan. (2010). Global learning for global citizenship. Retrieved from http://qep.fiu.edu/Pages/default.aspx

Flutter, J., \& Rudduck, J. (2004). Consulting pupils: What's in it for schools? New York, NY: Routledge Falmer.

Friedman, T.L. (2000). The lexus and the olive tree. New York, NY: Anchor Books.

Friedman, T. L. (2005). The world is flat: A brief history of the twenty-first century. New York, NY: Farrar, Straus and Giroux.

Friedman, T. L. (2006). The world is flat: A brief history of the twenty-first century. New York, NY: Farrar, Straus and Giroux.

Fry, E (1968). A readability formula that saves time. Journal of Reading, 11(7), 265-271.

Fujikane, H. (2003). Approaches to Global Education in the United States, the United Kingdom and Japan. International Review of Education, 49(1/2), 133-152.

Fullan, M. (1993). Change forces: Probing the depths of Educational reform. New York, NY: The Falmer Press.

Fullan, M. (2001). The new meaning of educational change. ( $3^{\text {rd }}$ ed.). New York, NY: teachers College press.

Gable, R. K., \& Wolf, M. B. (1993). Instrument development in the affective domain: Measuring attitudes and values in corporate and school settings ( $2^{\text {nd }}$ ed.). Boston, MA: Kluwer Academic.

Gallup, A. M. (1985). The 17th annual Gallup poll of the public's attitudes toward the public schools. Phi Delta Kappan, 67(1), 35-47.

Garnham. D. (1975). Foreign service elitism and U.S. foreign affairs. Public Administration Review, 35(1), 44-51.

Gaudelli, W. (2003). World class: Teaching and learning in global times. Mahwah, N.J.: Lawrence Erlbaum Associates, Publishers. 
George, D., \& Mallery, P. (2003). SPSS for Windows step by step: A simple guide and reference. $\left(4^{\text {th }}\right.$ ed.). Boston, MA: Allyn \& Bacon

Golay, P. (2006). The effects of study abroad on the development of global-mindedness among students enrolled in international programs at Florida State University. (Doctoral dissertation, Florida State University, 2006). Dissertations Abstracts International, 67.

Gomm, R., Needham, G., \& Bullman, A. (Eds.). (2000). Evaluating research in health and social care. London, UK: Sage Publications.

Good, T. L. (1999). Introduction: The Purposes of Schooling in America. The Elementary School Journal, 99(5), 383-389.

Green, A. (1997). Education, globalization and the nation-state. New York, NY: St. Martin's Press.

Green, L. (1997). Music, gender, education. London, England:Cambridge University Press

Guillory, E.B., \& Guillory, L.M. (1989). Demystifying global education. Momentum, 20(1), 58-63.

Haggerty, R. (1995). The crisis of confidence in American education:A blue print for fixing what is wrong and restoring America's confidence in the public schools . Springfield, IL: Charles C. Thomas.

Harter, S.P. (1992). Psychological relevance and information science. Journal of American Society for Information Science, 43(9), 602-615.

Hahn, C. L. (1998). Becoming political: Comparative perspectives on citizenship education. Albany, NY: SUNY Press.

Hammer, M., \& Bennett, M. (1998). Intercultural development inventory. Retrieved from http://www.greenleafconsulting.com/idi.htm

Hanvey, R. G. (1982). An attainable global perspective. Theory into Practice, 21(3), 162167.

Hargreaves, A. (2003). Teaching in the knowledge society: Education in an age of insecurity. New York, NY: Teachers College Press.

Harris, S. (1994). Entitled to what? Control and autonomy in school: A student perspective. International Studies in Sociology of Education, 4(1), 57-76. 
Harwell, M., LeBeau, B. (2010). Student eligibility for a free lunch as an SES measure in education research. Educational Researcher, 39(2), 120-131

Heater, D. (1999). What is citizenship? Cambridge, England: Polity Press.

Heater, D. (2004). Citizenship: The civic ideal in world history, politics, and education. Oxford: Manchester University Press.

Held, D., \& McGrew, A. (2002). Globalization/anti-globalization. Malden, MA: Blackwell Publishers Inc.

Hendrix, J.C. (1998). Globalizing the curriculum. The Clearing House, 71(5), 305-310.

Hett, J.E.(1993). The development of an instrument to measure global mindedness. (Doctoral dissertation, University of San Diego, 1993). Dissertation Abstracts International, 54(10), 3724A.

Hewitt Associates Survey (2004). Preparing for the workforce of tomorrow. Retrieved from http://jobfunctions.bnet.com/abstract.aspx?docid=170921\&tag=content;col1.

Hicks, D. (2003). Thirty Years of Global Education: a reminder of key principles and precedents. Educational Review, 59(3), 265-277.

Hosseinali, T. (1995). The relationship of global-mindedness to travel and living abroad experiences of university professors. (Doctoral dissertation, University of Arkansas, 1995). Dissertation Abstracts International, 56(07), 2544A.

Hovland, K. (2006). Shared futures: Global learning and liberal education. Washington, DC: Association of American Colleges and Universities

Howard, T. (2003). A tug of war for our minds:" African American high school students' perceptions of their academic identities and college aspirations. High School Journal, 87(1), 1-17.

Hull, F.W. (1972) Changes in world mindedness after a cross -cultural sensitivity group experience. Journal of Applied Behavioral Science, (Jan-Feb), 115-121.

Hunter, W. D. (2004). Got global competence. International Educator, (Spring). Retrieved from http://www.drake.edu/international/cgc/hunter.pdf

Hunter, B., White, G. P., \& Godbey, G. C. (2006). What does it mean to be globally competent? Journal of Studies in International Education, 10(3), 267-285. 
Huntington, S. (1996). The clash of civilizations and the remaking of world order. New York, NY: Simon \& Schuster, Inc.

Ivey, G., \& Broaddus, K. (2001). Just plain reading: A survey of what makes students want to read in middle school classrooms. Reading Research Quarterly, 36(4), 350-377. Retrieved from http://www.jstor.org/stable/748056

Jackson, S. A. (1980). Reading: Some can and some can't. Paper presented at the State reading Association and the State Department of Education, Houston, TX. (Retrieved from ERIC database. (ED184060)

Jencks, C., \& Phillips, M. (1998). (Eds). The black-white test score gap. Washington, DC: Brookings Institution Press.

Johnston, M., \& Ochoa, A. (1993). Teacher education in global perspectives. Theory Into Practice, 32(1), 64-68.

Kaiser, H. F. (1958). The varimax criterion for analytic rotation in factor analysis. Psychometrika, 23, 187-200.

Kao, G. (2004). Parental Influences on the Educational Outcomes of Immigrant Youth. International Migration Review, 38(2), 427-449: http://www.jstor.org/stable/27645384Accessed

Karp, B. (1981). The world view in American government textbooks. New Rochelle, N.Y.: Change Magazine Press.

Kehl, K. (2006). Differences in self-efficacy and global mindedness between short-term and semester-long study abroad participants at selected Christian universities. (Doctoral dissertation, Baylor University, 2006). Dissertation Abstracts International, 66(10), 3525A.

Kerr, C. (1979). Education for global perspectives. Annals of the American Academy of Political and Social Science, 442(Mar), 109-116.

Khishtan, M. (1990). An analysis of faculty awareness of and commitment to worldmindedness in selected universities. (Doctoral dissertation, The George Washington University, 1990). Dissertation Abstracts International, 51(09), 2995B.

King, J. (1977).The perceptions of black high school students toward vocational and technical education programs. The Journal of Negro Education, 46(4), 430-442.

Kirkwood, T. (2001). Our global age requires global education: Clarifying definitional ambiguities. Social Studies, 92(Jan/Feb), 10-16. 
Kitsantas, A., Ware, H., \& Martinez-Arias, R. (2004). Students' perceptions of school safety. Effects by community, school environment, and substance use variables. Journal of Early Adolescence, 24(4), 412-430.

Kline, P. (1993). The handbook of psychological testing. London, England: Routledge

Kniep, W. M. (1986). Defining a global education by its content. Social Education, $50(10), 437-446$.

Kuncel, N.R., Crede, M., \& Thomas, L. L. (2005). The validity of self-reported grade point averages, class ranks, and test scores: A meta-analysis and review of the literature. Review of Educational Research, 75(1), 63 - 82. doi: 10.3102/00346543075001063

Labbo, L.D., Reinking, D., \& McKenna, M. C. (1998). Technology and literacy education in the next century: Exploring the connection between work and schooling. Peabody Journal of Education, 73(3/4), 273-289.

Lamy, S. (1983). Defining global education. Educational Research Quarterly, 8(1), 9-20.

Lamy, S. L. (1987). The definition of discipline: The objects and methods of analysis on global education. New York, NY: Global Perspectives in Education.

Landorf, H. (2005, April). Student perceptions of Islam and the Muslim world. Paper presented at the annual conference of the American Educational Research Association, Montreal, Canada.

Lechner, F. J., \& Boli, J. (Eds.). (2000). The globalization reader. Malden, MA: Blackwell Publishing.

Lentz, T. F. (1950). Attitudes of world citizenship. The Journal of Social Psychology, 32, 207-214.

Lester, P. E., \& Bishop, L. K. (2000). Handbook of tests and measurement in education and the social sciences. Lanham, MD: Scarecrow Press.

Levin, B. (2000). Putting students at the centre in education reform. Journal of Educational Change, 1(2), 155-172.

Levinson, D.J. (1957). Authoritarian personality and foreign policy. Journal of Conflict Resolution, 1(1), 37-47.

Lynch, J. (1989). Multicultural education in a global society. New York, NY: Falmer Press. 
Main, R. S. (1978). The Treatment of Economic Issues in High School Government, Sociology, U. S. History and World History Texts. The Journal of Economic Education, 9(2), 115-118.

.Maira, S. (2004). Youth culture, citizenship, and globalization. In M. M. Suarez-Orozco \& D. B. Qin-Hilliard (Eds.). Globalization (pp. 203-234). Los Angeles, CA: University of California Press.

Manzo, K. K. (2005). Social studies losing to reading and math. Education Week, 24(27), $16-48$.

Marshall, H. (2003). Review: Global education: A re-emerging field. British Journal of Sociology of Education, 24(3), 397-405.

Marshall, T.H. (1964). Class, citizenship, and social development. Garden City, NY: Doubleday.

McCabe, L.T. (1994). The development of a global perspective during participation in semester at sea: A comparative global education program. Educational Review, $46(3), 275-286$.

McClaren, W. P. (2003). Life in schools: an introduction to critical pedagogy in the foundations of education. Boston: MA, Pearson Education, Inc.

McLuhan, M. (1967). The medium is the message. New York, NY: Bantam.

Mehdi, M. (2006). An evaluative case study of UNICEF global education project in Iran, 2002-2003. (Doctoral dissertation, University of Toronto, 2006). Dissertation Abstracts International, 68.

Merryfield, M.M. (1990). Teaching about the world: Teacher education programs with a global perspective. Retrieved from ERIC database. (ED339623).

Merryfield, M. M. (1991). Preparing American secondary social studies teachers to each with a global perspective: A status report. Journal of Teacher Education, 42(1), 11-20.

Merryfield, M. (1992). Preparing social studies teachers for the twenty-first century: Perspectives on program effectiveness from a study of six exemplary teacher education programs in global education. Theory and Research in Social Education, 20(1), 17-26.

Merryfield, M. M. (1994). From teacher education to the classroom: Reflections of teachers upon their teacher education experiences in global education. Retrieved from ERIC database. (ED392724). 
Merryfield, M. (1997). "A framework for teacher education in global perspective,"

Preparing teachers to teach global perspectives: A handbook for teacher educators, Thousand Oaks, CA: Sage Publications Company.

Merryfield, M. M. (1998). Pedagogy for global perspectives in education: Studies of teachers' thinking and practice. Theory and Research in Social Education, 26(3), 342-379.

Merryfield, M.M., Jarchow, E., \& Pickert, S. (1997). Preparing teachers to teach global perspectives: A handbook for teacher educators. Thousand Oaks, CA: Corwin Press, Inc.

Mikulecky. L., \& Kirkley, J.R. (1998). Literacy Education in the 21st Century. Peabody Journal of Education, 73, (3/4), 290-316.

Miller, D. (1993). (1993), In defense of nationality. Journal of Applied Philosophy, 10(1). Oxford: Wiley Blackwell.

Mitchell, P. (2007). Resourcing the curriculum: Global literacy. Retrieved from http://www.ala.org/ala/mgrps/divs/aasl/aaslpubsandjournals/kqweb/kqarchives/vo lume35/352/352Mitchell.cfm.

Moffatt, R. (2007). NAFSA's Role in Developing Global-Ready Graduates. Retrieved http://www.nafsa.org/partners.sec/global_workforce_development/nafsa_s_role_i n_developing.

Moon, S. S., Suk-Young, K., \& Soonok, A (2009). Predictors of immigrant children's school achievement: a comparative study. Journal of Research in Childhood Education 23(3), 278-289. Retrieved from Academic OneFile.

Mueller, D. J. (1986). Measuring social attitudes. New York, NY: Teachers College Press.

Mulvenon, S. W., Connors, J. V.F., \& Lenares, D. (2001). Impact of accountability and school testing on students: Is there evidence of anxiety? Paper presented at the Annual Meeting of the Mid-South Educational Research Association, Little Rock, AR. Retrieved from ERIC database. (ED460155).

Mundfrom, D. J., Shaw, D. G., \& Ke, T. L. (2005). Minimum sample size recommendations for conducting factor analyses. International Journal of Testing, 5(2), 159-168.

Muspratt, S., Luke, A., \& Freebody, P. (1997). Constructing critical literacies: Teaching and learning textual practice. Cresskill, NJ: Hampton Press. 
Myers, J.P. (2006). Rethinking the social studies curriculum in the context of globalization: Education for global citizenship in the U.S. Theory and Research in Social Education, 34(3), 370-394.

National Commission on Teaching and America's Future (1996). What Matters Most: Teaching for America's Future. Report of the National Commission on Teaching \& America's Future. Woodbridge, VA: National Commission on Teaching and America's Future.

Neef, D. (1999). A little knowledge is a dangerous thing: Understanding our global knowledge economy. Boston, MA: Butterworth Heinemann.

Neil, M., \& Guisbond, L. (2005). Excluded children, lost learning: The costs of doing business with NCLB. Social Studies and the Young Learner, 17(3), 30-32.

Neumann, G. A. (1926). A study of international attitudes of high school students. Teachers College Contributions to Education, No. 239. The School Review, 35(10), 795-796.

Newman, I., Benz, C, R., Weis, D., \& McNeil, K. (1997). Theses and dissertations: A guide to writing in the social and physical sciences. New York, NY: University Press of America.

Newman, I., \& McNeil, K. (1998). Conducting survey research in the social sciences. New York, NY: University Press of America.

Newman, I., \& Newman, C. (2006). Conceptual statistics for beginners. Washington, DC: University Press of America.

Noddings, N. (Ed.).(2005). Educating citizens for global awareness. New York, NY: Teachers College Press.

Nordgren, R. D. (2002). Globalization and education: What students will need to know and be able to do in the global village. The Phi Delta Kappan, 84(3). 318-321.

Nunnally, J. C. (1959). Tests and measurements: Assessment and prediction. New York, NY: McGraw-Hill.

Nunnally, J.C. (1970). Introduction to psychological measurement. New York, NY: Mcgraw Hill.

Nunnally, J.C. (1978). Psychometric theory. New York, NY: McGraw-Hill.

Nussbaum, M. (2002). Patriotism and cosmopolitanism. In J. Cohen (Ed.). For love of country (pp. 3-20). Boston, MA: Beacon Press. 
Ohmae, K. (1995). The end of the nation state: The rise of regional economies. New York: Free Press Paperbacks, a Division of Simon \& Schuster.

Onwuegbuzie, A. J. \& Leech, N. L. (2004). Post hoc power: A concept whose time has come. Understanding Statistics, 3(4), 201-230.

Osler, A., Vincent, K. (2002). Citizenship and the challenge of global education. Staffordshire, England: Trentham Books.

Ornstein R, Ehrlich P. (1989). New world/new mind: Moving toward conscious evolution. New York, NY: Doubleday.

O'Sullivan, B. (1999). Global change and educational reform in Ontario and Canada. Canadian Journal of Education, 24(3), 311-325.

Oxfam (2006). Education for citizenship: A guide for schools. Retrieved from http://www.oxfam.org.uk.

Parker, J. C. (2007). Gender differences in the motivation to learn. Retrieved from http://archives.evergreen.edu/masterstheses/Accession8910MIT/Parker_J\%20MITthesis\%202007.pdfk

Parker, W.C., Ninomiya, A., \& Cogan, J. (1999). Educating world citizens: Toward multinational curriculum development. American Educational Research Journal, $36(2), 117-145$.

Pascopella, A. (2004). Glimmers of hope in no child(Inside the law: analyzing, debating and explaining No Child Left Behind). District Administrator, 40(10), 23. Retrieved from EBSCO Host Research Databases.

Pedraza-Bailey, S. 1985. Political and Economic Migrants in America: Cubans and Mexicans. Austin, TX: University of Texas Press.

Pellegrini, R. J. (1982). College students perceptions of their high school social studies. Social Studies Review, 21(3), 6-14.

Phelan, P., Davidson, A. L., \& Cao, H. T. (1992). Speaking up: Students' perspectives on school. Phi Delta Kappan, 73(9), 695-704.

Piaget, J. (assisted by Anne-Marie Weil). (1951). The development in children of the idea of the homeland and or relations with other countries. International Social Science Bulletin (Bulletin International des Sciences Sociales), 3, 561-578.

Pike, G., \& Selby, D. (1988). Global teacher, global learner. London, England: Hodder and Stoughton. 
Pike, G., Selby, D. (2000). In the classroom. Toronto, Ontario: Pippin Publishing.

Pike, L. W., Barrows, T. S., Mahoney, M. H., Jungeblut, A. (1979). Other nations others peoples: A survey of student interests, knowledge, attitudes and perceptions. Washington, DC: U.S. Government Printing Office.

Popkewitz, T.S. (1980). Global education as a slogan system. Curriculum Inquiry, 10(3), 303-316.

Pyne, D., Nernes, K., Magnusson, K., \& Poulsen, J.,A (2002). Description of junior high and senior high school students' perceptions of career and occupation. Guidance and Counseling, 17, 65-72.

Qin, D. B. (2006). The Role of Gender in Immigrant Children's Educational Adaptation. Current Issues in Comparative Education, 9(1), 1-12.

Queensland of Technology. (2006). International and Global Studies Multidisciplinary Major Bachelor of Arts Handbook, p.2.

Rabb, T. K. (2004). "No Child” left behind historical literacy. Education Digest, 70(2), $18-21$

Reimers, F. (2009). Global competency is imperative for global success. The Chronicle of Higher Education, 55(21), 29

Rhoades, G., \& Slaughter, S. (1991). The Public interest and professional labor: Research universities. In W. Tierney (Ed.). Culture and ideology in higher education: Advancing a critical agenda (pp. 187-213). New York, NY: Praeger.

Rigby, K. 1987. Factors Influencing Support for Nuclear Disarmament in Australia. Paper presented at the XIVth Annual Social Psychology Conference, Australian National University, Canberra.

Rigby, K., Metzer, J., \& Dietz, B. (1990). Factors predisposing individuals to support nuclear disbarment: An international perspective. Journal of Peace Research, 27(3), 321-329.

Rogers, C. (1977). Carl Rogers on personal power. New York, NY: Delacorte.

Rogers, H. P., Kochunny, C. M. (1994). Assessing worldmindedness among students: An exploratory study. Journal of teaching in International Business, 5(4), 17-33.

Rong, X. L., \& Grant, L. (1992). Ethnicity, Generation, and School Attainment of Asians, Hispanics, and Non-Hispanic Whites. The Sociological Quarterly, 33(4), 625-636 
Rosenau, J.N. (1995). Governance in the twenty-first century. Global Governance, 1, 1343.

Rosenzweig, P. (1998). Managing the new global workforce: Fostering diversity, forging consistency. European Management Journal, 16(6), 644 - 652.

Rubio, D. M., Berg-Weger, M., Tebb, S. S., Lee, E, S \& Rauch, S. (2003). Objectifying content validity: Conducting a content validity study in social work research. Social Work Research, 27(2), 94-04

Ruddell, M. R. (1999). Of stand-up comics, statisticians, storytellers, and small girls walked backward: A new look at the discourses of literacy research. In T. Shanahan \& F.V. Rodriguez-Brown (Eds.). $48^{\text {th }}$ Yearbook of the National Reading Conference (pp. 1-16). Chicago: National Reading Conference.

Rust, E. (2007) Building a $21^{\text {st }}$ century U.S. education system. National Commission on Teaching and America's Future (NCTAF). (Retrieved from ERIC database. (ED504315)

Said, E. (1993). Culture and imperialism. New York, NY: Alfred A. Knopf.

Sampson, D. L., Smith, H.P. (1957). A scale to measure world-minded attitudes. The Journal of Social Psychology, 45, 99-106.

Saracevic, T. (1975). Relevance: A review of and a framework for the thinking on the notion in Information Science. Journal of American Society for Information

Schmidt, P. (2003). Academe's Hispanic future. The Chronicle of Higher Education 50(14). Retrieved from Academic OneFile.

Schuerholz-Lehr, S. (2007). Teaching for global literacy in higher education: How prepared are the educators. Journal of Studies in International Education. 11(2), 180-204.

Schur, L. M. (1970). The economist as consultant to the schools. The Journal of Economic Education, 2(1), 78-88. Retrieved from http://www.jstor.org/stable/1182363 .

Selby, D., \& Pike, G. (2000). Civil global education: Relevant learning for the twenty-first century. Convergence, 33(1/2), 138-149.

Shealy, C. N. (1990). Beliefs, Events, Values Inventory. Retrieved from http://www.sit.edu/SITOccasionalPapers/feil_appendix_f.pdf

Sheskin, D. J. (2004). Handbook of parametric and nonparametric statistical procedures. ( $3^{\text {rd }}$ ed.). Boca Raton, FL: CRC Press. 
Silvernail. D L. (1979). The Assessment of Teachers' Future World Perspective Values. The Journal of Environmental Education, 10(2), 7-11.

Singer, J. D. (1965). Cosmopolitan attitudes and international relations courses: Some tentative correlations. The Journal of Politics, 27(2), 318-338.

Sluys, K.V., Lewison, M., \& Flint, A. S. (2006). Researching critical literacy: A critical study of an analysis of classroom discourse. Journal of Literacy Research, 38(2). 197-233.

Smith, P. C., Kendall, L. M., \& Hulin, C. I. (1969). The measurement of satisfaction in work and retirement: A strategy for the study of attitudes. Chicago, IL: RandMcNally.

Soo Hoo, S. (1993). Students as partners in research and restructuring schools. The Educational Forum, 57(4), 386-393.

Spring, J. (1998). Education and the rise of the global economy. Mahwah, NJ: Lawrence Erlbaum.

Spring, J. (2004). How educational ideologies are shaping global society: New Jersey, NJ: Lawrence Erlbaum associates, Inc.

Spring, J. (2008). Research on Globalization and Education. Review of Educational Research, 78(2), 330-363

Stewart, F. (1991). Citizens of the planet earth. In G. Andrews (Ed.). Citizenship (pp. 6575). London, England: Lawrence and Wishart Ltd.

Stewart, V, \& Kagan, S. L. (2005). A new world view: Education in a global era. $\underline{P h i}$ Delta Kappan, 87(3), 241-255.

Stiglitz, J. E. (2004). Making globalization work. New York, NY: W.W. Norton Company.

Stromquist, N. P. (2002). Education in a globalized world.: The connectivity of economic power, technology, and knowledge. New York, NY: Rowman \& Littlefield Publishers, Inc.

Suarez-Orozco, M. M., \& Qin-Hilliard, D. B. (Eds.). (2004). Globalization: Culture and education in the new millennium. Los Angeles, CA: University of California Press.

Swift, J. (1980). Global education: What's in it for us? The English Journal, 69(9), 46-50. 
Tabachnick, B, G., \& Fidell, L. S. (2007). Using multivariate statistics $\left(5^{\text {th }}\right.$ ed.). Boston, MA: Pearson Education

Tarrow, N. (1992). Human rights education: Alternative conceptions. In J. Lynch (Ed.), Human rights education and global responsibilities. Washington, DC: The Falmer Press

Terenzini, P. T. 1989. Assessment with Open Eyes: Pitfalls in Studying Student Outcomes. Journal of Higher Education, 60(6), 644-664

Thorndike, R. L. (1982). Applied psychometrics. Boston, MA: Houghton Mifflin.

Thuermer, C. I. (1993) Global education: A response to five persistent issues in the high school social studies curriculum. Dissertation Abstracts International, 54(12), 4403A. Retrieved from http://proquest.umi.com.ezproxy.fiu.edu

Torney-Purta, J. (1982). The global awarenss survey: Implications for teacher education. Theory into Practice, 21(3), 200-205.

Torney-Purta, J. (1989). A Research Agenda for the Study of Global/International Education in the United States. (Abstract). Paper delivered at the Annual Meeting of the American Educational research Association, San Francisco, CA. Retrieved from ERIC database. (ED313295)

Torney-Purta, J., Schwille, J., \& Amadeo, J. A. (1999). Civic education across countries: Twenty-four national case studies from the IEA civic education project. Retrieved from ERIC database. (ED431705)

Torres, C. A. (1998). Democracy, Education and multiculturalism: Dilemmas of citizenship in a global world. Lanham, MD: Rowman \& Littlefield

Torres, C. A. (2002). Globalization, education, and citizenship: Solidarity versus markets. American Educational Research Journal, 39(2), 363-378.

Trice, A. G., \& Dey, E. L. (1997). Trends in faculty teaching goals: A longitudinal study of change. Journal of College Student Development, 38(5), 527-534.

Trilling, B., \& Fadel, C. (2009). 21st Century Skills: Learning for Life in Our Times. San Francisco, CA: John Wiley and Sons.

Triplett, C. F., \& Barksdale, M. A. (2005). Third through sixth graders' perceptions of high-stakes testing. Journal of Literacy Research, 37(2), 237-260. 
Tye, B. B., \& Tye, K. A. (1992). Global education: A study of school change. Albany, NY: State University of New York Press.

Tye, K. A. (2003). Global education as a worldwide movement. Phi Delta Kappan, 85(2), 165-168.

Van de Ven, A., \& Ferry, D. (1980). Measuring and assessing organizations, New York, NY: Wiley.

Van Houtte, M. (2004). Why boys achieve less at school than girls: the difference between boys' and girls' academic culture. Educational Studies, $30(2), 159-173$

Vaughn, S., Schumm, J. S., Klingner, J., \& Saumell, L. (1995). Students' views of instructional practices: Implications for inclusion. Learning Disability Quarterly, $18,236-248$.

Velicer, W. F., \& Jackson, D. N. (1990). Component analysis versus common factoranalysis - some further observations. Multivariate Behavioral Research, 25(1), $97-114$.

Verhoeven, L. (1998). Future perspective on literacy in Europe. Peabody Journal of Education, 73(3/4), 127-144.

Volet, S. E. (1997). Cognitive and affective variables in academic learning: The significanceof direction and effort in students' goals. Learning and Instruction, $7(3), 235-254$.

Volet, S. E., \& Lawrence, J. A. (1990). Goals in the adaptive learning of university students. In H. Mandl, E. Corte, N. Bennett, \& H. F. Friedrich (Eds.). Learning and instruction: European research in all international context: Social and cognitive aspects of learning and instruction (pp. 497-516). Oxford, England: Pergamon.

Wagner, T. (2008). The global achievement gap: Why even our best schools don't teach the new survival skills our children need--and what we can do about it. New York, NY: Basic Books.

Wallerstein, I. (1979). The politics of the world-economy. Cambridge, UK: Cambridge University Press.

Wang, J., Peyvandi, A., Moghaddam, J. M. (2009). Impact of short study abroad programs on students' diversity attitude. International Review of Business Research Papers, 5(2), 349-357 
Warren, P. (1992). Just what is a good citizen? Political literacy and its implication for teachers of history. Paper presented at the Annual Conference of the History Teachers' Association of Australia. Retrieved from ERIC database. (ED351266)

Wehling, B. (2007). Building a $21^{\text {st }}$ century U.S. education system. National Commission on Teaching and America's Future (NCTAF). Retrieved from ERIC database. (ED504315)

Weinberg, S. L., \& Abramowitz, S. K. (2002). Data analysis for the behavioral sciences using SPSS. Cambridge, UK: Cambridge University Press.

Weinstein, R. 1983). Student perceptions of schooling. The Elementary School Journal, 83(4), 286-312

Weissman, J., Bulakowski, C., \& Jumisko, M. (1998). A study of White, Black, and Hispanic students' transition to a community college. Community College Review, 26(2). 19-42.

Wheatley, M., \& Kellner-Roger, M. (1996). A simpler way. San Francisco, CA: BerretKoehler.

Wiggan, G. (2007). Race, school achievement, and educational inequality: Toward a student-based inquiry perspective. Review of Educational Research, 77(3), 310333.

Wing-Wah, L. (2004). Translating globalization and democratization into local policy: Educational reform in Hong Kong and Taiwan. International Review of Education, 50(5/6), 497-524.

Wiseman, R.L., Hammer, M.R., \& Nishida, H. (1989). Predictors of intercultural communication competence. International Journal of Intercultural Relations, 12(3), 349-370.

Wisconsin Department of Public Instruction. (2006). Strategies for achieving global literacy for Wisconsin students. Retrieved from http://www.21stcenturyskills.org/documents/global-litbrochure.pdf

Witte, J. F., \& Rigdon, M. E., (1993). Education choice reforms: Will they change American schools? The Journal of Federalism, 23(3), 95-114.

Wolfson, B.J., \& Nash, S. (1968). Perceptions of decision-making in elementary-school classrooms. The Elementary School Journal, 69(2), 89-93. 
Wolters, C. A., Pintrich, P. R. (1998). Contextual differences in student motivation and self-regulated learning in mathematics, English, and social studies classrooms Instructional Science, 26, 27-47.

World Bank. (2003). Lifelong learning in the global knowledge economy: Challenges for developing countries. International Education International Education Council

Yocum, M. J. (1992). An investigation of the effect of global education on the attitudes of high school. Review of Research in Education, 18(1), 111-161. doi: 10.3102/0091732X018001111

Zeleza, P. T. (2007). Knowledge, globalization, and hegemony: Production of knowledge in the twenty-first century. In S. Sorlin \& H. Vessuri (Eds.). Knowledge society vs. knowledge economy: Knowledge, power, and politics (pp. 79-106). New York, NY. Palgrave Macmillan

Zembylas, M. (2003). Reviews. (Review of the book Citizenship and the challenge of global education, by A. Osler \& K. Vincent). Journal of Curriculum Studies, 35(3), 387-408

Zhai, L., \& Scheer, S.D.(2004). Global perspectives and attitudes toward cultural diversity among summer agriculture students at the Ohio State University. Journal of Agricultural Education, 45(2) 39-51.

Zong, G. (1999). The effects of participation in an Internet-based project on the development of global knowledge, global mindedness and global pedagogy among preservice and social studies teachers. (Doctoral dissertation, Florida International University, 1999). Dissertations Abstracts International, 60, 2359.

Zuniga, M. E. (1998). Families with Latino roots, In E. W. Lynch, \& M. M. J. Hanson (Eds.). Developing cross-cultural competence. ( $2^{\text {nd }}$ ed.).(pp. 209-250). Baltimore, MD: Paul H. Brookes Publishing Co 
APPENDICES 


\section{MEMORANDUM}

$\begin{array}{ll}\text { To: } & \text { Renita Ferreira } \\ \text { CC: } & \text { Dr. Mohammed Farouk } \\ & \text { File } \\ \text { From: } & \text { Chris Grayson, CIM, Asst. Director of Research Compliance } \\ \text { Date: } & \text { September 2, 2008 } \\ \text { Proposal Title: } & \begin{array}{l}\text { A Development of an Instrument to Measure High School Students' } \\ \text { Perspectives of Global Education and Global Citizenship and its Relevance } \\ \text { to their Future. } \\ \text { Approval \# }\end{array} \\ & \end{array}$

Your study was deemed Exempt by the Institutional Review Board at Florida International University on August 28, 2008.

As a requirement of IRB approval you are required to:

1) Submit a completion report (Form B-2) upon completion of your project in order for the file to be closed.

2) Submit a proposal and receive approval for any additions or changes in the procedures involving human subjects.

3) Provide immediate written notification to the IRB of every serious or unusual or unanticipated adverse event as well as problems with the rights or welfare of the human subjects. You must confirm the receipt of serious AE reports with the IRB office.

Special Conditions: The Miami Dade County Public School permission letter must be obtained and submitted to the FIU IRB Office (MARC 430 - Attn: IRB Coordinator) prior to implementation.

Please note your approval number is indicated above. For further information, you may contact the IRB Coordinator by email at irbiacuc@fiu.edu or visit the OSRA - Human Subjects website at www.osra.fiu.edu. 


\section{APPENDIX B - Letter to the Principal}

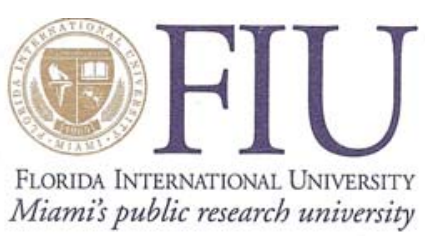

August 5, 2009

Dear Principal:

I am a doctoral candidate from Florida International University seeking your permission to allow one class each of $11^{\text {th }}$ and $12^{\text {th }}$ graders to participate in the development of an instrument. The title of the study is: The Development of an Instrument to Measure High School Students' Perspectives on Global Education and Global Citizenship, and their Relevance to the Students' Future in the Global Workforce. This is in partial fulfillment of the requirements for the Doctor of Education degree in Curriculum and Instruction. I have secured the necessary permission from the Miami-Dade Public Schools system (see enclosure).

The survey will be administered by me. It should take approximately 45 minutes from start to finish. It will be a simple paper and pencil survey. I have secured Institutional Review Board (IRB) approval and have the approved assent forms for the students and the parental consent forms ready for your perusal. I have also been finger printed. The instrument should be ready for distribution by the end of September 2009. I plan to administer the survey between October and November 2009.

I look forward to a favorable reply, and thank you in anticipation. If you have any questions, please feel free to contact at 305-279-4745 or via e-mail at rferr008@) fiu.edu.

Sincerely,

Renita Ferreira 


\section{APPENDIX C - Student's Assent Form}

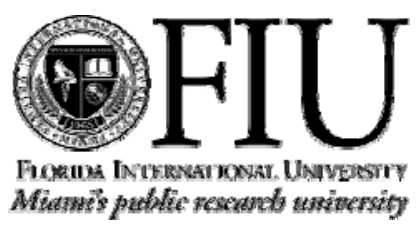

\section{INFORMED ASSENT}

\section{Informed Assent Format}

The following chart provides the required content areas of a child consent form (ages 7-17) and simple questions that an investigator may ask him/herself while preparing the document. For more information about the informed consent process, please go to the FIU IRB website.

\begin{tabular}{|c|c|}
\hline Consent Form Outline & Simple Questions to Address in a Consent Document \\
\hline Heading & $\begin{array}{l}\text { Development of an Instrument to Measure High School Students' } \\
\text { Perspectives of Global education and Global citizenship and its } \\
\text { Relevance to their Future }\end{array}$ \\
\hline Introduction & $\begin{array}{l}\text { You are chosen because your school gave me the permission to } \\
\text { give you a survey to find out if the education you are receiving is } \\
\text { getting you ready for jobs in a globalized world. Other high school } \\
\text { students will be doing the survey as well. }\end{array}$ \\
\hline Research Procedures & $\begin{array}{l}\text { You just have to answer the questions on the survey. It will take } \\
\text { about } 30 \text { minutes, maybe less. Your parents will also have to sign a } \\
\text { consent form. }\end{array}$ \\
\hline Risk to Subjects & There is no risk involved at all. It is a paper and pencil test \\
\hline Benefit to Subjects & $\begin{array}{l}\text { I am hoping to be able to make school administrators and policy } \\
\text { makers realize that you need more than what you are learning now. } \\
\text { You need some global education. I am also hoping that this "new" } \\
\text { education will make you a better person for employment in the } \\
\text { global workforce and a better global citizen. }\end{array}$ \\
\hline $\begin{array}{l}\text { Cost or Compensation to } \\
\text { Subject }\end{array}$ & There is no money involved \\
\hline Confidentiality of Data & $\begin{array}{l}\text { You are not asked to identify yourself. You will be just a number. } \\
\text { The information is for my research purpose only. }\end{array}$ \\
\hline $\begin{array}{l}\text { Subject participation or } \\
\text { Withdrawal from Study }\end{array}$ & You are perfectly free to withdraw. It will not be held against you \\
\hline Contact information & $\begin{array}{l}\text { You can contact me at } 3052794745 \text { or my major professor, Dr } \\
\text { Farouk at } 3053483199\end{array}$ \\
\hline $\begin{array}{l}\text { Statement of Understanding } \\
\text { and Signature }\end{array}$ & $\begin{array}{l}\text { If you sign this form it just means you have agreed to take the } \\
\text { survey }\end{array}$ \\
\hline
\end{tabular}




\section{ASSENT TO PARTICIPATE IN A RESEARCH STUDY}

\section{Title: Development of an Instrument to Measure High School Students' Perspectives of Global education and Global citizenship and its Relevance to their Future in the Global Workforce}

My name is Renita Ferreira and I am a student at Florida International University. You and your class members are being asked to participate in a research study.

We will need to get permission from your parent before you help with the study. If you decide to help, you will be asked to take a survey. The activity should take less than 30 minutes to complete. There are no good or bad time answers, just honest ones. We want to know if you are receiving an education that will get you ready for jobs in globalized world and make you good global citizens. I want to know what you think about your current education.

There is no charge or payment for your help. Filling out the survey will not harm you in any way. If you get tired or upset you can ask for a break. We only want you to do your best. Your help with this project will not help or hurt your school grades. You or your parent may ask to stop participating at any time.

The information we learn about you is private. It will only be shared with your teacher and parents.

If you have questions you may ask at any time. If you have questions about the study, you or your parent can call me, Renita Ferreira at 305279 4745, or Dr. Farouk at 305348 3199. If you or your parent feels like you weren't treated fairly during the study or you have questions regarding your rights as a volunteer in this research study you may call Dr. Patricia Price, the Chairperson of the Institutional Review Board at $305-348-2618$ or 305-348-2494.

If you would like to be in our study, sign your name here. You will be given a copy of this form.

Participant's Signature

Investigator Signature
Date

Date

\section{Florida International University}

Iniversitv Park. Miami. Florida 33199 


\section{APPENDIX D - Parent's Consent Form

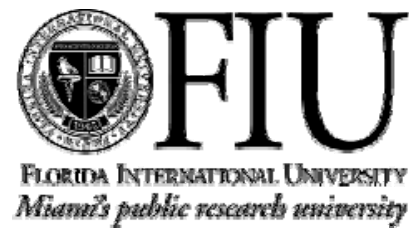

Note: The parent is NOT participating in this study CONSENT TO PARTICIPATE IN A RESEARCH STUDY

\section{Title: Development of an Instrument to Measure High School Students' Perspectives of Global education and Global citizenship and its Relevance to their Future in the Global Workforce}

We would like your child to be in a research study. The investigator of this study is Renita Ferreira, a doctoral student from the College of Education at Florida International University. The study will include twelve (12) high schools in your area grades 9 through 12. The study will require about a half hour (30 minutes) of your child's time. The study would like to garner information on your child's opinion about the appropriateness of his/her current education for his/her future in a global work force and his/her readiness to take his/her place in the world as a global citizen.

Your child will also be given a form that explains the study and asks for his/her agreement to be in the study. If you grant permission and your child wants to be a part of the study your child will be asked to complete a questionnaire about: 1) world issues, 2) global education and its relevance 3) global citizenship and its importance.

There are no known risks related to the questionnaires. Your child may skip any questions that they choose not to answer. If your child becomes anxious or upset they can take a break. Your child may not gain any direct benefit by being in the study. However, this research will give us information about high school students and help to provide vital information to bring about change in the curriculum.

There is no cost to your child to be in the study. All data will be identified by random numbers. All data in this research is private and will not be shared with you, school officials or anyone not directly related to the study unless required by law. The results will be presented as a group in all publications, at the general forum and conferences. You or your child may ask questions about the study at any time. You or your child may request to be removed from the study at any time and no one will be upset with you.

If you would like to know more about this research you can contact me, Renita Ferreira, at 305-279-47453 or Dr. Mohammed K. Farouk at 305-348-3199. If you feel that your teen was mistreated or you have questions regarding your rights as a volunteer in this 
research study you may contact Dr. Patricia Price, the Chairperson of the FIU Institutional Review Board at 305-348-2618 or 305-348-2494..................(OVER)

If you would like to know more about this research you can contact me, Renita Ferreira, at 305-279-47453 or Dr. Mohammed K. Farouk at 305-348-3199. If you feel that your teen was mistreated or you have questions regarding your rights as a volunteer in this research study you may contact Dr. Patricia Price, the Chairperson of the FIU Institutional Review Board at 305-348-2618 or 305-348-2494 .................(OVER) If you have had all of your questions answered to your liking and you would like your child, to be in the study, sign below. (Print Student's name)

Signature of Parent

Date

I have explained the research procedure, subject rights and answered questions asked by the participant. I have offered him/her a copy of this informed consent form.

Signature of Witness

Date 


\section{APPENDIX E - 36-Item Survey with Demographics}

Globalization is a word used to describe the world as it has become more interconnected through trade, economics, migration, and the worldwide web.

Global education is the education you must receive to make you a global citizen and make you competent to join and be successful in the global workforce.

\begin{tabular}{|c|c|c|c|c|c|}
\hline & & $\begin{array}{c}1 \\
\text { Strongly } \\
\text { disagree }\end{array}$ & \begin{tabular}{l}
\multicolumn{1}{c}{2} \\
Somewhat \\
disagree
\end{tabular} & \begin{tabular}{l}
\multicolumn{1}{c}{3} \\
Somewhat \\
agree
\end{tabular} & $\begin{array}{l}\quad 4 \\
\text { Strongly } \\
\text { agree }\end{array}$ \\
\hline 1. & $\begin{array}{l}\text { I need to learn more than one } \\
\text { language because people who speak } \\
\text { languages are generally considered } \\
\text { well-educated. }\end{array}$ & & & & \\
\hline 2. & $\begin{array}{l}\text { I am taught that competitiveness is } \\
\text { very important in an interconnected } \\
\text { world }\end{array}$ & & & & \\
\hline 3. & $\begin{array}{l}\text { I am made to understand that } \\
\text { problems in the Middle East can } \\
\text { become the problems of the United } \\
\text { States. }\end{array}$ & & & & \\
\hline 4 & $\begin{array}{l}\text { No need to learn to stay informed } \\
\text { about important global events in } \\
\text { school }\end{array}$ & & & & \\
\hline 5 & $\begin{array}{l}\text { Being globally interconnected means } \\
\text { I have to learn responsibility to others } \\
\text { in the world }\end{array}$ & & & & \\
\hline 6 & $\begin{array}{l}\text { Teachers discuss global issues and } \\
\text { problems in the social studies/global } \\
\text { studies/ international class. }\end{array}$ & & & & \\
\hline 7 & $\begin{array}{l}\text { Teachers help us understand our } \\
\text { interdependence by encouraging } \\
\text { community service }\end{array}$ & & & & \\
\hline 8 & $\begin{array}{l}\text { We learn that we do not depend on } \\
\text { other countries for our manufactured } \\
\text { goods and services }\end{array}$ & & & & \\
\hline 9 & $\begin{array}{l}\text { We are urged to know more than just } \\
\text { math and science to stay competitive }\end{array}$ & & & & \\
\hline 10 & $\begin{array}{l}\text { My teachers of history stress that } \\
\text { cooperation among countries is } \\
\text { required to maintain peace. }\end{array}$ & & & & \\
\hline 11 & $\begin{array}{l}\text { I need more discussions in school } \\
\text { about the interdependence of our } \\
\text { world and how it will affect me. }\end{array}$ & & & & \\
\hline 12 & $\begin{array}{l}\text { Learning about the environment is } \\
\text { important, doing something about it is } \\
\text { even more important }\end{array}$ & & & & \\
\hline
\end{tabular}




\begin{tabular}{|c|c|c|c|c|c|}
\hline & & $\begin{array}{c}1 \\
\text { Strongly } \\
\text { disagree }\end{array}$ & \begin{tabular}{l}
\multicolumn{1}{c}{2} \\
Somewhat \\
disagree
\end{tabular} & \begin{tabular}{l}
\multicolumn{1}{c}{3} \\
Somewhat \\
agree
\end{tabular} & \begin{tabular}{l}
\multicolumn{1}{c}{4} \\
Strongly \\
agree
\end{tabular} \\
\hline 13 & $\begin{array}{l}\text { I do not have to learn to respect other } \\
\text { people's cultural differences to be a } \\
\text { global citizen. }\end{array}$ & & & & \\
\hline 14 & $\begin{array}{l}\text { We are not advised to use technology } \\
\text { to help us become better global } \\
\text { citizens }\end{array}$ & & & & \\
\hline 15 & $\begin{array}{l}\text { We practice saving our limited } \\
\text { natural resources in school }\end{array}$ & & & & \\
\hline 16 & $\begin{array}{l}\text { Reducing waste is everyone's duty as } \\
\text { a global citizen. }\end{array}$ & & & & \\
\hline 17 & $\begin{array}{l}\text { Teachers emphasize that religion can } \\
\text { be an important part of culture in our } \\
\text { social studies classes }\end{array}$ & & & & \\
\hline 18 & $\begin{array}{l}\text { Global warming is not a serious threat } \\
\text { to our planet. }\end{array}$ & & & & \\
\hline 19 & $\begin{array}{l}\text { Understanding the cultures of the } \\
\text { world is not always informative and } \\
\text { interesting in school. }\end{array}$ & & & & \\
\hline 20 & $\begin{array}{l}\text { I learn to express my opinion when I } \\
\text { hear or see injustice towards other } \\
\text { human beings. }\end{array}$ & & & & \\
\hline 21 & $\begin{array}{l}\text { Expressing my views as a global } \\
\text { citizen is very important when I join a } \\
\text { global workforce }\end{array}$ & & & & \\
\hline 22 & $\begin{array}{l}\text { I learn how to make value judgments } \\
\text { on foreign policies. }\end{array}$ & & & & \\
\hline 23 & $\begin{array}{l}\text { Being a global citizen means I must } \\
\text { be prepared to take responsibility for } \\
\text { my actions. }\end{array}$ & & & & \\
\hline 24 & $\begin{array}{l}\text { Globalization makes it necessary for } \\
\text { me to receive a global education in } \\
\text { school, which I do.. }\end{array}$ & & & & \\
\hline 25 & $\begin{array}{l}\text { I am made to understand that progress } \\
\text { does not come with war. }\end{array}$ & & & & \\
\hline 26 & $\begin{array}{l}\text { "Caring" is an important word for } \\
\text { global citizens, and most teachers } \\
\text { make sure we practice it. }\end{array}$ & & & & \\
\hline 27 & $\begin{array}{l}\text { I believe that being a global citizen } \\
\text { means you are less patriotic }\end{array}$ & & & & \\
\hline
\end{tabular}




\begin{tabular}{|c|c|c|c|c|c|}
\hline & & $\begin{array}{c}1 \\
\text { Strongly } \\
\text { disagree }\end{array}$ & \begin{tabular}{l}
\multicolumn{1}{c}{2} \\
Somewhat \\
disagree
\end{tabular} & \begin{tabular}{l}
\multicolumn{1}{c}{3} \\
Somewhat \\
agree
\end{tabular} & $\begin{array}{l}\quad 4 \\
\text { Strongly } \\
\text { agree }\end{array}$ \\
\hline 28 & $\begin{array}{l}\text { Moet teachers prepare us to be } \\
\text { lifelong learners (keep learning) to } \\
\text { stay competitive }\end{array}$ & & & & \\
\hline 29 & $\begin{array}{l}\text { Our teachers explain people's } \\
\text { behavior in the context of their } \\
\text { religion and culture }\end{array}$ & & & & \\
\hline 31 & $\begin{array}{l}\text { I am taught as a global citizen I must } \\
\text { work towards peace }\end{array}$ & & & & \\
\hline 32 & $\begin{array}{l}\text { The social activities in school are } \\
\text { getting me ready to become a member } \\
\text { of a global society. }\end{array}$ & & & & \\
\hline 33 & $\begin{array}{l}\text { Knowing more that one language } \\
\text { improves my job opportunities in the } \\
\text { global workforce. }\end{array}$ & & & & \\
\hline 34 & $\begin{array}{l}\text { I am being prepared to assume my } \\
\text { role as a global citizen it the world. }\end{array}$ & & & & \\
\hline 35 & $\begin{array}{l}\text { The curriculum I experience in school } \\
\text { has made me more confident in } \\
\text { seeking work in the global workforce. }\end{array}$ & & & & \\
\hline 36 & $\begin{array}{l}\text { I do receive a global education in } \\
\text { some/all my classes at school }\end{array}$ & & & & \\
\hline
\end{tabular}


Please answer all the questions.

\section{Demographics}

1. What is your current GPA (on a range from 4.0 to 6.0$)$ ?

2. Ethnicity : (Circle one)
a. White
b. Black
c. American Indian
d. Asian/Pacific Islander
e. Hispanic
f. Other

3. Gender: (Circle one)
a. Male
b. Female

4. Have you visited other countries?

(Circle one)
a. Yes
b. No

5. Have you lived in other countries? (Circle one)
a. Yes
b. No

6. What do you mostly read?

(Circle one)
a. Newspapers
b. Magazines
c. Books
d. Internet
e. Other

7. How do you get current events' news? (Circle one)
a. Radio
b. TV
c. Internet
d. Other

There are no right or wrong answers Demographics

8. What kind of music do you listen to? (Circle one)
a. Hip Hop
b. Pop
c. Jazz
d. Other

9. Do you speak a second language? (Circle one)
a. Yes
b. No

10. Parents' education completed (Circle only one from either $\mathrm{a}, \mathrm{b}$, or c)

a. High school

1) Yes

2) $\mathrm{No}$

b. College

1) Yes

2) $\mathrm{No}$

c. Graduate school

1) Yes

2) No

11. SES - free/reduced lunch (Circle one)
a. Yes
b. No

12. Have you taken a class in: (Circle one)
a. Social studies
b. History (American/
World)
c. Global studies
d. International studies
e. Economics/Government 


\section{APPENDIX F - School Participants}

Location of School Participants with number of students in Miami-Dade County

School Participants from Miami-Dade County

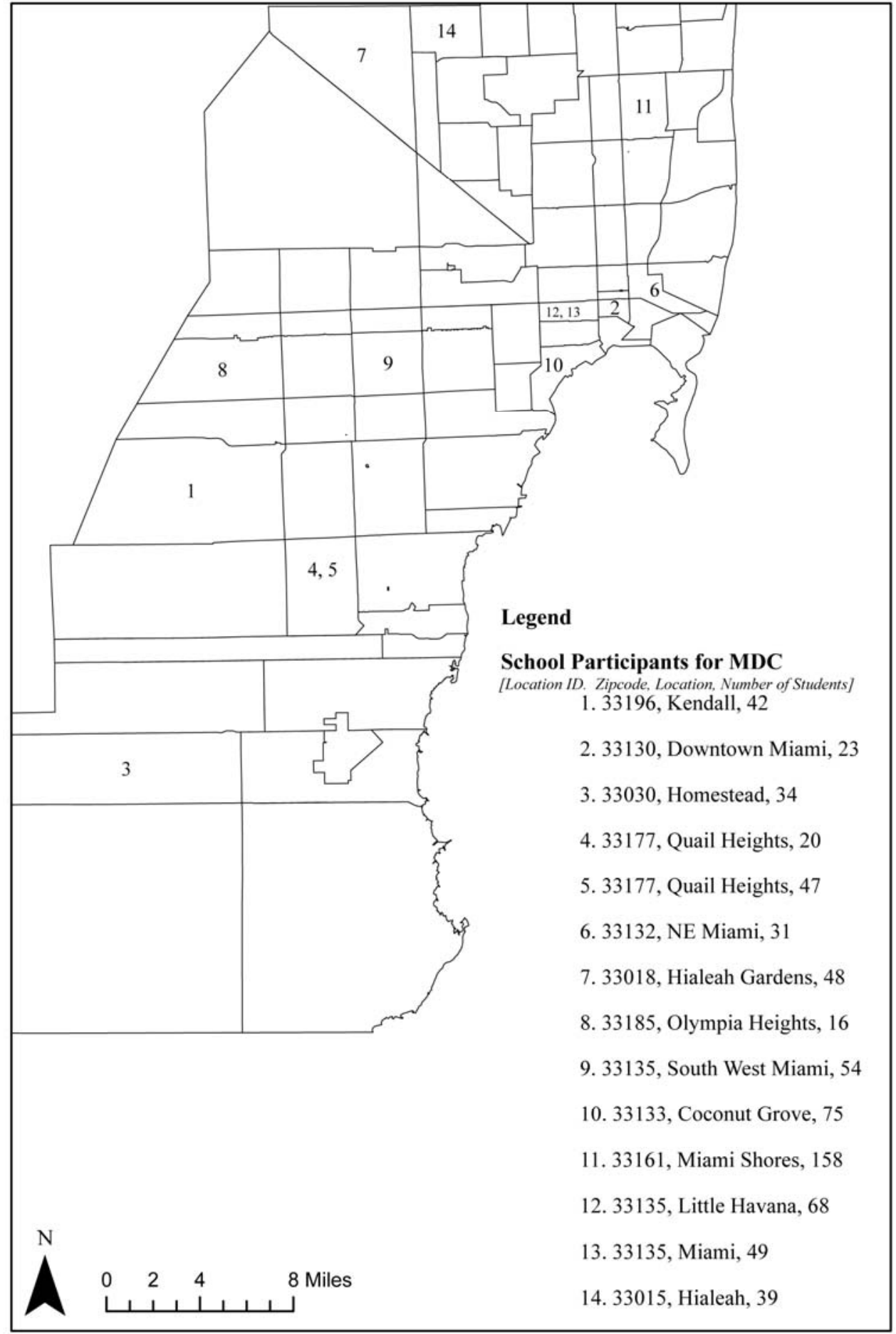




\section{APPENDIX G - Eigenvalues for the 36-item Survey}

\begin{tabular}{|c|c|c|c|}
\hline Component & Total \% & $\%$ of variance & Cumulative \\
\hline $1 *$ & 6.189 & 17.193 & 17.193 \\
\hline $2 *$ & 2.843 & 7.896 & 25.089 \\
\hline 3 & 1.599 & 4.442 & 29.531 \\
\hline 4 & 1.513 & 4.202 & 33.732 \\
\hline 5 & 1.285 & 3.568 & 37.301 \\
\hline 6 & 1.209 & 3.359 & 40.660 \\
\hline 7 & 1.151 & 3.197 & 43.857 \\
\hline 8 & 1.108 & 3.079 & 46.936 \\
\hline 9 & 1.089 & 3.026 & 49.962 \\
\hline 10 & 1.026 & 2.850 & 52.812 \\
\hline 11 & 1.007 & 2.797 & 55.609 \\
\hline
\end{tabular}

Note. ${ }^{*}$ Factors retained 


\section{APPENDIX H - Two-Factor Rotated Component Matrix}

\begin{tabular}{|c|c|c|c|}
\hline $\begin{array}{l}\text { Survey } \\
\text { Item }\end{array}$ & & $\begin{array}{l}\text { Self-Perception of } \\
\text { Global Awareness }\end{array}$ & $\begin{array}{l}\text { Attitudes Towards } \\
\text { Global Social Issues }\end{array}$ \\
\hline Numb. & Item Text & Factor 1 & Factor 2 \\
\hline
\end{tabular}

32 The social activities in school are

.697

.064

getting me ready to become a member

of a global society.

35 The curriculum I experience in school

.685

.007

has made me more confident in seeking

work in the global workforce.

36 I do receive a global education in

.639

$-.019$

some/all my classes at school

34 I am being prepared to assume my role

.639

.175

as a global citizen it the world

.632

to receive a global education in school, which I do.

$7 \quad$ Teachers help us understand our

.547

$-.007$

interdependence by encouraging

community service

26 "Caring" is an important word for global

.546

.006

citizens, and most teachers make sure

we practice it.

31 I am taught as a global citizen I must

.525

.289

work towards peace

$28 \quad$ Most teachers prepare us to be lifelong $\quad \mathbf{. 5 1 7}$

learners (keep learning) to stay

competitive

(table continues) 
(continued)

\begin{tabular}{|c|c|c|c|}
\hline $\begin{array}{l}\text { Survey } \\
\text { Item }\end{array}$ & & $\begin{array}{l}\text { Self-Perception of } \\
\text { Global Awareness }\end{array}$ & $\begin{array}{l}\text { Attitudes Towards } \\
\text { Global Social Issues }\end{array}$ \\
\hline Numb. & Item Text & Factor 1 & Factor 2 \\
\hline
\end{tabular}

15 We practice saving our limited natural

22 I learn how to make value judgments on foreign policies

29 Our teachers explain people's behavior in the context of their religion and culture

6 Teachers discuss global issues and problems in the social studies/global studies/ international class.

10 My teachers of history stress that cooperation among countries is required to maintain peace.

9 We are urged to know more than just math and science to stay competitive

25 I am made to understand that progress $\quad .286$ does not come with war.

17 Teachers emphasize that religion can be an important part of culture in our social studies classes.

12 Learning about the environment is important, doing something about it is even more important.

16 Reducing waste is everyone's duty as a .151 global citizen. 


\section{Survey}

Item

Numb.
Item Text
Self-Perception of

Global Awareness

Factor 1
Attitudes Towards

Global Social Issues

Factor 2

33 Knowing more that one language $\quad .256$

improves my job opportunities in the global workforce.

30 I must learn to work with others because .265

I will be required to so in the future.

23 Being a global citizen means I must be $\quad .257$

prepared to take responsibility for my actions.

13 I do not have to learn to respect other $\quad-.027$

.528 people's cultural differences to be a global citizen.

$21 \quad$ Expressing my views as a global citizen $\quad .257$

518 is very important when I join a global workforce.

18 Global warming is not a serious threat to -.040 our planet.

8 We learn that we do not depend on other -.262 countries for our manufactured goods and services.

19 Understanding the cultures of the world -.054 is not always informative and interesting in school.

$4 \quad$ No need to learn to stay informed about $\quad-.021$ important global events in school. 
Survey

Item

Numb.
Item Text
Self-Perception of Global Awareness

Factor 1
Attitudes Towards Global Social Issues Factor 2

20 I learn to express my opinion when I $\quad .263$

hear or see injustice towards other human beings.

14 We are not advised to use technology to -.045 help us become better global citizens.

3 I am made to understand that problems $\quad .092$

in the Middle east can become the problems of the United States.

2 I am taught that competitiveness is very .157 important in an interconnected world.

11 I need more discussions in school about -.051 the interdependence of our world and how it will affect me.

$5 \quad$ Being globally interconnected means I $\quad .244$ have to learn responsibility to others in the world.

1 I need to learn more than one language $\quad .190$ because people who speak languages are generally considered well educated. 


\section{APPENDIX I - Cronbach's Alpha if Item Deleted for Factor 1}

Item Total Statistics

\begin{tabular}{|c|c|c|}
\hline $\begin{array}{l}\text { Item } \\
\text { Number }\end{array}$ & Item Text & $\begin{array}{l}\text { Cronbach's Alpha } \\
\text { if item deleted for } \\
\text { Factor } 1\end{array}$ \\
\hline
\end{tabular}

32 The social activities in school are getting me ready to become a member of a global society. more confident in seeking work in the global workforce.

36 I do receive a global education in some/all my classes at school

34 I am being prepared to assume my role as a global citizen it the world

24 Globalization makes it necessary for me to receive a $\quad .808$ global education in school, which I do. encouraging community service and most teachers make sure we practice it.

31 I am taught as a global citizen I must work towards peace

28 Most teachers prepare us to be lifelong learners (keep learning) to stay competitive school 
(continued)

\begin{tabular}{ll}
\hline $\begin{array}{l}\text { Item } \\
\text { Number }\end{array}$ & \multicolumn{1}{c}{$\begin{array}{c}\text { Cronbach's Alpha } \\
\text { If item deleted for } \\
\text { Factor 1 }\end{array}$} \\
\hline $29 \quad \begin{array}{l}\text { Our teachers explain people's behavior in the } \\
\text { context of their religion and culture }\end{array}$ & 821 \\
$6 \quad \begin{array}{l}\text { Teachers discuss global issues and problems in the } \\
\text { social studies/global studies/ international } \\
\text { class. }\end{array}$ & .820 \\
$10 \quad \begin{array}{l}\text { My teachers of history stress that cooperation } \\
\text { among countries is required to maintain peace. }\end{array}$ & .819 \\
\hline
\end{tabular}




\section{APPENDIX J - Cronbach's Alpha if Item Deleted for Factor 2}

Item Total Statistics

Item

Number
Cronbach's Alpha

if item deleted for

Factor 2

12 Learning about the environment is important, doing something about it is even more important our manufactured goods and (reversed scored).

18 Global warming is not a serious threat to our planet (reversed scored).

30 I must learn to work with others because I will be required to so in the future.

33 Knowing more that one language improves my job opportunities in the global workforce.

23 Being a global citizen means I must be prepared to take responsibility for my actions.

21 Expressing my views as a global citizen is very important when I join a global workforce.

16 Reducing waste is everyone's duty as a global citizen. 
Item

Number

Item Text

6 Teachers discuss global issues and problems in the social studies/global studies/international class

$7 \quad$ Teachers help us understand our interdependence by encouraging community service

8 We learn that we do not depend on other countries for our manufactured goods and services

10 My teachers of history stress that cooperation among countries is required to maintain peace

12 Learning about the environment is important, doing something about it is even more important.

13 I do not have to learn to respect other people's cultural differences to be a global citizen.

15 We practice saving our limited natural resources in school.

16 Reducing waste is everyone's duty as a global citizen.

18 Global warming is not a serious threat to our planet.

21 Expressing my views as a global citizen is very important when I join a global workforce.

22 I learn how to make value judgments on foreign policies.

23 Being a global citizen means I must be prepared to take responsibility for my actions

24 Being a global citizen means I must be prepared to take responsibility for my actions. 
Item

Number

Item Text

26 "Caring" is an important word for global citizens, and most teachers make sure we practice it.

28 Most teachers prepare us to be lifelong learners (keep learning) to stay competitive.

29 Our teachers explain people's behavior in the context of their religion and culture

30 I must learn to work with others because I will be required to so in the future

31 I am taught as a global citizen I must work towards peace

32 The social activities in school are getting me ready to become a member of a global society

33 Knowing more that one language improves my job opportunities in the global.

34 I am being prepared to assume my role as a global citizen in the world.

35 The curriculum I experience in school has made me more confident in seeking work in the global workforce.

36 I do not receive a global education in some/all my classes at school 
VITA

\section{RENITA FERREIRA}

Born, Mumbai, India

1963

B. A., French Honors

Sophia College

Mumbai, India

1968

B. Ed., Education

St. Xavier's University

Mumbai, India

$1964-1971$

Secondary School Teacher

Sacred Heart High School

Mumbai, India

1971

M. Ed. Comparative Education

St. Xavier's Institute of Education

Mumbai, India

$1972-1975$

Secondary School Teacher

Sacred Heart High School

Manama, Bahrain

1980

B.S., Travel \& Hospitality

Florida International University

Miami, Florida

$1984-2010$

Business Owner (Travel With Ren)

Miami, Florida

2004

M.S., International Development Education

Florida International University

Miami, Florida

$2005-2007$

Adjunct Instructor, Education

Miami Dade College

Miami, Florida

$2010-2011$

Adjunct Instructor, Hospitality

Miami Dade College

Miami, Florida 


\section{PRESENTATIONS}

Ferreira, R. (2006). Global Education: An Integral Part of Preservice Teacher Training. Paper presented at the Scholarly Forum at Florida International University, Miami, Florida.

Ferreira, R. (2006). Global education and Teachers in the Classroom. Paper presented at the Educational Conference at Miami Dade College, Miami, Florida.

Ferreira, R. (2007). Conflict in the Classroom and in the Workplace. Paper presented at the Educational Conference at Miami Dade College, Miami, Florida.

Farouk, M., \& Ferreira, R. (2007). Global Literacy: Challenges, Choices, and Convictions from Student Perspectives. Paper presented at the American Educational Research Association conference, Chicago, Illinois.

Ferreira, R (2008). A Preliminary Development of a Global Education and Global Citizenship Assessment Instrument: A Discussion of Reliability and Validity Procedures and Estimates. Paper presented at the Florida Education Research Association, Orlando, Florida.

Ferreira, R. \& Farouk, M. (2008). Global Literacy: An Essential Component of Contemporary Education. Paper presented at the Conference of University Faculty Association (CUFA), Houston, Texas.

Ferreira, R. (2009). Global Literacy for a Global Society: Expanding Literacy Studies. Paper presented at the Literacy Conference at Ohio State University, Columbus, Ohio.

\section{PUBLICATIONS}

Ferreira, R. and Farouk, M.K. (2007) Global Literacy: Challenges, Choices, and Convictions. In M.S. Nielsen \& M. S. Plakhotnik (eds.). Proceedings of the Sixth Annual College of Education Research Conference: Urban and International Section, (pp. 12-17). Florida International University, Miami, Fl. http://coweb.fie.edu/research_conference 